This informal document contains information which is preliminary and may be fragmentary or of .

1 imited scope. The assumptions, views, and conclusions expressed in this document are those of the author and are not to be interpreted as those of Union Carbide Corporation, Nuclear Division, or USERDA.

\title{
REVIEW OF APPLICABLE TECHNOLOGY - SOLUTION MINING OF CAVERNS IN SALT DOMES TO SERVE AS REPOSITORIES FOR RADIOACTIVE WASTES
}

\section{MASTER}

Prepared for

OAK RIDGE NATIONAL LABORATORY

B1dg. 9104-3, Room 6

Post Office Box Y

Oak Ridge, Tennessee 37830

By

This report was prepared as an account of work sponsored by the United States Government. Neither the United States nor the United States Energy Research and Development Administration, nor any of subcontrayses, nor any of their contractors, warranty, express or implied, or assumes any legal liability or responsibility for the accuracy, completeness or usefulness of any information, appyaralus, product or process disclosed, or represents that its use would not infringe privately owned rights.

FENIX \& SCISSON, INC.

P.0. Box 15609

Tulsa, Oklahoma 74115 


\section{DISCLAIMER}

This report was prepared as an account of work sponsored by an agency of the United States Government. Neither the United States Government nor any agency Thereof, nor any of their employees, makes any warranty, express or implied, or assumes any legal liability or responsibility for the accuracy, completeness, or usefulness of any information, apparatus, product, or process disclosed, or represents that its use would not infringe privately owned rights. Reference herein to any specific commercial product, process, or service by trade name, trademark, manufacturer, or otherwise does not necessarily constitute or imply its endorsement, recommendation, or favoring by the United States Government or any agency thereof. The views and opinions of authors expressed herein do not necessarily state or reflect those of the United States Government or any agency thereof. 


\section{DISCLAIMER}

Portions of this document may be illegible in electronic image products. Images are produced from the best available original document. 
Historical Development of Solution Mining Concepts

Patented Storage Concepts

Salt Domes - A Geological Viewpoint

Leaching Water

Cavern Leaching We11

Leaching Process

Direct Circulation

Reverse Circulation $\quad 30$

Modified Technique . $\quad 36$

$\begin{array}{ll}\text { Sample Cavern Sizes } & 38\end{array}$

6

ESTABLISHMENT OF DOME LIMITS

Preparation of Structure Map

Preparation of Geologic Cross Section

Alternate Disposal Methods $\quad 47$

Subsurface Brine Disposal $\because . \quad 50$

Brine Disposal Reservoir Analysis . . 54

Factors Relevant To Big Hole Drilling 61

Cavern Entry Concepts 69 
Factors Affecting Stability 92

Cavern Failures

11

SALT DOME CAVERNS NOT USED FOR HYDROCARBON STORAGE

101

Reasons For Cavern Abandonment

101

Tabulation of Existing Caverns Not Used For Hydrocarbon Storage

Screening Process Criteria

103

104

12

CONSTRUCTION COSTS

109

Cost Curves

110

APPENDIX

-- $\quad$ BRINE DISPOSAL RESERVOIR ANALYSIS

NUMERICAL EXAMPLE

115

REFERENCES

121 


\section{ILLUSTRATIONS}

3-1 Principal salt deposits within the United States

3-2 Illustration showing the intrusive nature of salt domes

4-1 Casing configuration for typical leach water supply well.

4-2 Casing configuration for cavern development well

4-3 Typical cavern construction using reverse circulation

5-1 Cavern shapes resulting from direct circulation

5-2 Casing configuration for sump and cavity construction

5-3 Cavern shape resulting from reverse circulationupper cavern injection

5-4 Cavern shapes resulting from reverse circulationmid cavern injection

5-5 Cavern shapes resulting from reverse circulationlower cavern injection

5-6 Modified technique used to develop a cavern whose shape is a spherical approximation

5-7. Model of cavern constructed using modified circulation technique

5-8. Dimensions of various shapes of caverns (14 million cubic foot volume)

6-1 Base map with well locations

$\begin{array}{lll}\text { 6-2 } & \text { Structure map } & 44\end{array}$

6-3 Geologic cross section A-A' 45

7-1 Typical disposal well casing configuration 52

7-2 Brine reservoir pressure profile for two adjacent brine disposal wells 
8-1 Typical casing \& hole configuration for 59 ID "big hole" access

8-2 Large diameter casing details

8-3 Illustration of a massive "super rig" required for drilling hole \& installing large diameter casing (122" diameter surface casing in foreground)

8-4 84" drill string assembly

8-5. Concepts for large diameter cavern entry

9-1 Partial view of caverns showing accumulation of insolubles \& dewatering zones

9-2 Zone I dewatering techniques

9-3 Single-well dewatering of Zone II

9-4 Well configuration for offset well dewatering methods

9-5 Plan view \& vertical cross section of offset well directionally drilled to a predetermined target

9-6 Circulation of drying air for different types of cavern construction

9-7 Concept for isolating sump from cavern (without manned entry)

10-1. Experimenta]. curve of closure rate vs time (moditied trom Jessen \& Nowotny)

10-2 The underground laboratory for Project Salt Vault (The Kansas City Star, November 1, 1959)

10-3 Summary of yielded zones for different shapes. and initial stress conditions

10-4 Surface subsidence due to collapse of an old brine well (Tulsa Daily World, April 28, 1976)

12-1 Unit cost vs cavern development time for varlous cavern depth intervals 


\section{SECTION 1}

\section{INTRODUCTION}

This report, prepared by Fenix \& Scisson, Inc. for the Oak Ridge National Laboratory, is a review of applicable technology for the solution mining of caverns in salt domes to serve as repositories for radioactive waste. The study was authorized on January 14, 1976 under the client's Purchase Order No. $78 \mathrm{X}-92880 \mathrm{~V}$.

This assignment originated after Oak Ridge, charged with examining the feasibility of using solution mined salt dome caverns for long term storage of radioactive wastes, came to Fenix \& Scisson with numerous questions regarding dome salt.

Although Oak Ridge has given considerable attention to the use of bedded salt for waste storage, it has only limited experience with dome salt. It became apparent in its discussions with Fenix \& Scisson that a state of the art or review of applicable technology could be beneficial to them.

Consequently, Fenix \& Scisson submitted a proposal to accomplish the following work:

1) Provide a brief history of solution mining in salt domes.

2) Describe fundamental procedures used in cavern development.

3) Discuss means of obtaining various cavern shapes.

4) Deseribe techniques for brine disposal.

5) Discuss big hole drilling procedures and how they might be used for entry into solution mined caverns.

6) Describe procedures that might be used to remove brine from a cavern, including an assessment of difficulties in drying insoluble rubble. 
7) Discuss variables affecting stability, including depth, temperature, differential pressure, etc.

8) Tabulate stable caverns known to exist in salt domes that are not being used for hydrocarbon storage.

9) Discuss briefly the costs involved in construction of solution mined caverns using conventional oil fleld drilling practices.

Because no information is available at this time on the nature of wastes which would be stored, either the size or shape of the container, or the level of radioactivity; subjects included in the proposal must be discussed only in general terms. This report, which serves as completion of the study, is designed to serve as a primer in solution mining, with particular attention to salt dome construction projects. 
Solution mined, subsurface caverns in salt domes have been used to store hydrocarbon products for the past 20 years. Today, advances in solution minIng technology are enabling industry and government to construct these subterranean storage vessels for a host of new applications--among them the storage of radioactive wastes.

Some of the problems which once confronted engineers interested in constructing waste repositories in salt domes have been eliminated; others still remain.

There is an abundance of salt domes in the Gulf Coastal region. Techniques exist that can accurately determine the limits of a dome. There is an adequate supply of fresh water that can be used for cavern leaching, and formations surrounding Gulf Coast domes provide excellent reservoirs for disposal of the brine resulting from cavern construction.

With existing technology, we can construct shape-controlled cavities In salt domes, evacuate the brine, and drill a large diameter hole for manned entry into the cavity.

Advances is leaching technology and cavern shape control make it possible to build large caverns with configurations approaching teardrops, cylinders, and spheres. Fenix \& Scisson has desiged-and constructed several dozen caverns in sizes up to three million barrels (16.8 million cubic feet).

It is now within current technological bounds to evacuate the brine left in the cavern following construction, dehumidify the cavern atmosphere and supply conditioned cavern ventilation. In our present work with natural gas 
storage we are already removing brine from a cavity after leaching has been completed. As gas is injected into the cavern, brine is forced out through a special tubing set near the bottion of the cavity.

The state of the art in drilling large diameter holes has advanced to the point that it is now possible to drill 120 fnch diameter holes as deep as 6,000 feet and 144 inch holes to lesser depths. Therefore, large diameter access holes might be used for entry into a solution mined cavern.

Additional research is needed in the area of cavern stability. Even though some 10 years of research have been devoted to rock mechanics relating to cavern stability, no universally accepted technique to predict cavern closure has yet been developed. It is generally felt that closure in caverns constructed above 2,500-3,000 feet is negligible.

Cavern shrinkage rates are known to increase with depth because of lower salt strengths at higher pressures and temperatures. Recent tests run on a spherical cavity created by a nuclear detonation at a depth of 2,700 feet indicated negligible closure. By contrast, closure in caverns constructed at depths of 6,000 feet can run as high as 30 percent a year if the cavern pressure is allowed to drop too low.

It is technically possible to construct shape-controlled cavities in a salt dome; however, it is suggested that Fenix \& Scisson work with ERDA technical personnel to establish exact criteria for a radioactive waste repository before final decisions are made regarding technical feasibility: 


\section{SECTION 3}

\section{BACKGROUND}

Solution mined salt caverns have become one of the most popular methods of storing large volumes of products. Since 1950, advances in engineering and construction techniques and experience in solution mining have made possible a more diversified use of salt for underground storage.

The use of salt formations as a storage medium for radioactive waste has been under investigation since 1956. From November, 1965 to June, 1967, Project Salt Vault was performed to demonstrate the disposal of high level radioactive solids in bedded salt deposits. 1,2

The project, sponsored by the United States Atomic Energy Commission under contract with Union Carbide Corporation, was conducted at an inactive mine owned by Carey Salt Company near Lyons, Kansas. Results of the demonstration that relate to this study are discussed in Section 10.

Salt exhibits a unique combination of characteristics, making it the ideal rock for cavern construction. It is generally impervious to liquid and gas, has a compressive strength comparable to concrete, moves plastically to seal fractures or voids, and can be easily mined by dissolution in water. Construction is feasible wherever salt, leaching water and conditions for brine disposal coexist in adequate quantity and form.

The fundamental technique of cavern development is simply to expose the salt in a drilled hole, inject raw (fresh or low salinity) water into the hole, allow time for the water to dissolve the salt, and displace the resultIng brine from the hole. As the salt dissolves, the hole enlarges and eventually forms a cavern. 
In actual practice, the procedure for cavern development is somewhat more complex and will be covered in a later section.

\section{HISTORICAL DEVELOPMENT \\ OF. SOLUTION MINING CONCEPTS}

Since the $1880^{\prime}$ 's--when some of the first solution mining methods and equipment were patented--until the 1950's, efforts were aimed at brine production. The commercial value of caverns, left after removal of large volumes of salt, was not initially recognized. Since 1950, however, not only are some of the caverns which were once created by brine production being converted to storage of hydrocarbon liquids and gases, but new caverns are being constructed specifically for storage purposes.

Prior to the 1930's brine was produced from a single well drilled into a salt deposit. Piping in the well was arranged either side-by-side or concentrically. Water was introduced through the feed pipe set near the top of the deposit, and the resulting brine was removed through a second pipe set near the bottom of the cavity being formed. Brine was either mechanically pumped to the surface or forced out of the cavity under pressure supplied by

a fresh water injection system.

Two important additions to solution mining technology occurred in the 1930's. The first of these was the introduction of a "blanket" of air between the cavern roof and the leaching water which established better leaching control and protected the ronf from upward migration. Additional air was Injected into the cavity to control the level of solvent in the cavity.

Secondly, the dual well concept of mining bedded salt was introduced. W1th this leaching method, a communication channel between the wells is formed 
by operating each well separately until the caverns eventually "grow". together, or coalesce. Brine is then produced by the contact of water with the walls of the channel as it flows from one well to the other.

In the 1950's, attention was focused not only on brine production but also on the leaching of caverns suitable for storage of hydrocarbon liquids and gases. Liquid non-solvent blanket materials were introduced, and the level of blanket material in the cavity and the position of tubing strings were adjusted during leaching to influence cavity shape and size.

Introduction of the sonar survey also represented an important advancement in subsurface engineering. This survey tool, an acoustical device, is lowered into the cavern to take measurements which are used to plot cavern shape and calculate cavern volume.

The dual well concept of mining was enhanced by the inception of fluid fracturing techniques which helped to create communication and improve flow paths between distant wells.

One of the most recent patents, issued in March of this year, deals with a dual well technique for mining bedded salt deposits which are intermingled with layers of insoluble material.

\section{PATENTED STORAGE CONCEPTS}

A German patent, issued in 1919, pioneered the concept of storing petroleum and related liquid hydrocarbons in underground cavities. The patent specifically mentions the use of bedded rock salt and potash salt as possible storage mediums and room-and-pillar mining as an excavation technique. Methods for storing hydrocarbon liquids and gases have been the subjects of several 
United States patents during the past 20 years.

The technology of constructing a cavern for the storage of hydrocarbon liquids and gases has advanced since the 1950's, due to experience gained from construction and operation of many storage caverns.

\section{SALT DOMES - A GEOLOGICAL VIEWPOINT}

Large deposits of salt exist in many areas of the world and are usually found lying between beds of shale, anhydrite, gypsum, or limestone. Salt is an evaporite sediment, an accumulation of crystals precipitated from impounded sea water in an arid environment. Even today, beds of salt are forming in places like the Great Salt Lake of Utah. Principal salt deposits within the United States are shown in Figure 3-1.

Bedded salt in the Gulf Coastal regions of Texas, Louisiana and Mississippi is buried so deeply under sediments that it has not been penetrated with a drill bit. Based on the depth of its northern fringe, its rate of dip to the south and the thickness of upper sediments, geologists postulate that the bed--known as the Louann Salt--is very thick and is more than 30 thousand feet below the carth's surface. It is from thjs bed that salt domes are born.

\section{SALT DOMES}

Salt domes are relatively narrow stems of salt extending upward from great depth, far enough in some instances to outcrop at surface. Figure 3-2 illustrates the intrusive nature of salt domes as they penetrate overlying sedimentary formations. No one knows how many domes actually exist; many 


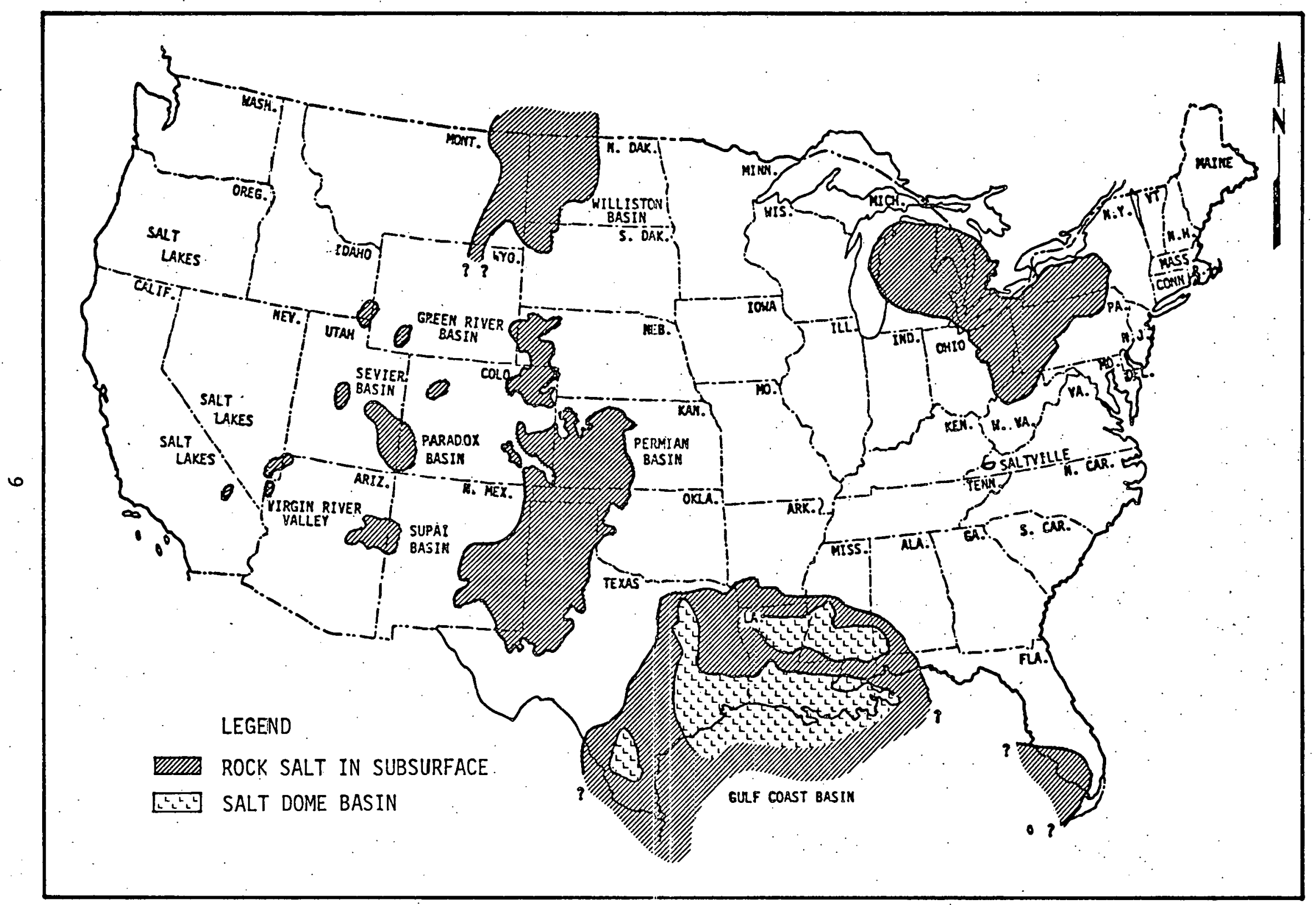

Figure 3-1. Principal salt deposits within the United States 


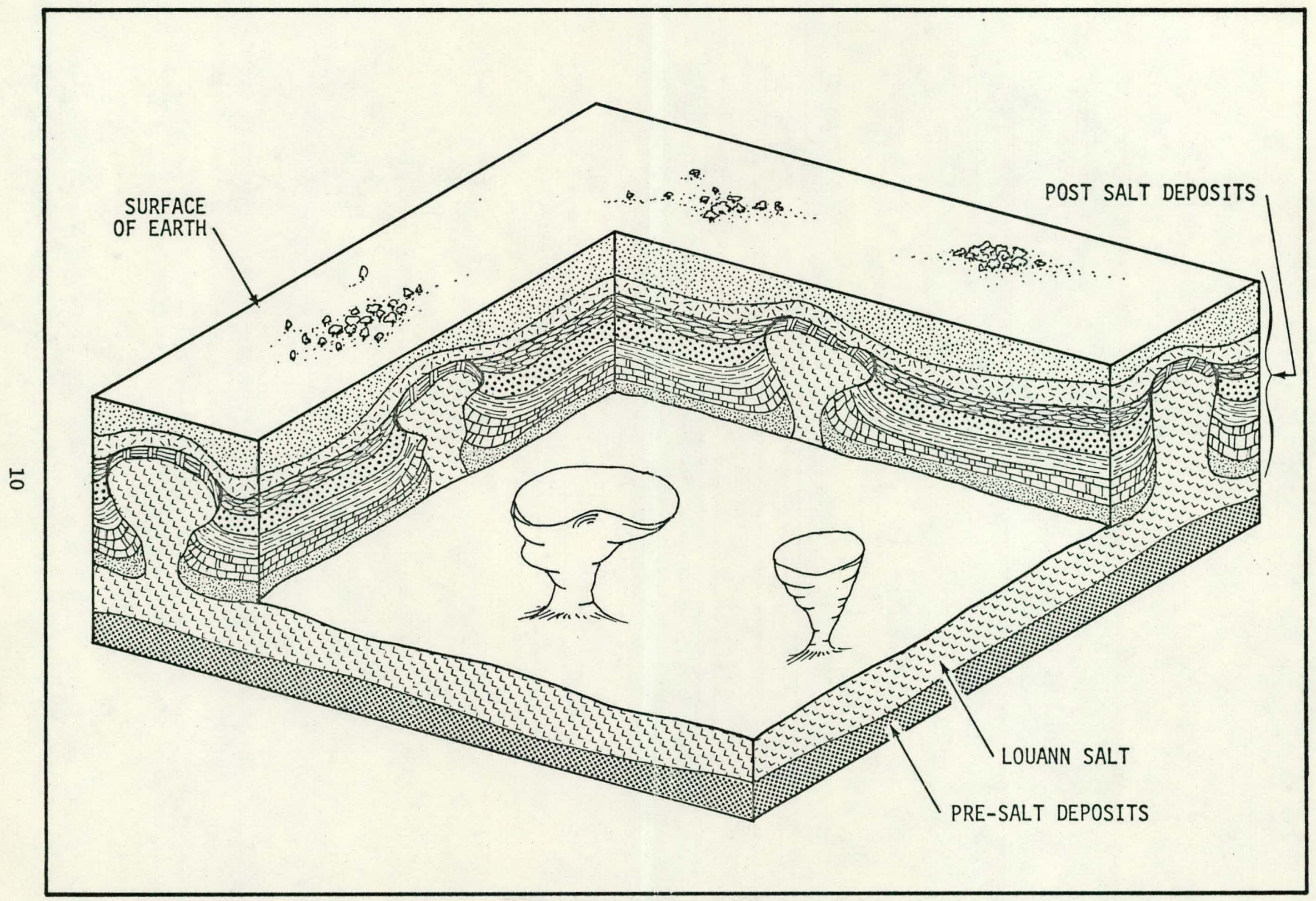

Figure 3-2. Illustration showing the intrusive nature of salt domes 
domes terminate at such great depth that their presence is undetectable.

Over 320 have been discovered, however, and many are shallow enough to be potential candidates for radioactive waste repositories.

Several geological theories have been expounded on the origin of salt domes. The true origin of the domes still remains a subject of conjecture. There is general agreement, however, that the stems of most salt domes extend downward to the Louann Salt. Subjected to extremely high temperatures and tremendous pressure from overlying sediments, the behavior of the Louann bed is similar to that of a very fluid plastic. When relieved of significant overburden pressure, as when a core is brought to surface, the salt becomes brittle and often displays a coarse, crystalline structure.

It is the hard plastic characteristic of salt, when made parent to a cavern at the proper depth, that causes it to be an excellent high pressure storage vessel. The material can yield sufficiently to distribute stress away from the cavern wall, thus nullifying the stress concentrations that can cause other parent rocks to spall or cave. The plastic characteristic also allows the salt to close and seal fractures. One Mississippi salt dome cavern was used to contain a series of three detonations, each equivalent to approximately 300 tons of TNT, and survived without developing leakage.

Every salt dome has its own unique shape and size but a typical dome might be described as being reasonably cylindrical and symmetrical, about a mile in diameter, and terminating about 1,500 feet below surface. It might have a 500 foot thick cap rock consisting of anhydrite, gypsum, calcite, and sometimes free sulfur. A few domes are known to consist of essentially pure salt (halite). Most, however, contain dispersed grains of anhydritic sand, often comprising five to ten percent of the total mass. 
A great deal of geologic effort, time and money has been expended in the search of salt domes. The earliest investigations were directed toward locating domes that reached or nearly reached the surface and toward removing the salt as a mined commodity. In later years, salt has also been recovered from deeper domes by solution mining, primarily to provide saturated brine as feedstock to the chemical industry.

Salt dome cap rocks have also been the object of considerable commercial interest. In fact, much of the drilling performed over domes has been conducted to evaluate possibilities for sulfur recovery from the cap rock, using the Frasch process.

The origin of cap rocks, like the origin of salt domes, remains a subject of dispute amnng geologists. However, most investigators now seem to agree that cap rocks represent an accumulation of insoluble material, originally transported within the salt. Presumably, as the salt moved upward relative to the surface of the earth, its upper face was continually leached by unsaturated brines lying above. As salt dissolved, gypsum, sulfur and other. minerals may have evolved as the products of altered anhydrite.

As the cap rock gained in thickness and maturity it, too, was leached by shallow ealine waters. Abundant vugular zones are usually found in cap rocks, and occasionally a drilling bit will drop through what appears to be a large cavern. Perhaps as a result of the weaknesses caused by natural leaching, most cap rocks are highly fractured.

The petroleum industry has conducted by far the most intensive salt dome exploration effort. Here, the motivation has been a search for oil traps. Whether sedimentary beds have been tilted upward by the rising plug of salt or tilted downward by sinking beds of adjacent sediment remains a 
geologic riddle. There is no doubt, however, that relatively high spots within oil bearing formations can be found in the vicinity of salt domes. These zones, or traps, frequently contain accumulations of oil and/or gas and consequently, have been the subject of intensive exploration efforts. As a result of the search for oil, holes have been drilled around the flanks of most domes. Although the holes seldom penetrated the salt, they have provided information on the nature of deep formations which surround the domes. 


\section{SECTION 4 \\ Parameters of Leaching}

Three ingredients--a thick salt formation, a supply of fresh (or low salinity) water, and a means of brine disposal--are necessary to develop a solution mined storage cavern. Caverns are formed by the continuous injection of fresh or low salinity water through a well drilled into the salt deposit. The water dissolves the salt, becoming brine which is withdrawn from the cavity.

This section discusses leaching water sources and the development of water wells, and covers some of the more important physical elements of cavern construction such as the cavern leaching well, the leaching process and accumulation of insolubles.

\section{LEACHING WATER.}

Although other possible water sources will be mentioned, this report will emphasize the use of fresh water wells for supplying leach water.

Water sources are available in abundance in many areas of the United States, particularly in the Gulf Coastal region where many commercial leaching projects have been conducted without detrimental effects to the local hydrologic environment. Under ideal conditions, about six cubic feet of fresh or moderately saline $(3,000-10,000 \mathrm{mg} / \mathrm{L}$ dissolved solids) water will be required to develop one cubic foot of storage space. About seven cubic feet of sea water, which is less efficient because of its higher salinity, are needed to. produce one cubic foot of storage space. 
In addition to water supply wells, other sources of water for cavern leaching in the Gulf Coastal region include lakes, rivers, marshes, bayous or the Gulf of Mexico. Use of these waters must frequently be preceded by environmental assessments and/or impact statements to study the possibility of undesirable effects to the natural environment.

Unlike water wells, which often can be drilled near the cavern development well, other water sources may require pipelines of great lengths. Not only are these lines costly, but extensive ditching and dredging frequently create environmental impact problems.

\section{LEACHING WATER SUPPLY WELL}

Fresh water aquifers exist at relatively shallow depths in the Gulf Coastal region. This water, or deeper, more saline aquifers may be tapped for use, leaving potable water zones undisturbed. In some cases, where potable water essentially floats on saline water, the saline-potable interface may move downward and actuaily increase the supply of potable ground water.

When water is not being produced from a supply well, it stands in the well at a depth called the static water level. When the pump is in operation, the water level in the well is drawn down to a greater depth known as the operating level. The difference between the two levels is referred to as the drawdown.

To work properly, the operating level must be kept a certain distance (specified by the pump manufacturer) above the pump suction, so that minimum pump inlet pressure will be maintained. 'To accomplish this, the rate that water flows into the well must be at least equal to the water withdrawal rate 
when the minimum operating level has been reached.

Water withdrawn from the well is replaced by water flowing horizontally through the aquifer for many miles from the point of recharge.

DEVELOPMENT OF WATER SUPPLY WELL

The following procedure for establishing a leach water supply we11:is illustrated by the casing configuration shown in Figure 4-1.

PRODUCT CASING

The purpose of product casing is to keep the borehole open and to isolate upper formations from the well. After the hole has been drilled and casing installed; the lower portion of the casing is cemented in the hole.

\section{LINER OR SCREEN}

The liner or screen is installed in the lower portion of the borehole to keep the hole open as water is drawn to the well. Liners may be perforated or slotted. A screen may be thought of as a series of concentric rings, stacked on top of each other and separated by small open spaces. Gravel is sometimes packed between the liner (or screen) and the borehole to improve flow characteristics around the well bore.

PUMP

Turbine and submersible electrical pumps are used to produce leaching water from the well. Motors of turbine pumps are mounted on the wellhead, 


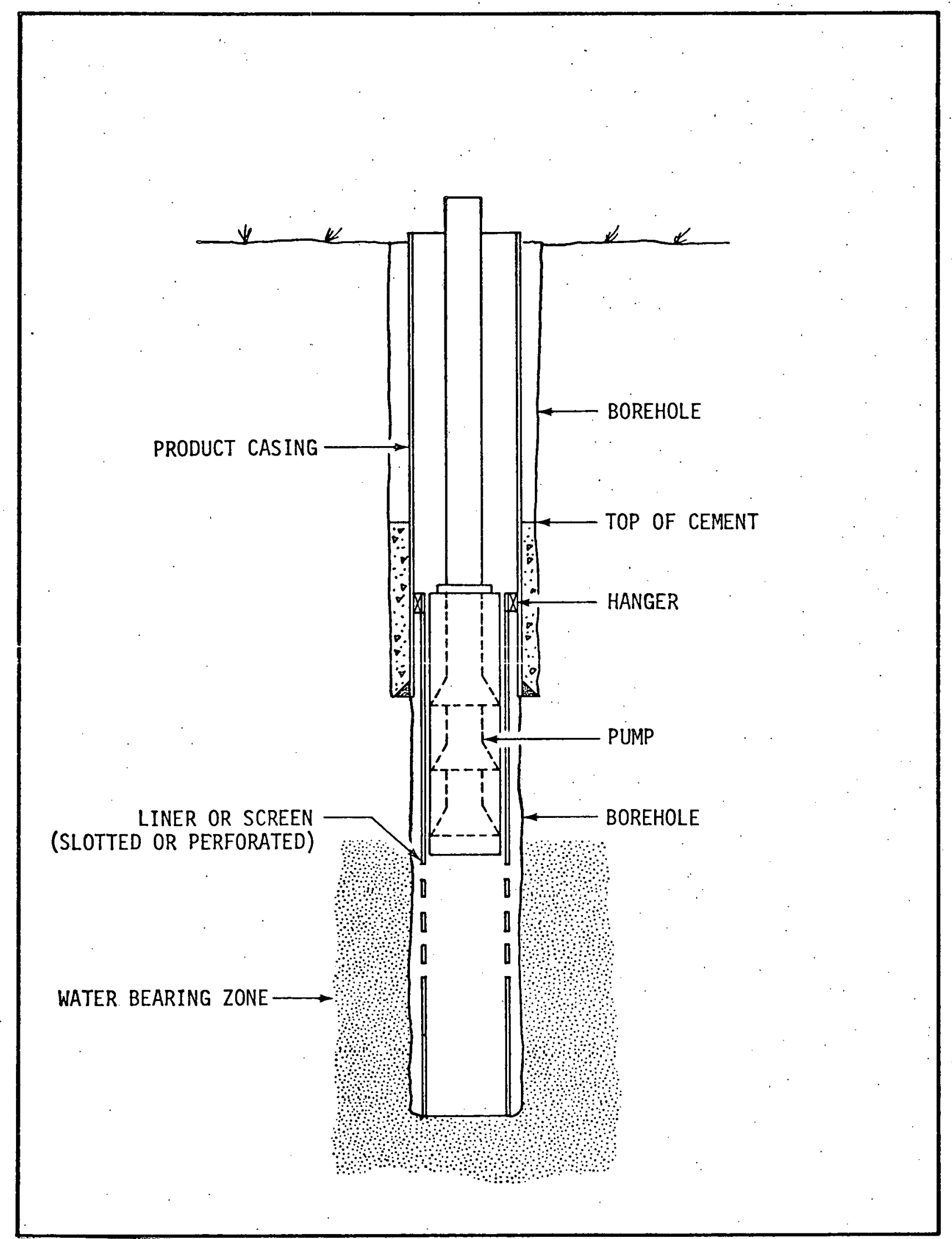

Figure 4-1. Casing configuration for typical leach water supply well 
with a rotating shaft connected to the pumping unit. An advantage of this type of pump is that the motor is readily accessible for maintenance or replacement. A disadvantage, however, is that as depth increases, larger shafts are required to drive the pumping unit.

Submersible pumps are available with the electric motor connected directly to the pumping unit. These pumps may generally be used at greater depths than turbine pumps, but when motor repair or maintenance is required the entire pumping unit must be pulled from the well.

\section{CAVERN LEACHING WELL}

Drilling and cementing procedures ised for the cavern leaching well are similar to those used for water and brine disposal wells.

\section{DRILLING THE BOREHOLE}

The well used for cavern leaching is drilled with "oilfield" type rotary drilling procedures. The bit is rotated with torque transmitted from the surface through the drillpipe and collars. Bits generally consist of three rolling cones (tricone bits), each serrated with short, husky. teeth. As each tooth is pressed against the bottom of the hole, a small chip is fractured away from the parent rock.

For drilling to proceed, chips must be transported from the face of the culters lo the surfacc. This is accomplished hy pumping a fluid known as mud down the pipe to the bit where it exits, picking up the cuttings and carrying them to the surface through the borehole annulus. Besides transporting cuttingo, the mud also conls the bit and supplies a stabilizing pressure to the 
borehole walls to prevent sloughing of unconsolidated sediments.

Many sedimentary rocks are so weak that they would cave if mud support were not available. Maintaining the proper composition and quality of mud is a critical factor in any drilling program. The wrong mud can cause hydration of shales, dissolve salt, slow drilling penetration, cause walls to fail and pipe to stick, along with numerous other problems.

Regardless of how good the mud is, however, circulation must be maintained if the mud is to do its job. Many rocks are porous, permeable and contain fluids existing at pressures less than that of the borehole mud. Consequently, the mud must be able to seal the walls of the hole or. it will flow into the rock rather than back to the surface. Although the drilling Industry has developed muds for almost every drilling condition, vugular or cavernous structures occasionally defy sealing and circulation fails.

If the uncased borehole is composed of competent rocks when circulation is lost, the driller can utilize many materials including cement to seal the loss zone. In some instances, he may be able to proceed with drilling by sacrificing his mud and allowing cuttings to be deposited into the loss zone. If he can tolerate a reduction in hole size, he may choose to isolate the zone by installing a steel intermediate casing.

However, if the uncased borehole consists of weak or unconsolidated sediments, the driller may never get an opportunity to re-establish circulation. The weak walls may begin to cave and bridge the hole. The drilling assembly máy become stuck, and in severe instances of caving, the drilling Ilg wiay have to be moved to a new 1 nration and a new hole started. 
CEMENTING THE CASING

It is usually necessary for the permanent casings to be sealed into the hole. This is accomplished by pumping cement down the casing and up into the annular space outside the casing. After the proper quantity of cement slurry has been placed in the casing; a separation plug is inserted and pumped down the casing with mud. The plug seals against a shoe installed at the base of the casing, preventing mud from escaping into the annulus.

The slurry of high strength cement is quite dense, exerting much more pressure on the borehole than the lighter mud it replaces. Consequently, a hole that can support a full column of mud may fail under the pressure induced by a similar column of cement. At the instant of such a failure, a rather tall column of cement may exist in the annulus; but as a result of the failure, the cement may fall downward until the pressure exerted by the remaining column is no greater than the natural fluid pressure within the thieving strata.

The result of attempting to raise cement too high in the annulus may be a shorter cement column than would have been achieved if a more conservative objective had been set. There are procedures that can be used to place a second stage of cement above the first following a failure; but the results are seldom equal in quality to those'dchieved with a properly placed primary stage.

DEVELOPMENT OF LEACHING WELL

A procedure will now he discussed that is used to develop a cavern leachIng we1l. Figure 4-2 j.11.ustrates the casing configuration used in a typical well. CONDUCTOR CASING

A short section of casing called "conductor casing" is usually set prior 


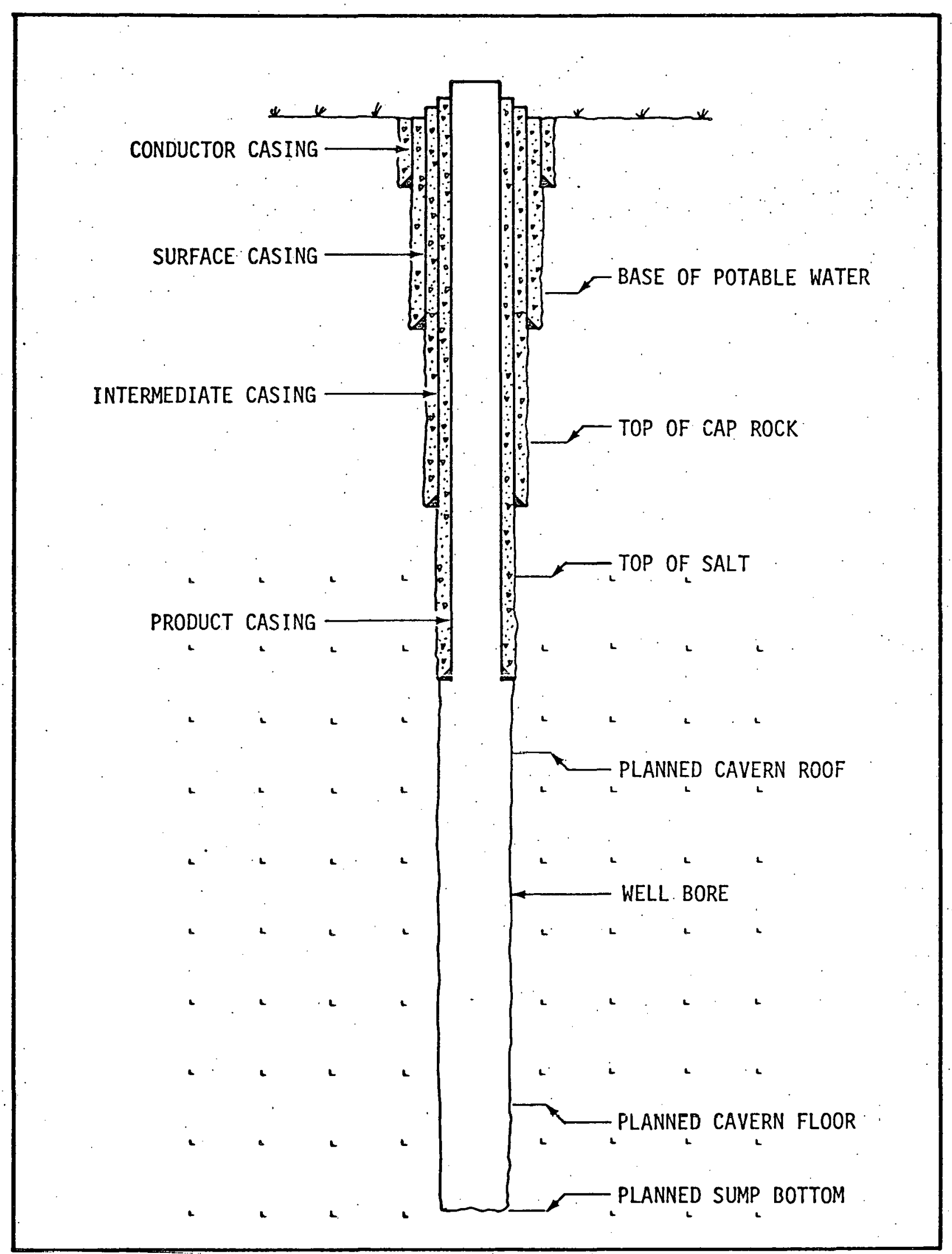

Figure 4-2. Casing configuration for cavern development well 
to mobilizing the rotary drilling rig. This casing may be driven into place under swampy conditions or may be set in a hole dug with an auger drill.

The conductor casing has two purposes. First, it prevents the loose soil and shallow unconsolidated sands and gravels from continually sloughing into the borehole as it is being drilled. Also, while the hole for the surface casing is being drilled, drilling mud is circulated down the inside of the drillpipe and back up the drillpipe-borehole annulus. As mud returns to the surface, the conductor casing contains it and "conducts" it to surface mud pits through an outlet connection near the top of the casing. After the well is drilled the conductor casing is usually cut off at ground level.

\section{SURFACE CASING}

A somewhat longer string of pipe called "surface casing" is required after the hole has been advanced through the potable water zones. This protects the water from mud contamination and from fluids or gases that might be encountered deeper in the hole. Since those fluids or gases may be under high pressure, a blowout prevention device is usually mounted on the top of the surface casing.

\section{INTERMEDIATE CASING}

Intermediate casing may be required to isolate very porous "loss of circulation" zones or intervals where formation caving occurs. These zones often occur near to or in the cap rock. 
Product casing is the last casing to be cemented in the well. Before It is installed, the borehole may be drilled to the planned depth of the bottom of the sump if suitable geological conditions exist. The casing is cemented from its lower end upward at least into the intermediate casing or up into the surface casing if an intermediate string is not used. During cavern construction this casing is used to supply blanket material to the cavity.

\section{LEACHING PROCESS}

Raw water injected into a salt cavern becomes saline because of circulation and diffusion. Circulation is the dominant factor, bringing unsaturated fluid to the salt face where dissolution occurs. The two elements contributing to circulation are gravity and pressure. The injected raw water, being lighter than brine, tends to rise, causing a "rolling" effect throughout the cavern. This agitation is responsible for the major portion of the dissolution. The pressure difference between point of entry and point of exit within a cavern also affects the pattern of fluld movement. The pressure differential is the dominant factor in bringing low salinity water to the salt face during the initial phase of leaching. As the cavern grows, differences in fluid density become increasingly important and evenlually dominate the process. 


\section{LEACHING TECHNIQUES}

Two basic leaching techniques--direct circulation and reverse circulation--are normally used. Direct circulation is most common, involving injection of raw water near the bottom of the cavern and withdrawal of brine through the casing annulus near the top of the cavern. In reverse circulation, water is injected down the casing annulus, entering near the top of the cavern, displacing brine into the tubing at the bottom of the cavern. Both methods utilize the same drilling and casing procedures.

Figure 4-3 illustrates cavern construction using reverse circulation.

\section{BLANKET MATERIAL}

Blanket material is any substance (gas, propane, butane, diesel oil, crude oil) lighter than water, which occupies the space in the topmost interval of the cavern. Its purpose is to prohibit leaching of salt from around the cemented casing. It also protects the product casing from internal corrosion and can be used to initially depress leaching to the bottom of the borehole for construction of a sump.

The protective blanket is extremely important, requiring careful monitoring and maintenance. Protection of the cemented casing serves the dual purpose of insuring a pressure-tight cavern and prohibiting development of high spots.

\section{INSOLUBLES ACCUMULATION}

Some insoluble material is present in most dome salt. It may be sand, anhydrite or a similar material. As leaching proceeds, an accumulation of 


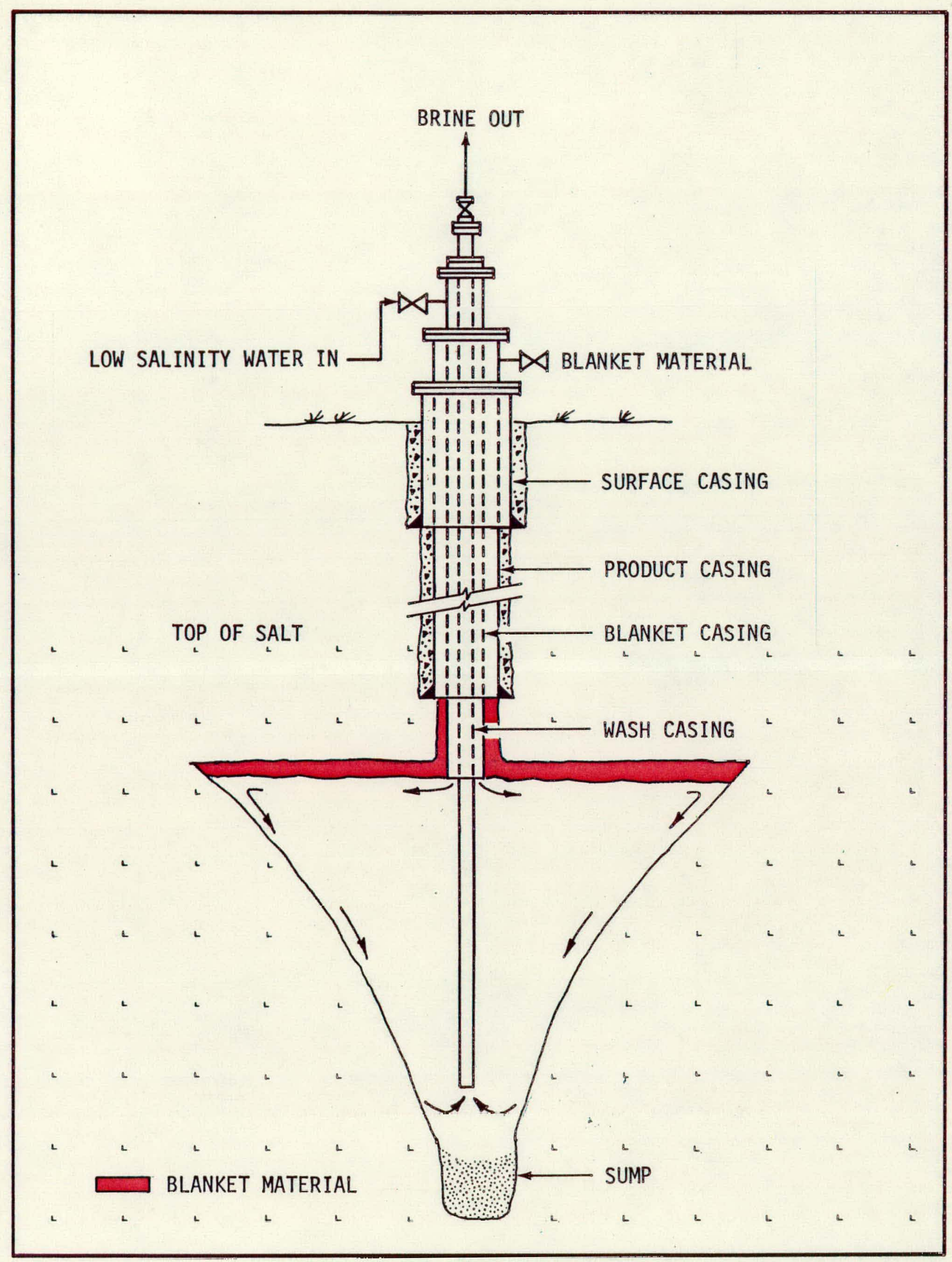

Figure 4-3. Typical cavern construction using reverse circulation 
insoluble material builds up in the bottom of the cavern, which may cause plugging of the wash casing or inhibit free circulation. If this occurs it may be necessary to raise the wash casing to a new position before leaching continues.

The problem of insoluble accumulations can be treated in at least two ways: physical removal of the rubble and construction of a sump below the cavern interval to collect the rubble.

\section{REMOVAL OF INSOLUBLES}

This technique requires the use of reverse circulation because the insolubles are transported out of the cavity through the wash casing. High brine velocities must be maintained in the wash casing in order to keep the solids in suspension. If circulation is interrupted for any reason, such as a power failure, suspended insolubles in the wash casing will try to fall back into the cavity and a bridging or plugging condition can occur. If bridging or plugging does occur, attempts to re-establish circulation either by direct circulation or reverse circulation or a combination of the two usually fail.

If the plug cannot be removed with the casing in the hole, the casing. is pulled and either cleaned or replaced. Plugs have been removed by high velocity water or nitrogen jetting supplied by a separate tubing lowered inside the wash casing. The jetting action erodes the plug and transports the insolubles to the surface in the annular space between the wash casing and the tubing. 
If the plug occurs at the lower end of the wash casing, because insolubles have settled around the casing bottom and entrapped solids, raising the casing may allow the plug to clear. The casing then would be repositioned at some point above the pile of insolubles before leaching resumes. If the plug is determined to be within the cavern interval, another alternative might be to shoot off the casing above the plug, add more casing at the wellhead, lower the string to a position above the pile of insolubles, and then resume circulation.

COLLECTION OF INSOLUBLES IN A SUMP

Instead of removing insolubles from the cavern, they can be allowed to accumulate in a sump constructed for that purpose. A sump is leached below the storage interval before cavern washing begins. The size of the sump depends upon the amount of insolubles estimated to be produced during leaching. The shape of the sump depends on the construction technique which will be discussed in Section 5 . 


\title{
SECTION 5 \\ Cavern Shape Control
}

\begin{abstract}
Although a variety of configurations can be constructed, the ultimate size and shape of a cavity depend on such factors as its height, rate of leaching, overall leaching time, degree of blanket level control, percent of insolubles in the salt stock, the solubility of the salt stock, and space limitations with respect to adjacent caverns or the edge of the dome.

The direction and point of injection of fresh water and the level of the contact surface between the blanket and the water are also essential factors governing shape control.
\end{abstract}

\section{DIRECT CIRCULATION}

With direct circulation, water is injected through the wash casing set near the bottom of the well bore and is discharged through the blanket casing often set near the desired roof of the cavern (see Figure 5-1).: The blanket interface is maintained near the bottom of the blanket casing. When this leaching melliod is used it is not uncommon for the brine discharge to be slightly undersaturated.

Leaching is inftiated in the lower cavern by circulation of the water in the confined well bore. Salinity increases not only radially outward from the centerline of the wash casing but vertically from the point of injection to the point of discharge from the cavern.

Th1s growth pattern continues until the "teardrop" cavern shape is developed. The heavier brine solution tends to collect near the bottom of 


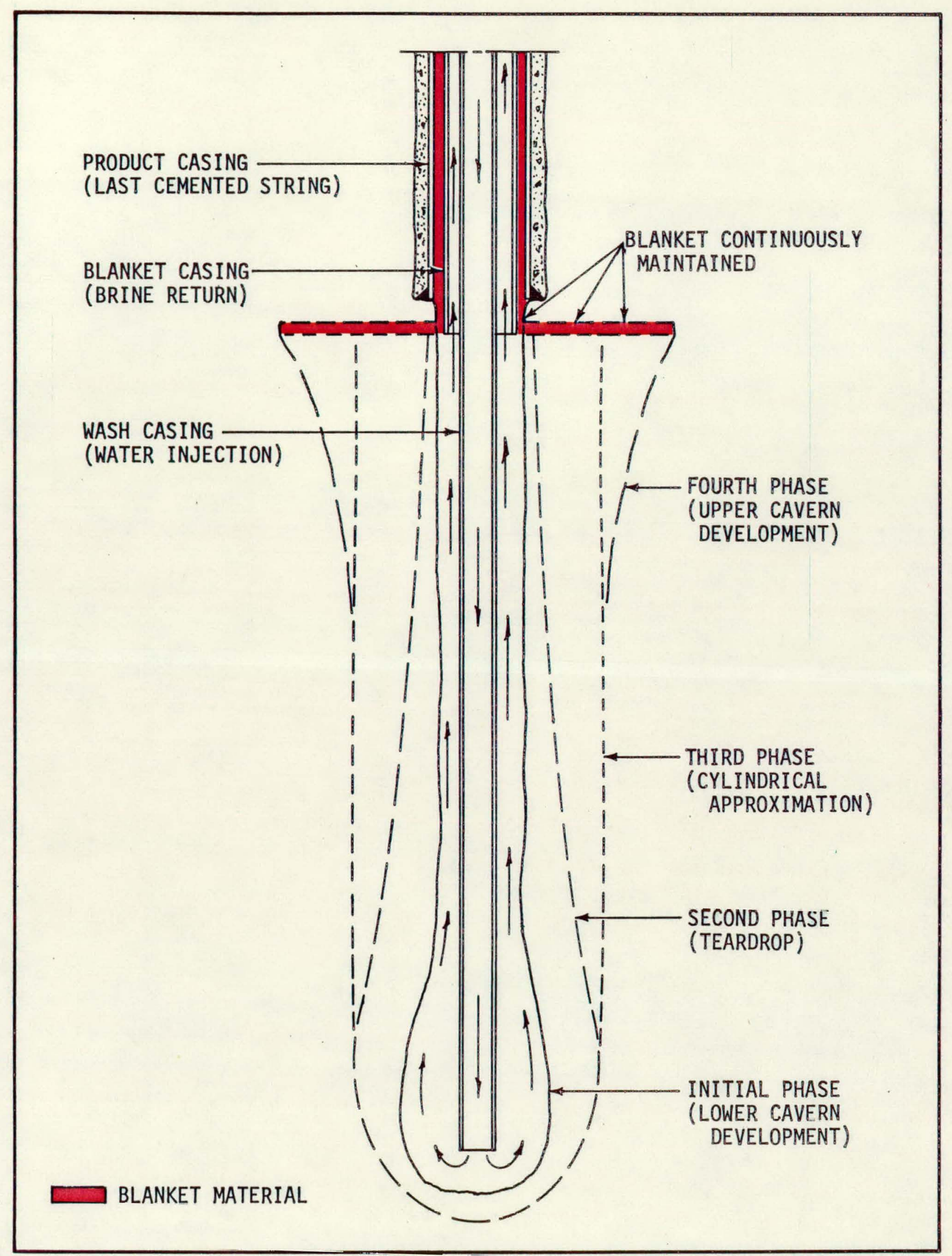

Figure 5-1. Cavern shapes resulting from direct circulation 
the cavern, forcing the inlet water to rise rapidly with decreasing exposure to lower portions of the cavern. Continued leaching develops the intermediate and upper portions of the cavern which results in the formation of a cylinder.

Once the cylinder is formed, further leaching develops the upper cavern. As additional water is injected it tends to rise rapidly to the point of discharge. A rolling motion is produced which facilitates mixing and helps to distribute a nonsaturated solution over the blanket interface.

Upon contact with the interface, some of the nonsaturated solution is discharged from the cavity; the rest is forced radially outward and dissolves salt exposed at the upper walls of the caverns. As the solution becomes more saline it tends to migrate toward the bottom of the cavity. In actual practice, advancing upper cavern development beyond the cylindrical stage with direct circulation requires extended leaching time and the development of very large caverns.

Direct circulation is sometimes used to develop the sump below the cavern interval. Blanket casing is positioned at the upper limit of the sump and the blanket is maintained at that level. Leaching continues until the predetermined sump interval, which is commonly cylindrical in shape, is developed. Wash and blanket casings are then repositioned for cavern development (see Figure 5 2).

\section{REVERSE CIRCULATION}

Like direct circulation, flow patterns for reverse circulation (see Figure 4-3) enable a variety of cavern shapes and sizes to be constructed, but there are many variables. The position of the blanket casing is an 


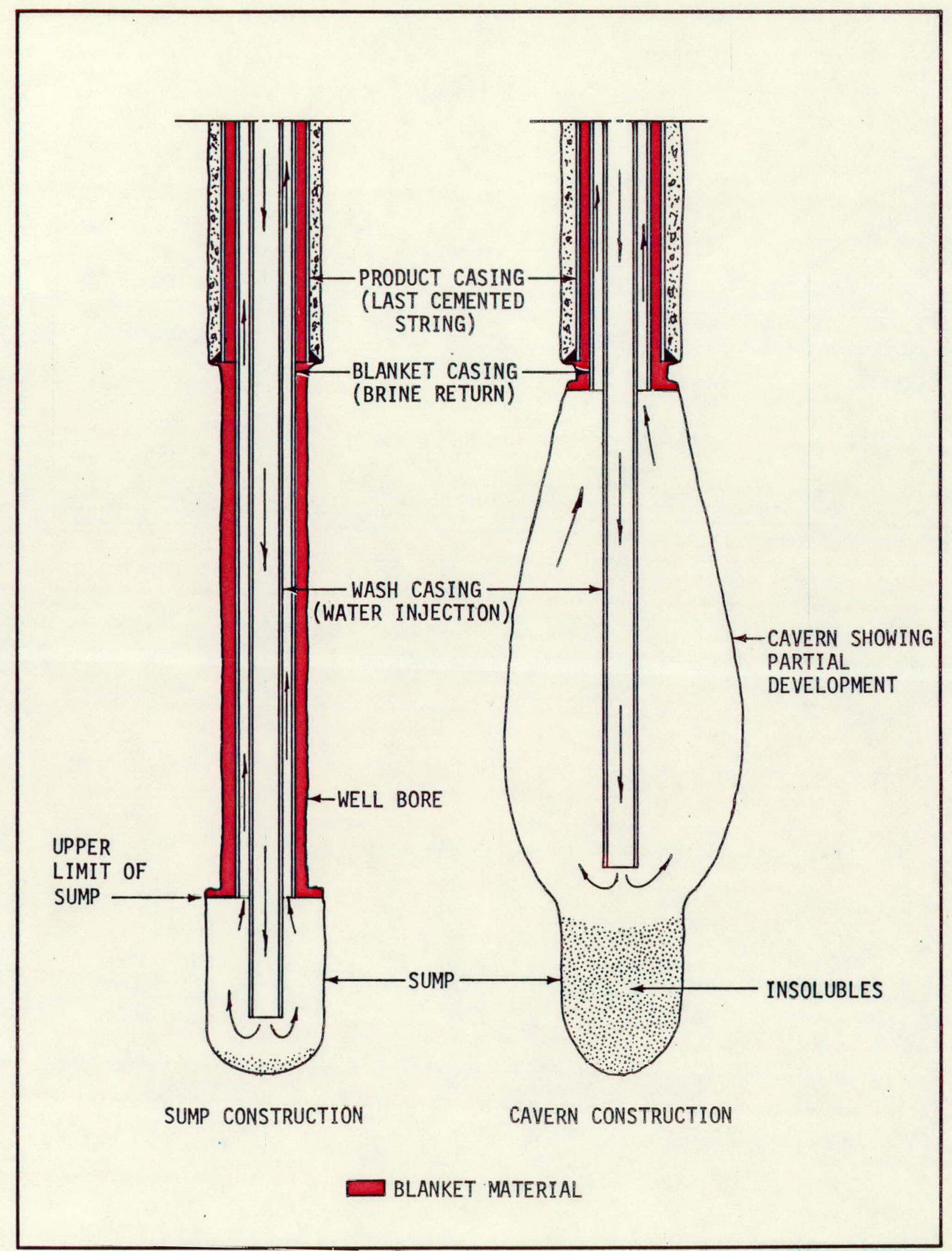

Figure 5-2. Casing configuration for sump and cavity construction 
important factor in determining the shape of caverns when reverse circulation is employed (see Figures 5-3 through 5-5).

The casing configuration for upper cavern injection is the same as shown in Figure 5-1, but the flow is reversed. Because it is lighter than brine, water which is continuously injected into the cavity rises to the blanket interface. It is then forced radially outward until it contacts and begins to dissolve the salt. As the solution increases in salinity and becomes heavier, it migrates toward the bottom of the cavern where the discharge pipe is set. This results in the "morning glory" shaped cavern illustrated in Figure 5-3.

Reverse circulation is also used in cases where the blanket casing is positioned, not at the roof, but at any point in the cavern interval from the roof to near the bottom of the wash casing. These positions characteristically result first in an enlargement of the we1l bore near the point of injection and later in a teardrop shape.

Continued leaching produces gradual enlargement toward the top of the cavern and an eventual cylindrical cavern. The final phase results in upper cavern development. Figures 5-4 and 5-5 show cavern shapes resulting from reverse circulation using blanket casings set at the midpoint of the cavern interval and near the bottom of the cavern respectively.

Reverse circulation can also be used to develop the sump below the cavern interval. Casing is set as shown in Figure 5-2; however, flow is down the blanket casing and up the wash casing, resulting in a morningglory shaped sump. 


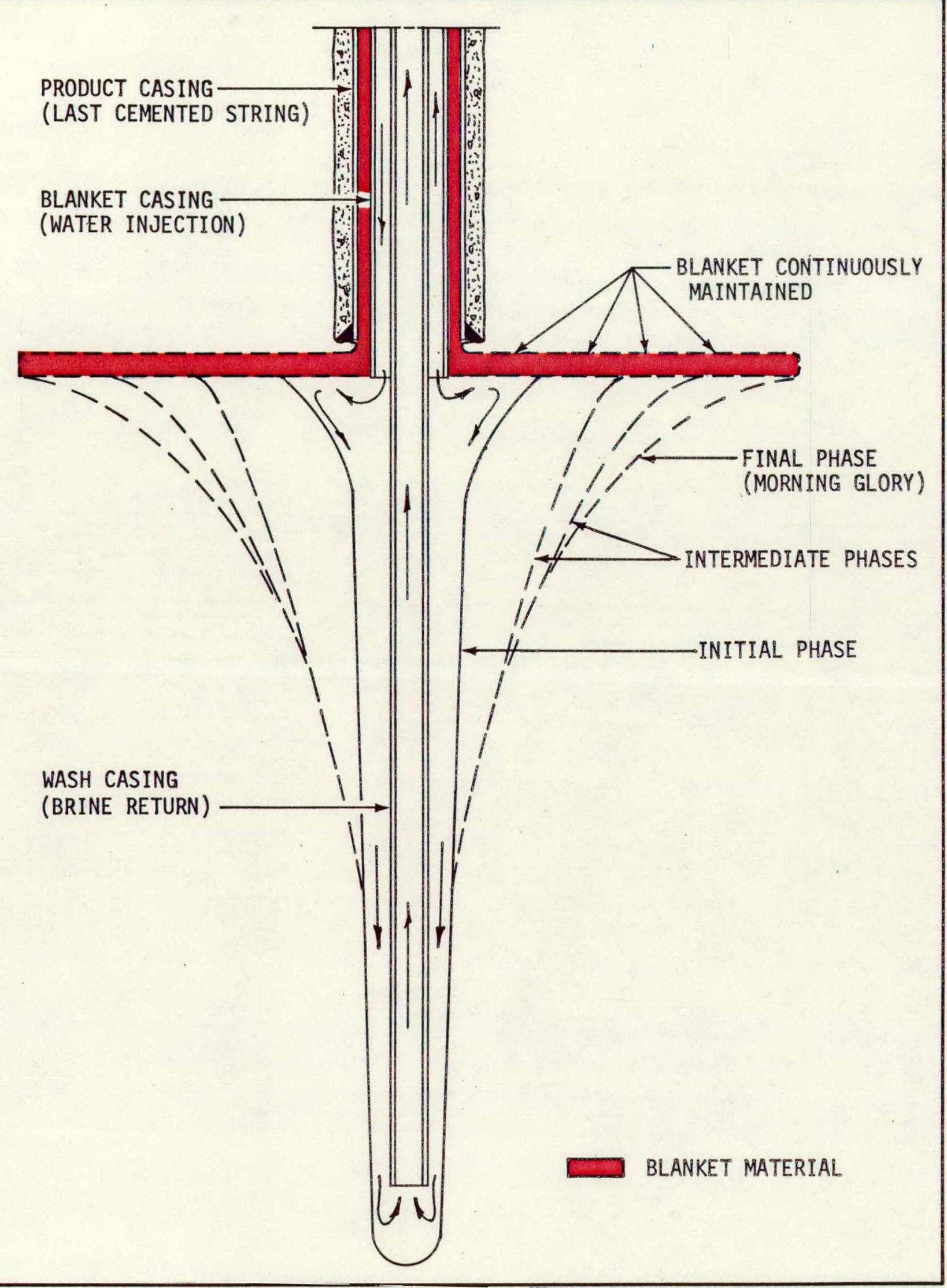

Figure 5-3. Cavern shape resulting from reverse circulation upper cavern injection 


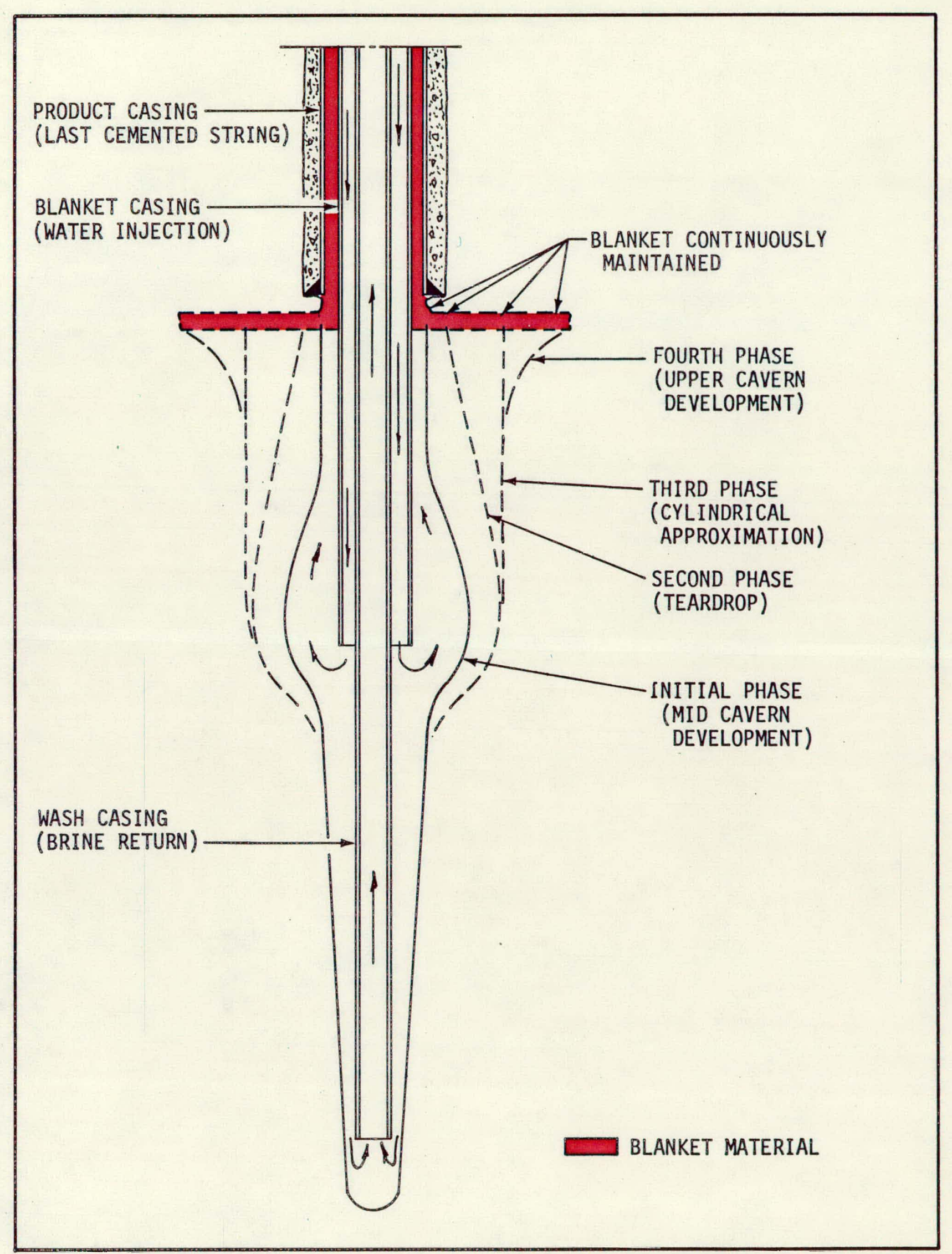

Figure 5-40. Cavern shapes resulting from reverse circulationmil cavern injection 


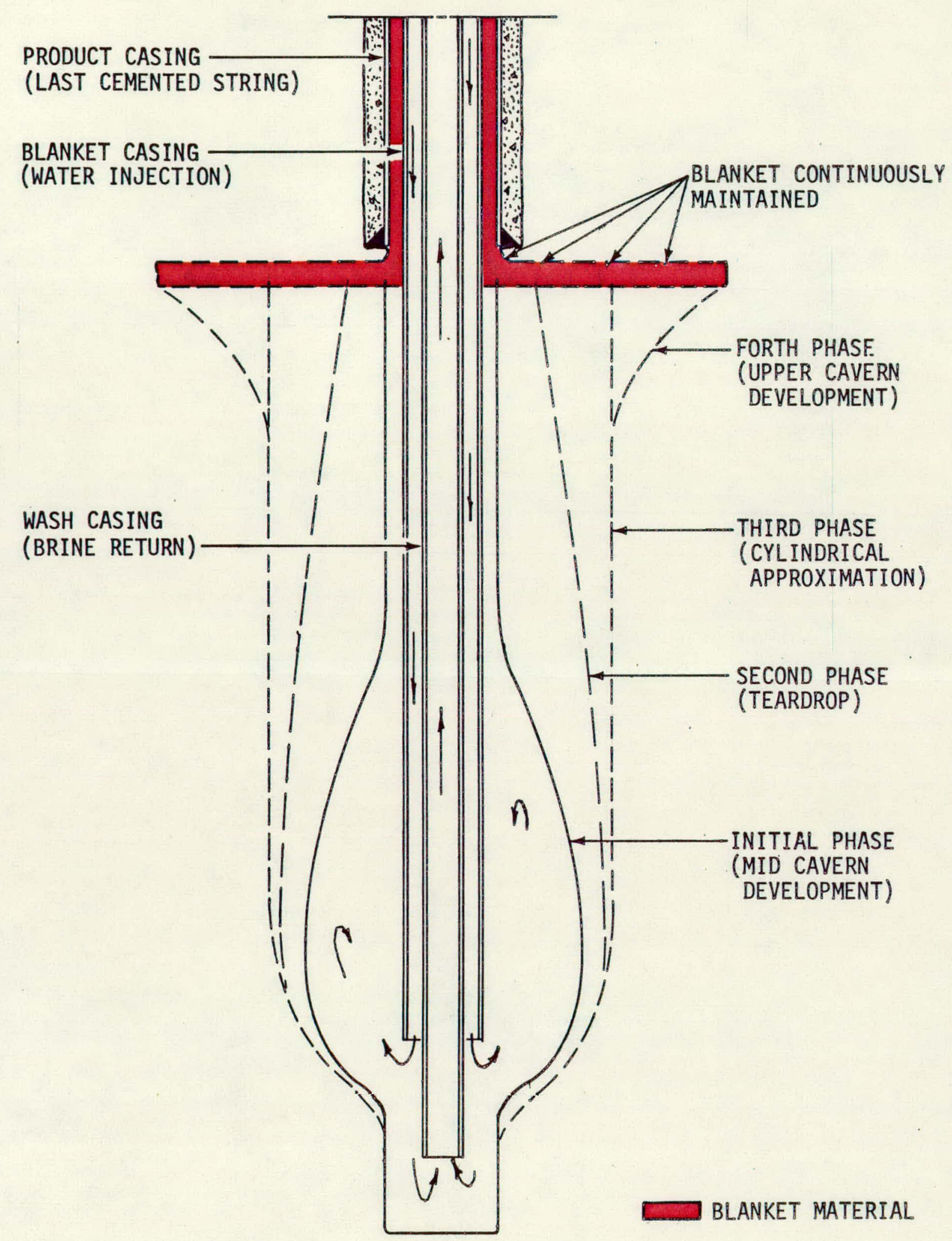

F1gure 5-5. Cavern shapes resulting from reverse clrculationlower cavern injection 


\section{MODIFIED TECHNIQUE}

Modifications of direct and reverse circulation techniques have been studied in the laboratory and are used today to construct storage caverns. Many model caverns have been washed under laboratory conditions in order to study resulting shapes due to various leaching techniques. ${ }^{3}$ Extensive laboratory research ${ }^{4,5}$ has been devoted to developing techniques for creating spherical caverns.

The creation of a 315 foot diameter sphere at a depth of 2,700 feet was the subject of a study conducted for the U.S. Atomic Energy Commission. 6 The sphere represented the largest, shape-controlled cavity ever proposed by solution mining techniques. A movable blanket technique with insolubles removed by jetting and a combination of solution-conventional mining methods were proposed.

Fenix \& Scisson uses a modified technique for washing caverns which approximate the spherical shape. During development of the sump and the cavern, casing configuration is changed only once from its original setting as shown in Figure 5-6.

The sump is developed first. The well bore extends to the bottom of the predetermined sump interval. Wash casing is set near the bottom of the well bore and blanket casing is set at an intermediate point in the cavern interval. Direct circulation is used to develop the sump with either the teardrop or cylindrical shape.

Cavern development begins after the wash casing is repositioned. The position of the blanket casing remains unchanged, but the wash casing is raised to prevent it from plugging as insolubles collect in the sump during development. Reverse circulation with mid-cavern injection is used for 


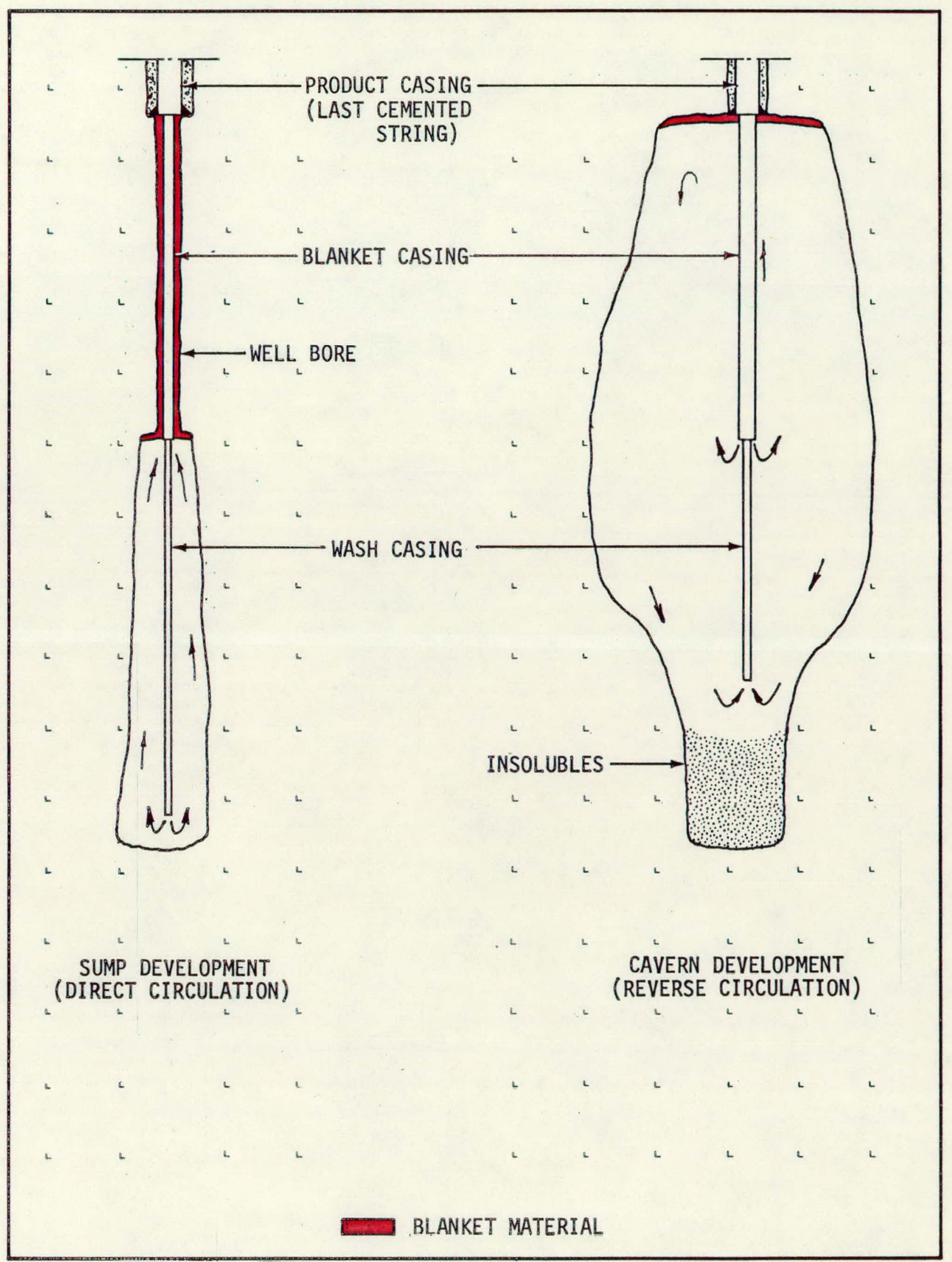

Figure 5-6. Modified technique used to develop a cavern whose shape is a spherical approximation 
cavern washing. The blanket is maintained near the desired roof of the cavity. Figure 5-6 illustrates typical cavity profiles resulting from the use of the modified technique and Figure 5-7 shows a plastic model (horizontal to vertical scale is $2: 1$ ) constructed from a Dowell sonar caliper survey of a typical cavern.

\section{SAMPLE CAVERN SIZES}

In order to better grasp the magnitude of space created by solution mining, several example shapes are illustrated in Figure 5-8 with approximate dimensions given for an arbitrary cavern volume of 14 million cubic feet.

Except for the sphere, dimensions are given for 500 and 1,000 foot cavern intervals. The morning glory was approximated by a cone. The spherical approximation is shown to progress from a narrow cylinder to a barrel shape that continues to enlarge more in the upper portion than in the lower part. This is due to circulation of fresh water in the upper cavern before it becomes saline and migrates to the bottom. 


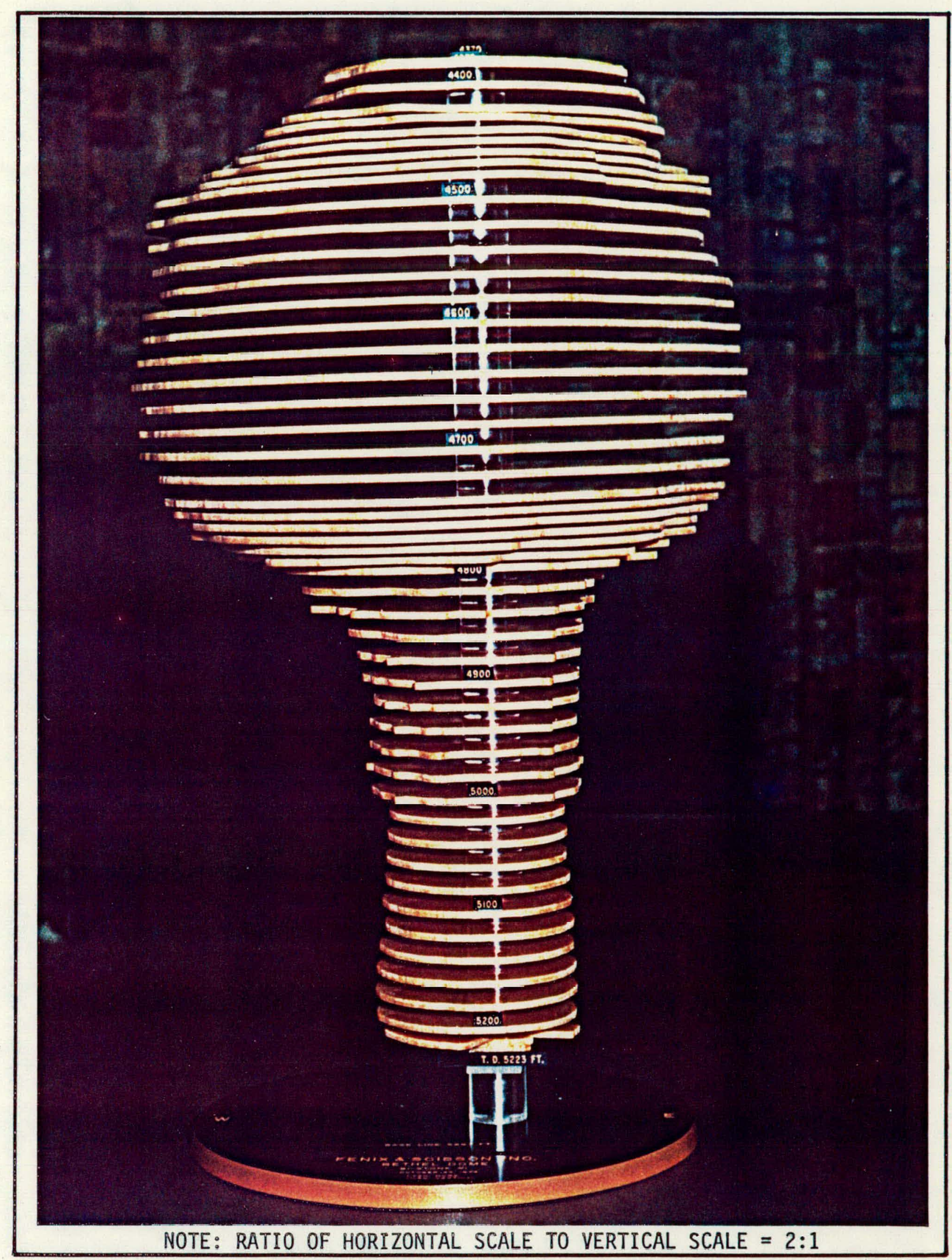

Figure 5-7. Model of cavern constructed using modified circulation technique 


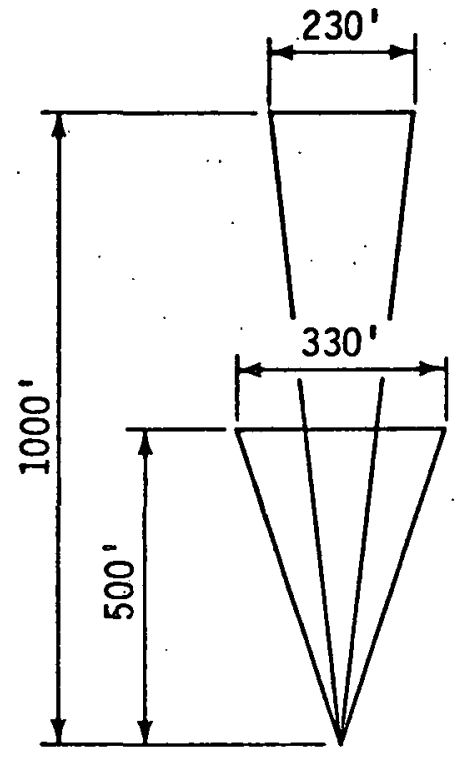

MORNING GLORY

(CONICAL APPROXIMATION)

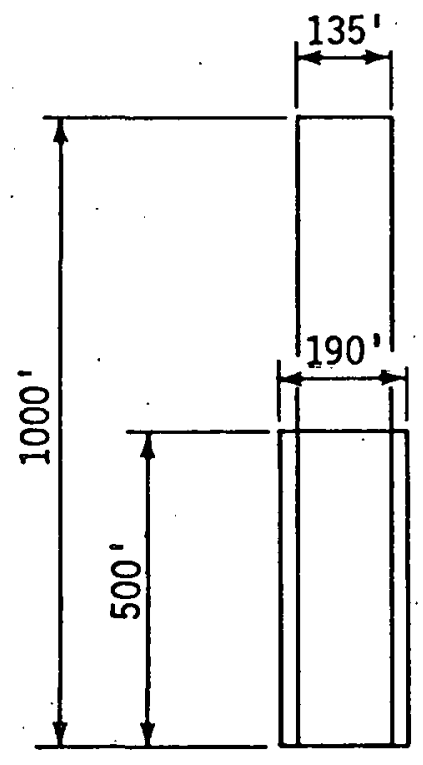

CYLINDER

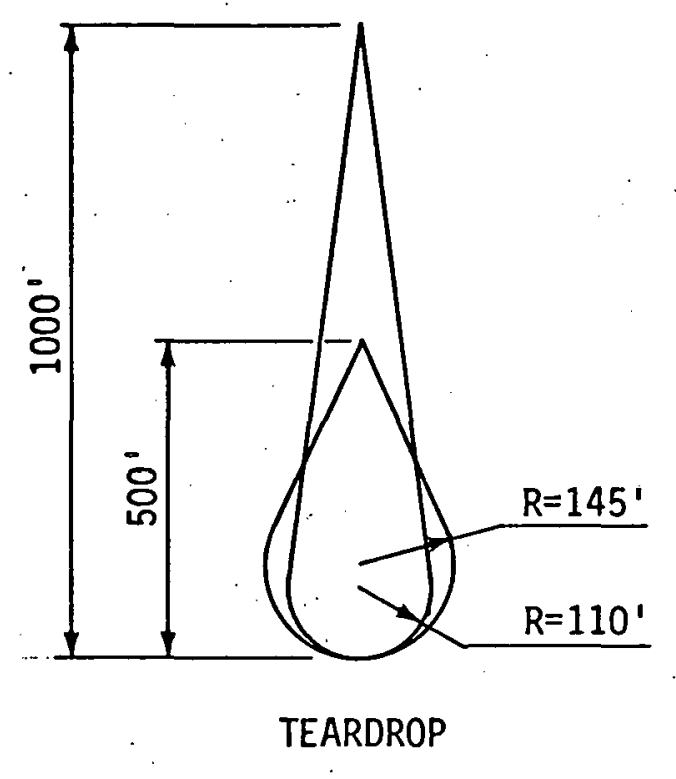

PROGRESSION OF CAVERN GROWTH

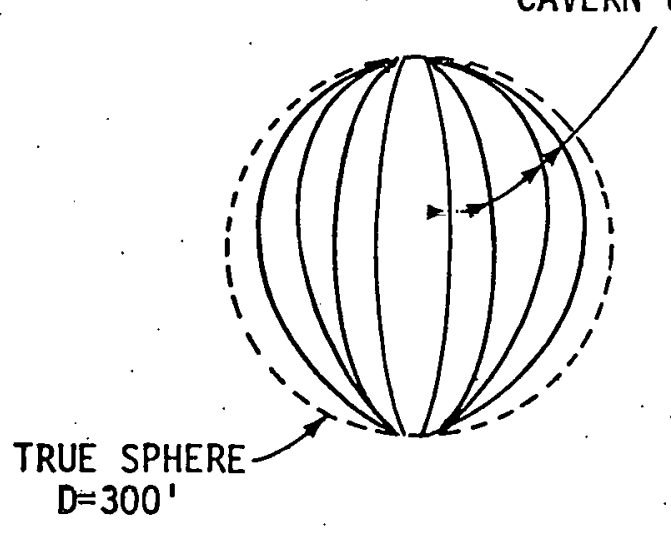

SPHERICAL APPROXIMATION

Figure 5-8. Dimensions of varlous shapes of caverns (14-million cublc foot volume) 


\section{SECTION 6 \\ Establishment OF Dome Limits}

One of the first tasks in determining the feasibility of using a dome for storage is to establish its areal extent. Two other important considerations to be determined are the depth to the top of the salt and the presence of overhang. The latter is a condition existing in mushroom shaped domes where the top of the salt overlaps or extends out over the main trunk of the dome. Dome configurations can be seen on the structure map (Figure 6-2) and the geologic cross section (Figure 6-3) which accompany this section.

Preliminary work involves the accumulation of available subsurface information concerning the dome and surrounding area. Sources of information include various state agencies and oil and gas industry regulatory bodies. Also, most domes suitable for storage operations have received some attention in technical publications. 7

The type of information available includes logs and completion records of wells that have been drilled. Generally, depths to the tops of formations penetrated during drilling are included, as well as depths to the cap rock and top of the salt if encountered.

\section{PREPARATION OF STRUCTURE MAP}

Preparation of a structure map begins with a base map of the general area of interest which includes location of known wells. Figure 6-1 is a base map, overlying a Gulf Coast salt dome. Well locations are plotted on the 


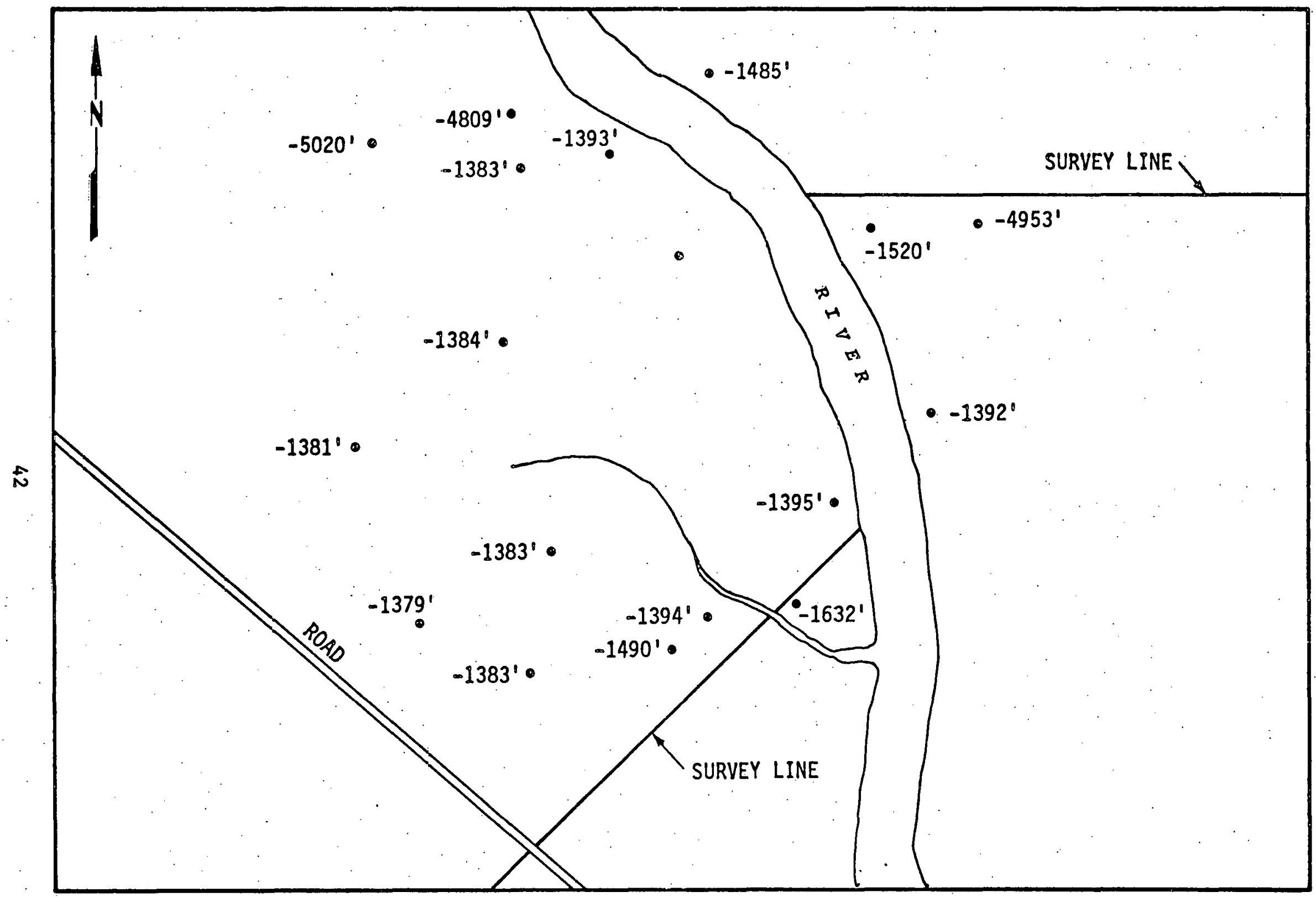

Figure 6-1. Base map with well locations 
map with adjacent numbers indicating depth to the top of the salt.

Also, thickness of the cap rock is mapped if sufficient data are available. This information is of interest to those responsible for drillIng the necessary wells because loss of drilling fluid is often encountered when drilling through cap rock.

Next, contour lines (i.e., lines connecting points of equal depth, cap rock thickness, etc.) are drawn to define the top of the salt at specific depths. For example, the $-3,000$ foot depth contour maps the salt boundary at $-3,000$ feet. Figure 6-2 shows a structure map constructed from the base map of Figure 6-1.

\section{PREPARATION OF GEOLOGIC CROSS SECTION}

The geologic cross section is constructed from the structure map and technical data derived from the logs and well completion records. Orientation of the cross sectional cut through the dome is selected where sufficient data are available and/or to intersect features of interest such as overhang (see Figure 6-3).

After the structure map and geologic cross section have been completed, there may be areas of interest on the dome about which data are insufficient to determine the nature of the underlying salt. Supplementary data can be obtained by drilling additional holes and by using seismic measurement techniques. Information derived from drilling includes the depths to various formations such as the cap rock and top of salt. . Seismic techniques give definition of the shape of the dome such as the perimeter of the salt at various depths and the presence of overhang. 


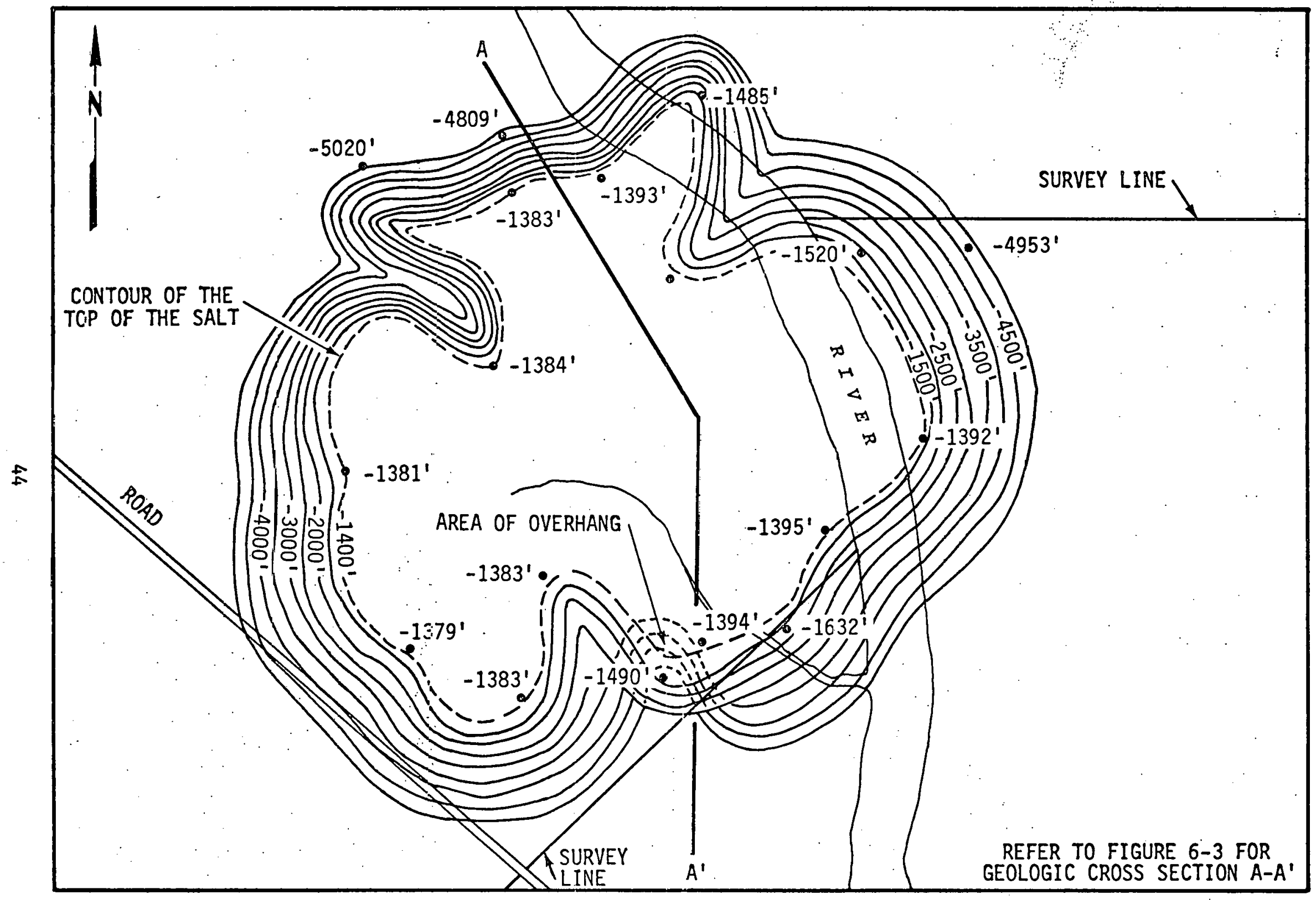

Figure 6-2. Structure map 


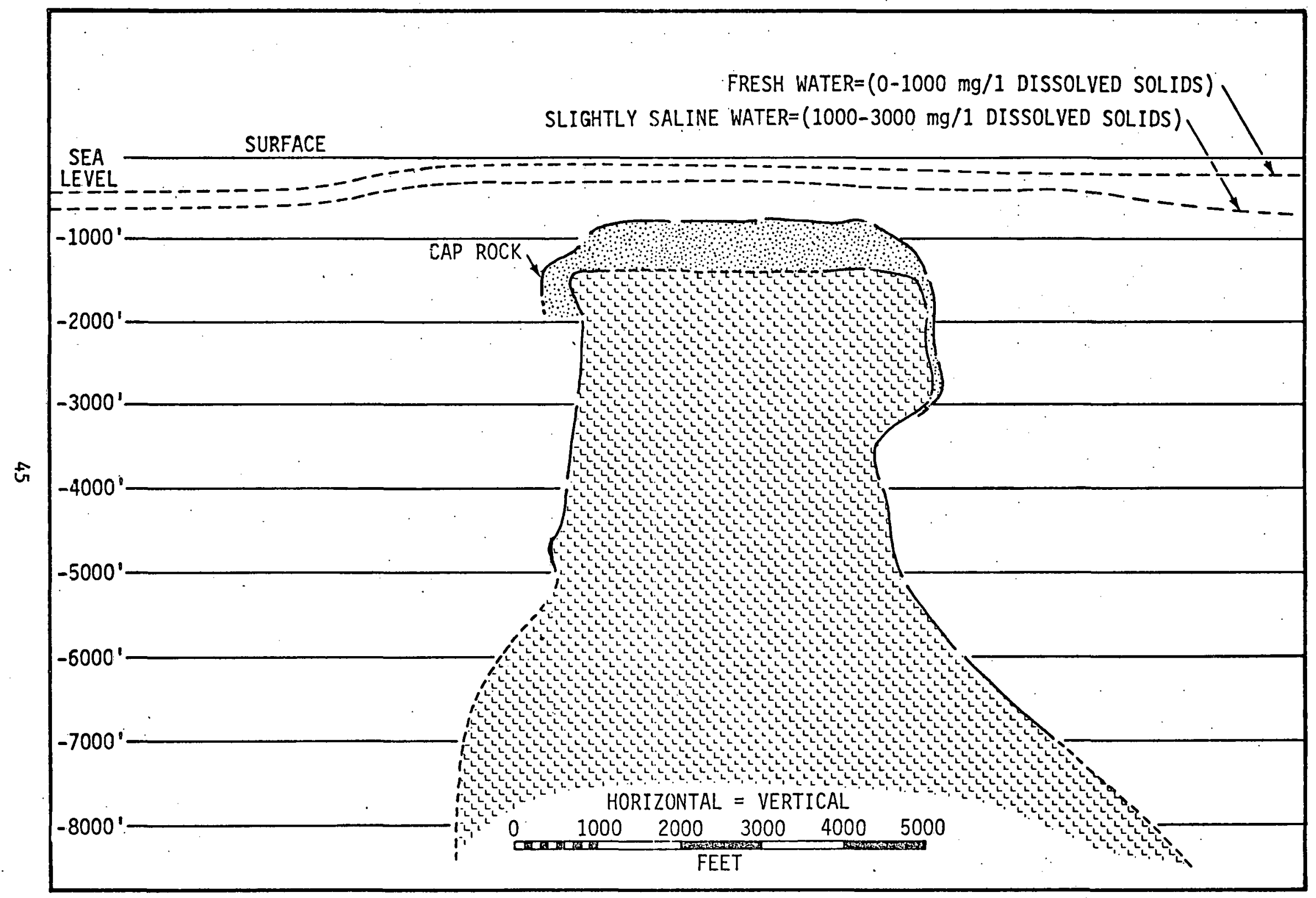

Figure 6-3. Geologic cross section A-A' 


\section{Section 7}

\section{Brine Disposal}

Brine production began to affect the environment long before the recorded presence of man. Even today, much of the salt entering the sea stems from natural causes of rivers and streams passing through exposed beds of salt or salt bearing rocks.

Natural leaching has been a slow process permitting living organisms to evolve and adjust to the changing conditions of salinity. It is the accelerated leaching caused by man that attracts attention in this era of environmental concern.

One of the significant causes of increasing salinity in our surface waters today is irrigation. Tremendous quantities of salt are leached from the soil each year as water drains from the fields back into the rivers. The lower Colorado river has become so saline that our treaty commitments to Mexico are in jeopardy. However, this too has been a gradual process and man has been slow to awaken to its ramifications.

Far more obvious were the side effects of early oil production. Early producers had no facilities for handling water that rose to surface with their oil. They simply released it upon the land, into the streams and down the rivers. When they could direct it into flowing water, dilution was usually adequate and no apparent damage was observed. When it lay on the land, however, the effect was devastating. Forests died, land became barren, erosion developed and many oil fields became national eyesores.

Laws were passed and safe brine disposal became mandatory. The cost of proper brine disposal became a major factor in the cost of oil production and 
many oil fields were abandoned because revenue was inadequate to fund brine disposal.

Fortunately, the oil industry was able to solve the problems of brine disposal in most instances. Much of the brine now produced is reinjected into oil bearing formations to drive additional oil to production wells. Where this is not possible or practical, it is injected into naturally saline. aquifers located far below those bearing potable water.. Although the oil industry may have been negligent at one time in its attitude toward brine, its expertise in this field is now unquestioned. Most of the technology used to dispose of brine during cavern leaching is directly rooted in the experience and knowledge developed within the oil industry.

To date, regulatory enforcement has been reasonable and effective. The views of environmentalists, however, have been much more extreme, and should these views eventually be adopted into law present practices could be inhibited.

\section{ALTERNATE DISPOSAL METHODS}

Although subsurfacc brine dieposal is usually emplnyed, there are three other possible means for handling the brine resulting from cavern development.

TRANSFER OF BRINE TO CHEMICAL INDUSTRY USERS

Transferring brine to industries to be used as feedstock for salt and chemical production may be possible in some localities, but depends on certain economic and operational considerations. 
Two main economic factors involved in transferring brine to other users are the financial agreement concerning the brine and the cost of the physical transportation system. It is unlikely that the brine can be sold. Instead, industrial users usually charge a fee to accept the brine. The fee may be charged to cover additional processing costs to the user, such as raising the salinity of the brine to full saturation (if it is not already fully saturated) and/or removing insolubles or unwanted soluble chemicals. If the brine is 100 percent saturated and of high chemical quality, it might be possible to negotiate a transfer without paying a fee.

Because of the expense of transportation the distance between the cavern and the industrial user is important. Although it is theoretically possible to use rail or highway transportation for brine transferral, a brine pipeline is usually necessary. Pipeline construction is a major cost item and if the user is not located on adjacent property, costs including right-of-way can be prohibitive.

OPERATIONAL CONSIDERATIONS

In general, it is usually more desirable for the operator developing underground storage to maintain total control over all aspects of the project, including the disposal of brine. Schemes dependent upon other companies represent potential problem areas. The brine user may have a production shutdown, a strike, go out of business, etc., leaving the development project without a means of completion. In view of the numerous problems and uncertainties involved $1 \mathrm{t}$ is seldom that transfer to industrial users can provide 
the solution for economical, dependable brine disposal.

DISPOSAL OF BRINE IN SURFACE WATERS OR AT SEA

The disposal of brine either in surface waters or in the sea involves legal considerations that may cause projects to be delayed or rejected.

Most early hydrocarbon storage caverns were constructed at locations distant from established users of brine. Thus, the brine was valueless and was usually dumped into rivers, "'Until recent years, leaching rates were low and river flows were high, and dumping was permitted in Gulf Coastal regions. The environmental effects of dumping were negligible. Marine life in these coastal rivers was tolerant of minor salinity variations, having already adapted to the natural variations caused by tides.

Although the practice of river dumping is now usually prohibited, many operators of early caverns stoutly defend the practice as harmless. They point out that a $1,000 \mathrm{gpm}$ discharge of saturated brine into a river flowing at four million gpm would cause only an 80 part per million rise in salinity. Radian Corporation findings suggest that an increase of less than 500 ppm could not be detected by organisms. ${ }^{8}$ Nevertheless, existing regulations may prohibit any program of cavern construction dependent on dumping of brine into rivers.

An analysis of brine discharge and resultant environmental effects is beyond the scope of this study, but it possibly can be acquired from other sources. LOOP, Inc. financed such a study for eventual submission as part of an environmental impact statement supporting crude oil storage at locations near the Gulf. We were unable to obtain the study but were given assurances that no unsolvable technical problems exist. 
If brine disposal to the sea is chosen as a design parameter for cavern construction, the expected problems will be legal rather than technical. Even the most exhaustive study proving negligible environmental damage could be challenged in the courts, causing project delay.

EVAPORATION OF BRINE IN SURFACE PITS

Impounding brine in surface pits is technically possible during cavern construction. However, the salt resulting from the evaporation process must later be disposed of. The rate of evaporation varies at different salt dome localities, and in most areas annual rainfall would make the evaporation process difficult if not imposstble.

Even if a means is devised to dispose of the salt after evaporation, the cost of pit construction and maintenance will be a major percentage of the total project expense. For example, if a one million barrel cavern is to be constructed using fresh water for leaching, then approximately six to seven million barrels of brine will be produced. To hold this quantity of brine would require a 60 acre pit some 20 feet deep at a cost of roughly one dollar per barrel of usable pit volume. A major cost item is the membrane liner installed to prevent brine migration from the pit into shallow ground water aquifers. If unusual construction conditions are present, such as swampy terrain, the cost could easily double.

\section{SUBSURFACE BRINE DISPOSAL}

Brine discharge into saline aquifers is a long established practice by 
the oil industry. Although regulation of the practice varies somewhat between states, all oil producing states accept the principle that such disposal can be accomplished without ecological harm. Regulatory and technical requirements generally mandate that the following conditions be met:

- Water within the recipient aquifer must be sufficiently saline that the aquifer has no plausible use other than as a source of saline water.

- The recipient aquifer must have adequate reservoir characteristics of porosity, permeability, thickness, and areal extent to contain the projected volume of injected fluid.

- The point of injection must be located and designed in a manner that will prevent harmful effect on hydrocarbon production associated with that aquifer.

- The injection well must be completed in a manner that will assure complete isolation of the injected fluid from all aquifers other than the recipient aquifer.

o Injection pressure at the point of entry into the recipient aquifer must be less than the pressure required to fracture the rock strata.

DEVELOPMENT OF DISPOSAL WELLS

A procedure will now be discussed that can be used to develop a brine disposal well. Figure 7-1 illustrates the casing configuration used in a typical disposal well. 


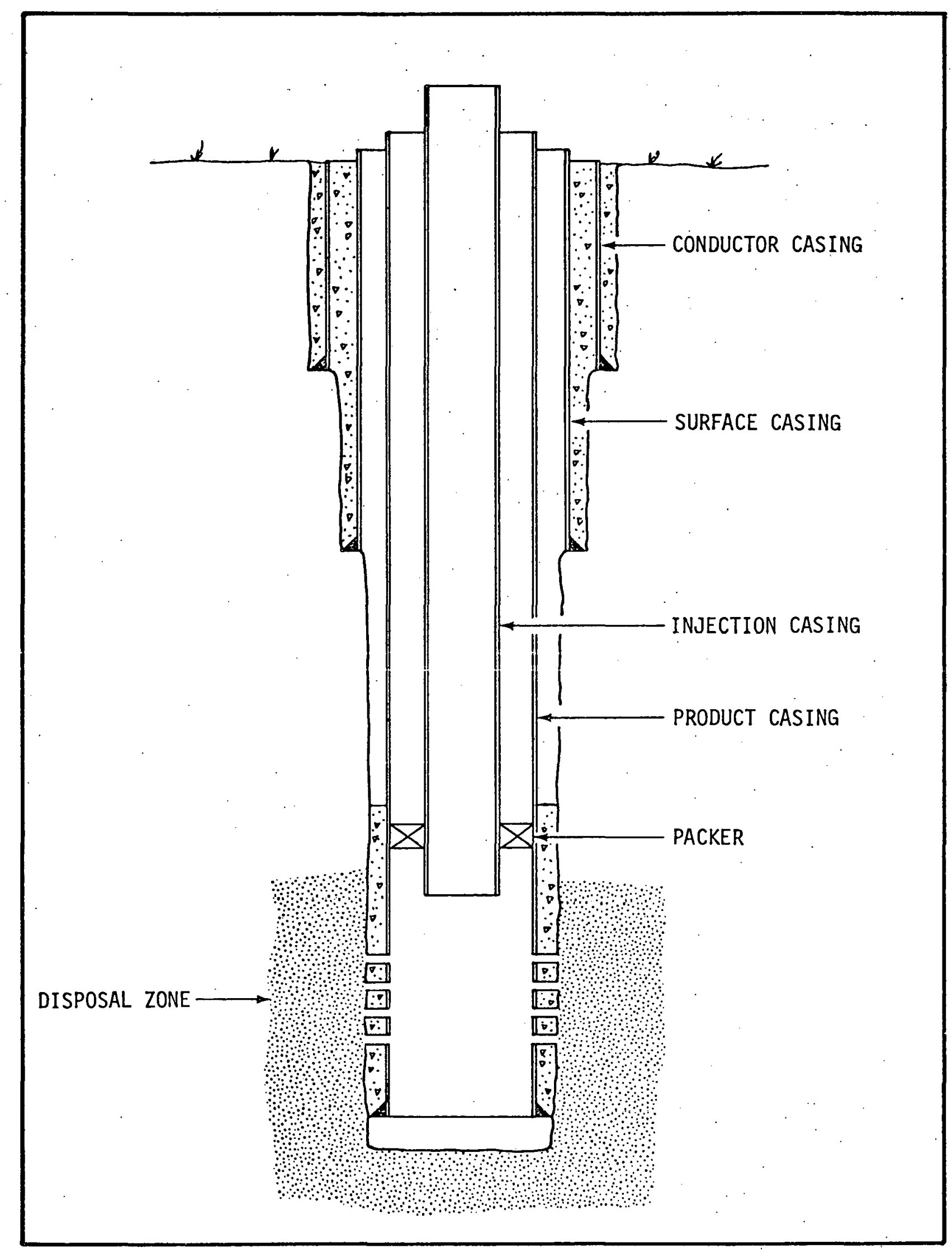

PIgure 7-1. Typlcal disposal well casing configuration 
After the site has been selected for the brine disposal well the conductor casing is the first casing to be installed. Its purpose is to keep the well bore open through the shallow surface formations and to conduct drilling mud to the mud pits while the hole for the surface casing is being drilled. After the hole for the conductor casing is drilled, and the casing installed, the space between the casing and hole is cemented to the surface.

\section{SURFACE CASING}

The hole for surface casing is drilled next, and casing is installed and cemented from the bottom to the surface. The purpose of this casing is to isolate all fresh water bearing formations from the injected fluid.

PRODUCT STRING

The hole for the product string is then drilled to the total planned depth. The product string is installed and is cemented from the bottom to a point above the perforated zone. The purpose of the string and the cement is to prevent migration of fluids between the formaliuns penetratid.

Following installation of the product string, perforations are made into the disposal zone (s) and an acid treatment is performed. A perforating gun is suspended inside the product string and shaped charges are used to make perforations through the wall of the string and the cement sheath. An acid is then injected into the well and forced out the perforations. The acid opens the holes made by the perforations and cleans the cement and drilling mud left on the face of the formation. 
An injection tubing string is often used as additional protection against. contamination of upper formations. A packer is installed on the lower end of the injection tubing and set inside the product string at a point above the perforations. The packer forms a mechanical seal between the injection tubing and product string. Hydrocarbons or treated fluids may be used in the injection tubing-product string annulus to protect against corrosion.

After the proper fittings and valves have been installed on the wellhead, the well is tested and connected to the brine disposal pipeline and is ready for operation.

\section{BRINE DISPOSAL RESERVOIR ANALYSIS}

Any discussion of underground brine disposal must hinge on the subject of reservoir analysis. This is a highly developed science peculiar to the oil industry. The same factors that govern oil flow to a well also regulate brine flow from a well.

For many surface design considerations water can be treated as an incompressible fluid. But for the purpose of brine disposal--where subsurface, high-pressure conditions extst--both water and reservoir rock are slightly compressible. This characteristic is very important in reservoir calculations.

As an illustration, assume that it is possible to construct a reservoir 100 feet high and $31 / 2$ miles in diameter. Further assume that it is filled with a section of typical Gulf Coastal disposal reservoir material comprised of sandstone and saline water. If all of the brine produced while leaching 
and filling a million barrel storage facility were added to the contents of the reservoir, the result would be an increase in pressure within the reservoir of about 1,250 .psi (pounds per square inch).

This illustration has little relationship to the actual process of brine disposal, but it is interesting to note that most typical Gulf Coastal disposal reservoirs located at depths of more than 5,000 feet could tolerate a 1,250 psi rise in pressure without fracturing overlying rock strata.

In the Gulf Coastal region, multiple saline aquifers exist, often totaling several thousand feet in thickness. These sands are believed to extend over vast areas.

Although reservoir capacity may be considered adequate, there are some physical limitations on how brine can be delivered into the reservoir. The hydraulic implications of disposal injection are roughly equivalent to those of pumping into the small end of a large funnel: There is a large pressure drop as brine travels the first few feet away from the well bore. However, the cross section of flow area increases as the square of the radial distance from the well bore.

Thus, during injection the reservoir pressure at the well bore might be 1,000 psi higher than the reservoir pressure at a point several hundred feet away from the well bore. Gulf Coastal aquifers are so thick, porous and permeable that the pressure profile will drop rapidly and will be only a few pounds above the normal reservoir pressure at a relatively short distance from the we11.

The pressure profile and zone of interference created by adjacent wells in a brine disposal reservoir is shown in Figure 7-2. 


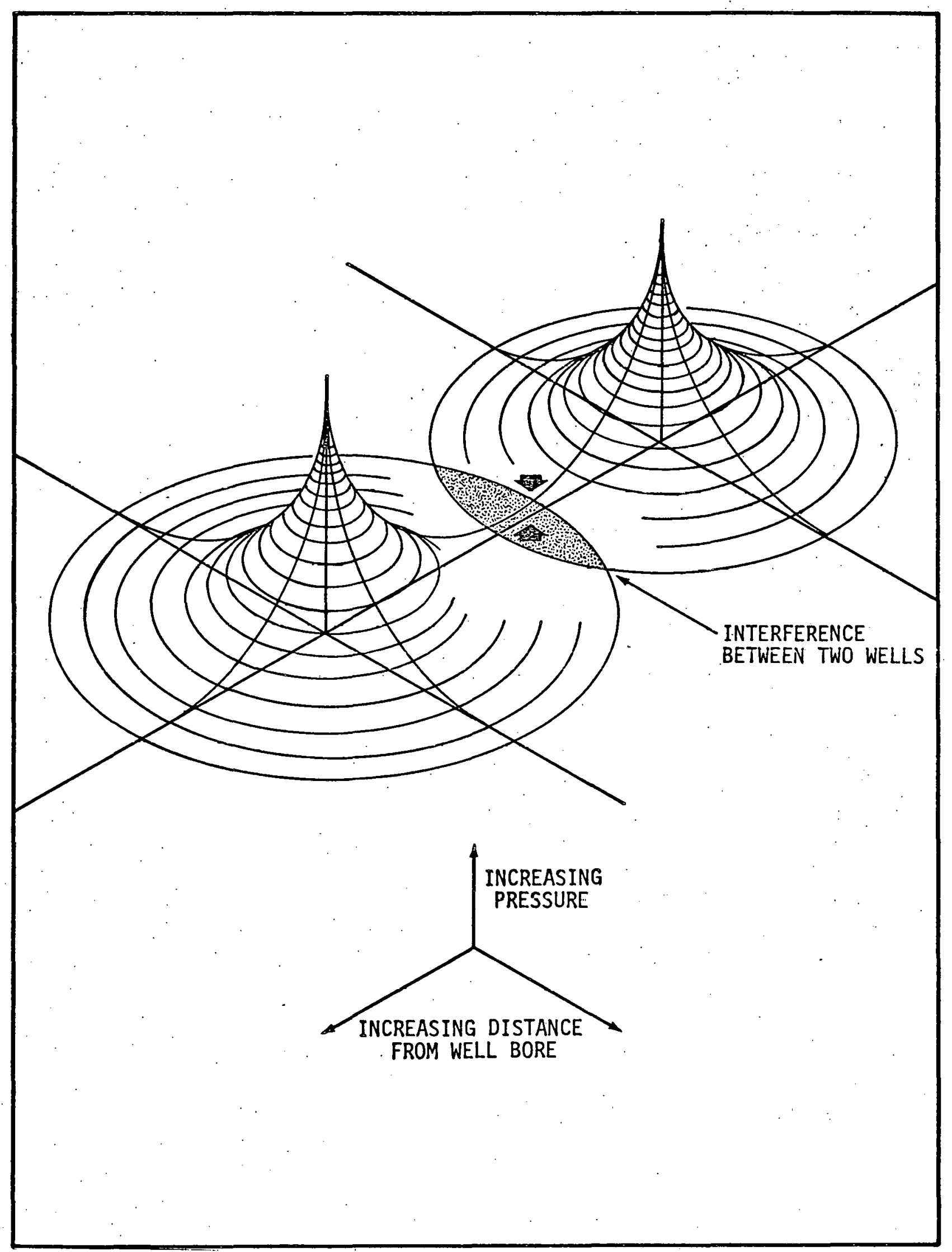

Figure 7-2: Brine reservolr pressure profile for two adjacent brine disposal wells 


\section{PARAMETERS OF RESERVOIR ANALYSIS}

Many studies have been conducted on the behavior of fluid flow through porous rocks and unconsolidated sand, and many of the theories and equations describing the fluid distributions have been field proven.

\section{FORMATION POROSITY}

Formation porosity is the fraction of total volume that is not occupied by the solid framework of reservoir rock. The porosity of a formation is a measure of the fluid carrying capacity of the rock. Because fluids within a formation are slightly compressible, there should be a large amount of freely connected pore space to allow for compression of the fluid. 9 Porosity is usually given as a percent.

\section{PERMEABILITY}

Permeability is the property of a porous medium which measures the ease with which fluids. flow through the medium under the influence of a driving pressure. The product of the formation permeability and thickness is referred to as the formation capacity. The allowable injection rate is directly proportionate to formation capacity. Therefore, the higher the capacity, the higher the injection rate for a given pressure differential.

The unit of permeability measurement is the darcy or millidarcy named after the French engineer, Henry Darcy, who was responsible for development of the theory of flow through porous media. 
More than one formation may be used for brine disposal.. Therefore, the formation thickness is the sum of the vertical intervals of the formations to be used.

AREAL EXTENT

The areal extent is a measure of the external reservoir boundary and, when multiplied by the formation thickness, gives the total aquifer volume.

DISPOSAL DEPTH

The disposal depth is the depth to the disposal fornation.

RESERVOIR TEMPERATURE

The reservoir temperature is the temperature of the formation.

VISCOSITY OF FORMATION WATER

The viscosity of the water in the disposal aquifer is a function of the formation temperature and salinity and is obtained from handbooks or from well service companies.

FORMATION COMPRESSIBILITY FACTOR

The formation compressibility factor is the sum of the compressibilities of formation water and reservoir rock. 
As brine is continually injected into the disposal aquifer, the reservoir pressure decreases as the distance from the injection source increases. A numerical example. for a hypothetical disposal situation of 1,500 gpm for 18 months is presented in the Appendix with the pressure gradient curve given in Figure $7-3$ 


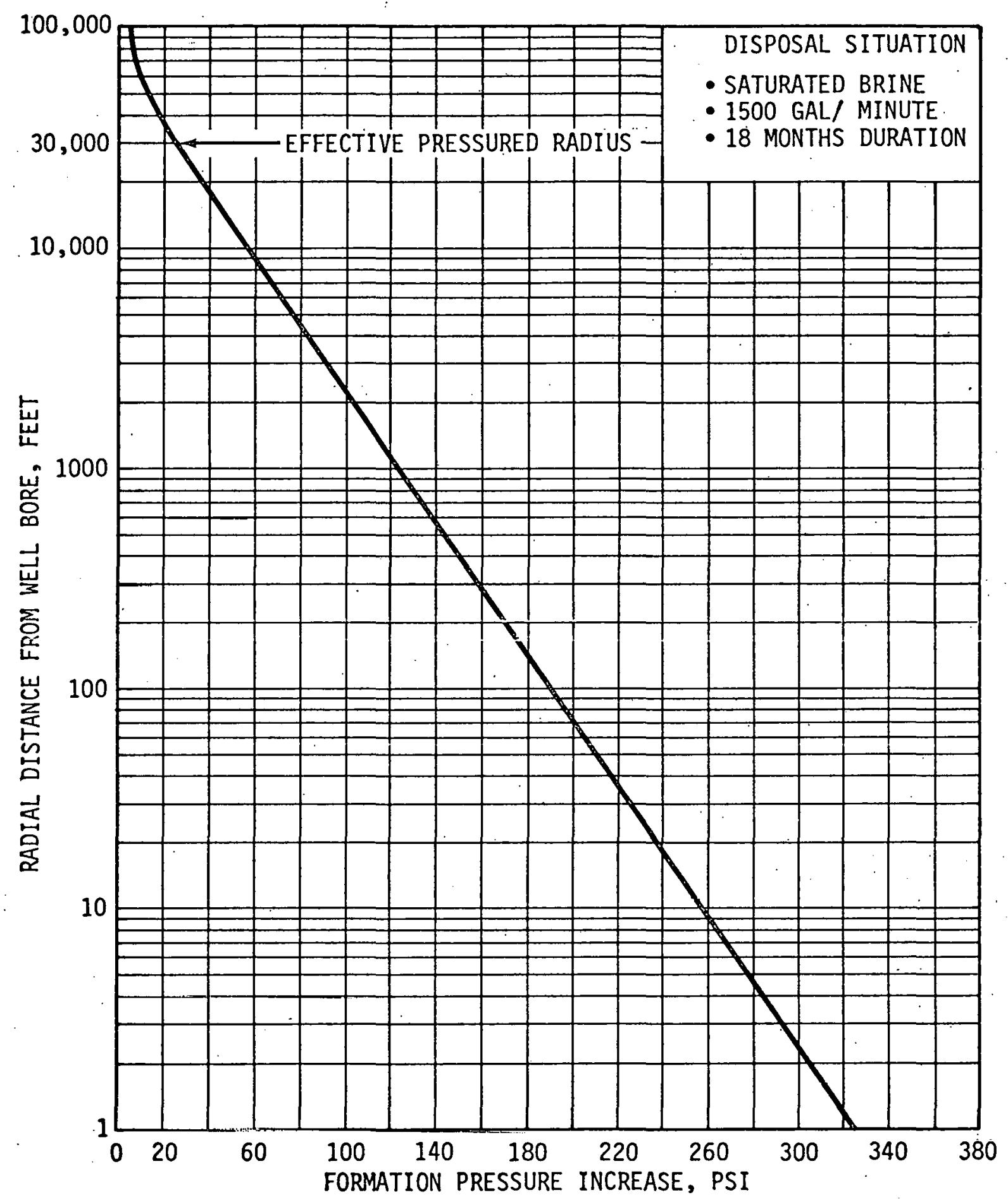

Figure 7-3. Pressure gradient curve 


\section{SECTION 8}

\section{Large Diameter Access Holes}

The drilling of large diameter holes is not a new concept. For over 30 years "big holes" have been drilled to shallow depths as mine access shafts. It wasn't until 1961, however, when a need arose for large diameter shafts for atomic testing at the Nevada Test Site, that development of "big hole" equipment and techniques began. Technology in "big hole" equipment and techniques has advanced to the point that it is now possible to drill 120 inch diameter holes as deep as 6,000 feet and 144 inch holes to some lesser depth at reduced penetration rates.

\section{FACTORS RELEVANT TO BIG HOLE DRILLING}

Factors which affect "big hole" drilling are essentially the same as those encountered in conventional oilfield drilling. However, the impact of large equipment presented problems which had to be surmounted before "big hole" drilling became an acceptable practice. These factors are as follows:

1. Hole size and depth

2. Bit performance - weight, speed, and torque

3. Circulating. system and media

HOLE SIZE AND DEPTH

Holes sizes in any drilled hole are normally governed by the size of the casing (steel liner) to be run. The hole has its smallest diameter at the 
bottom and increases in diameter toward the surface. Figure 8-1 shows the progression of hole sizes for a typical big hole access with 59 inch inner diameter casing. After the product casing (long string) size has been determined, the bit size is chosen based upon the outer diameter of the - casing. In oilfield practice a relatively small annular space is required to pass the casing. (This space is generally determined from geological - knowledge of the area to be drilled).

In big hole drilling, however, the annular space is not only dependent upon geological conditions but also upon the depth to which the hole is to be drilled. Since large diameter casings are weak in collapse resistance, wall thicknesses have to be increased and/or external stiffener rings must be added, increasing the total outer diameter of the casing.

In casing deeper holes it is almost impossible to cement the casings back to the surface in one stage or through the use of stage collars, as is possible with smaller diameter casings. Practice, therefore, is to attach slotted pipes called grout line guides to the outer diameter of the casing to ensure proper cementation.

Figure 8-2 illustrates a large diameter casing with external stiffener rings and grout line guides. A grout line, which is a pipe smaller in diameter than the guide, is inserted into the guide and run to the bottom of the casing. Cement is then pumped down the grout line and is forced into the annular space between the hole and the casing through the slots in the guide. While cementing a large diameter casing the grout lines may be periodically repositioned at more shallow elevations as the cement fills the annular space. The use of stiffener rings and guides can add as much as 14 inches to the outside diameter of the casing. A casing string of this configuration 1 s 


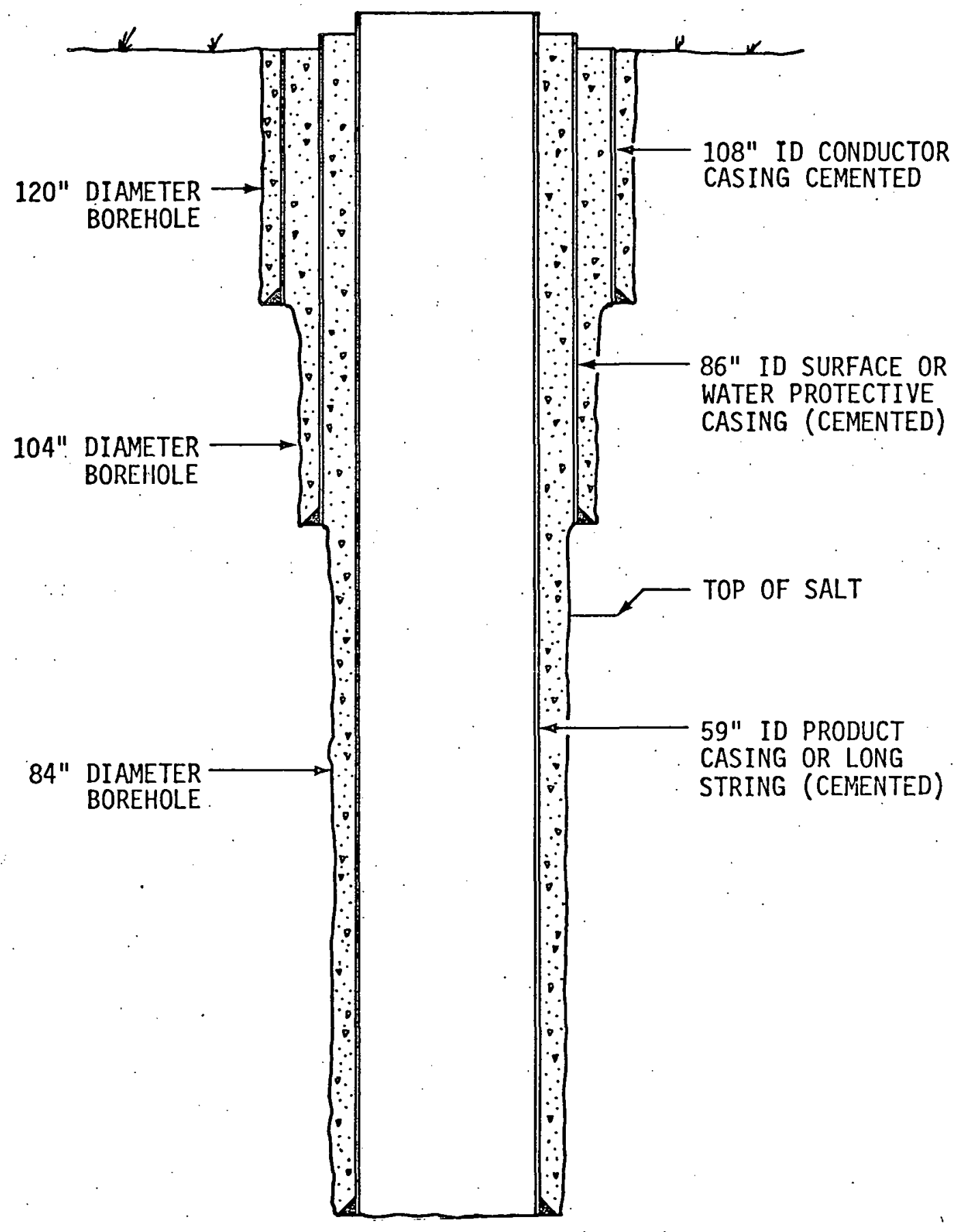

FIgure 8-1. Typlcal casing \& hole configuration for 59" ID "bIg hole" access 


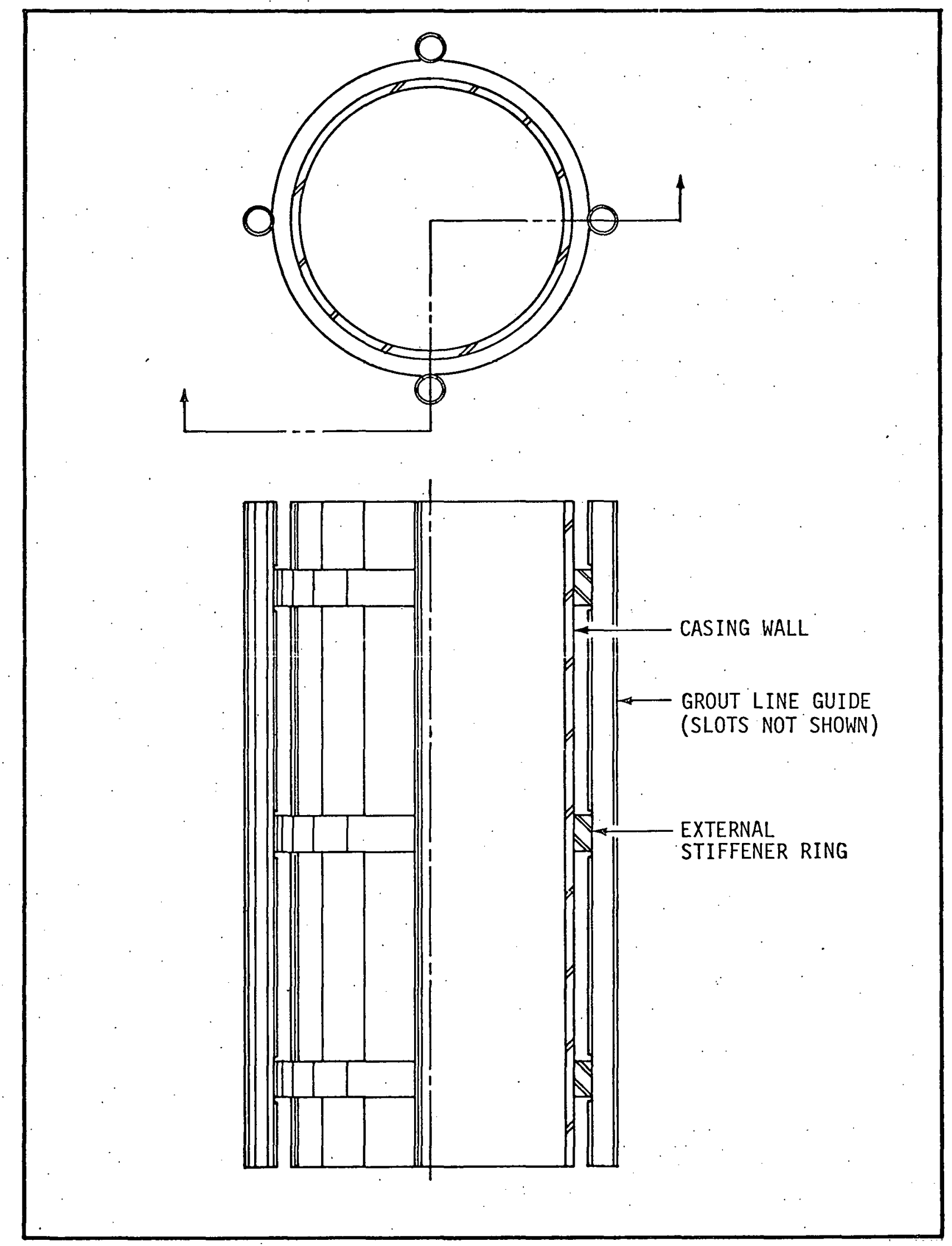

Figure 8-2. Large dlameter casing detalls 
extremely rigid and can only be run in a very straight hole of ample diameter. Experience at the Nevada Test Site has demonstrated a need for at least four inches of annular clearance. The required hole size therefore, can be as much as 2.5 inches greater than the required internal diameter of the casing depending upon depth. Succeeding hole and casing sizes up the hole are then chosen dependent upon geological conditions and sizes used.

Figure 8-3 illustrates the massive size of the derrick and substructure required to drill. the hole and install large diameter casing. The photograph shows the super rig installing a 122-inch diameter, ring-stiffened surface casing.

\section{BIT PERFORMANCE}

When using tricone bits for drilling conventional oilfield holes, weight on the bit is generally increased as hole size increases to maintain a satisfactory drilling rate. "Big hole" bits, however, must be considered in a different manner. Heavy bit loadings may be impractical or uneconomical to obtain. Bottom hole cleaning, drilling pipe torque, or hole deviation may limit the permissible load that can be applied.

Weight is normally applied to the bit through the use of drill collars located just above the bit. All of the available weight cannot normally be applied to the bit, since some weight must be suspended to plumb the drill string and keep the hole drilling vertically.

For a given size and type of bit, the penetration rate (assuming good bottom hole cleaning) increases as a function of the rotary speed. For "big holes", however, peripheral speeds of the outside bit cutters and the resultIng torque dictate that rotary speeds must be kept low in order to extend bit 


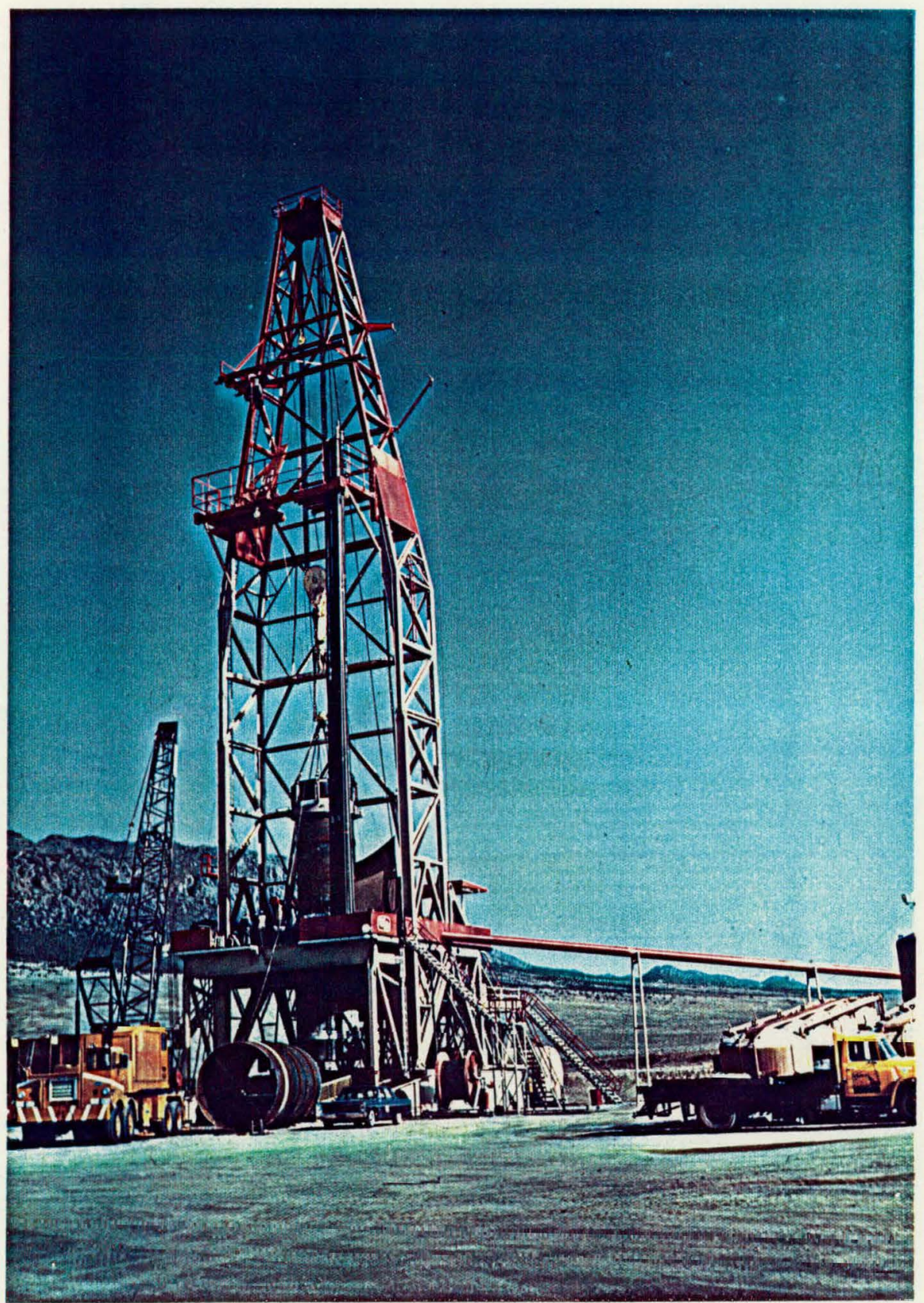

Figure 8-3. Illustration of a massive "super $\mathrm{Ilg}^{\text {" }}$ required for drilling hole \& installing large diameter casing (122" diameter surface casing in foreground) 
life. Figure 8-4 illustrates components used in a drill string assembly for drilling an 84 inch diameter hole.

CIRCULATING SYSTEM AND MEDIA

Special fluids called circulation media or drilling mud are used to clean the bit and return the cuttings to the surface. Chip removal in conventional-sized holes is accomplished by pumping drilling mud down the drillpipe; the mud then returns to the surface through the drillpipe borehole annulus, bringing with it the cuttings. Annular velocity must be high enough, for the fluid used, to elevate the cuttings.

In large diameter holes, the annular region becomes so large that adequate rising velocities become economically prohibitive due to the high pumping rates that would be required. Reverse circulation (flow down the annulus and up the drillpipe) becomes the only practical means of cuttings removal. Air or foam drilling techniques can be used under certain conditions but are unsuited for Gulf Coastal drilling.

Reverse circulation is a common oilfield technique used during remedial work within a cased hole. However, attempts to use the technique in uncased holes have been notably unsuccessful. The pressure required in the annulus to induce flow up the drillpipe generally results in unacceptable fluid loss into the exposed formations. This causes borehole instability, high fluid replacement costs, and frequently, total inability to maintain adequate circulation:

These problems have been overcome in "big hole" drilling by pumping fluid from the drillpipe rather than by increasing pressure in the annulus. The large diameter drillpipe required to transmit. the necessary torque to the bit 


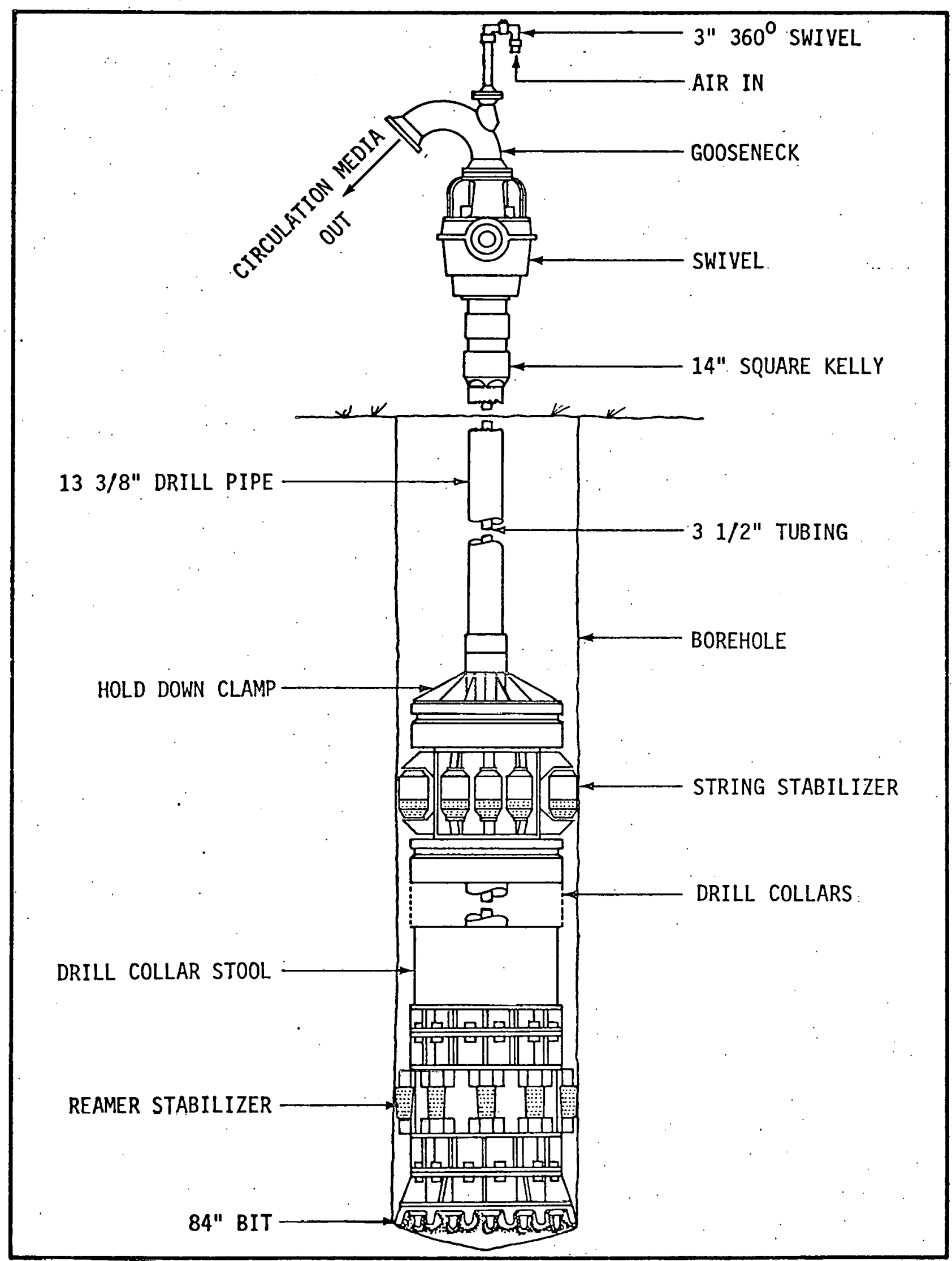

Plgure 8-4. 84" dr111 string assembly 
provides sufficient internal diameter to permit the insertion of a concentric air-1ift string. Thus, fluid flow can be maintained across the bit and into the drillpipe by lightening the internal fluid through aeration rather than by pressuring the external fluid.

\section{CAVERN ENTRY CONCEPTS}

Two concepts for large diameter entry into a cavern are 1) drilling a large diameter hole into the cavern, and 2) drilling a vertical hole adjacent to the cavern and mining an access tunnel(s) horizontally into the cavern.

DRILLED CAVERN. ENTRY

Figure 8-5a illustrates a cylindrical cavern with a iarge diameter access shaft which is drilled and offset from the cavern development well. If this access shaft is intended for manned entry, an additional casing may be required to enclose the elevator shaft and protect the emergency braking system. Fitted with elevator guides, the casing prevents the elevator from. twisting and swinging and maintains the operating capabilities of the braking system.

DRILLED/MINED C.AVERN ENTRY

Entry into a cylindrical cavern using drilling and mining may be seen in Figure 8-5b. A vertical hole is drilled and cased adjacent to the cavern, and then one or more tumnels are mined into the cavity. This entry technique 


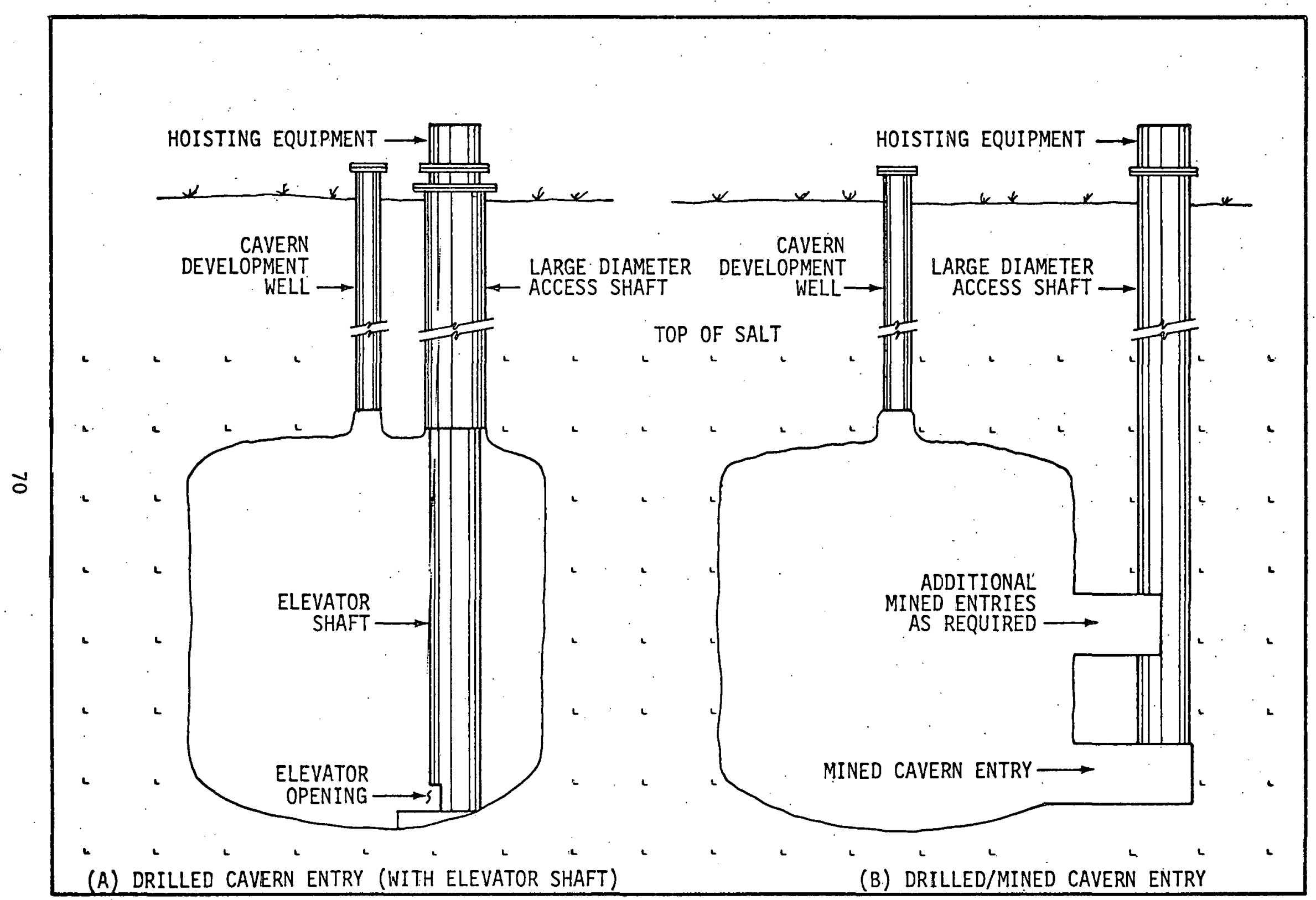

Figure 8-5. Concepts for large diameter cavern entry 
was included in work performed for the United States Atomic Energy Commission 10 in 1967 and was discussed in a technical paper ${ }^{6}$ in 1968. 


\section{SECTION 9 \\ Cavern Evacuation}

In certain situations it may be necessary to dewater and dry the cavern. Dewatering refers to the removal of accessible liquid brine, while cavern drying techniques are used to remove residual brine left after dewatering and to reduce humidity.

\section{CAVERN I DEWATERING}

For simplicity, brine in the cavern can be divided into two zones. Zone I contains most of the brine and extends from the wellhead downward to a point near the surface of the insolubles. Zone II extends from the bottom of Zone I to the bottom of the insolubies, which includes brine filling voids in the accumulation of insolubles. Techniques used to dewater Zone. I involve fluid movement, while dewatering Zone II may involve transporting some insoluble material with the brine.

Figure 9-1 illustrates the two dewatering zones for caverns constructed with and without sumps. The cavern without a sump was constructed using a removal technique which may not have resulted in removal of all insolubles.

The surface of the insoluble accumulation may be irregular, depending on such factors as direction and rate of circulation, size of cavern and position of casings. Insolubles usually consist of a mixture of sand and anhydrite with an angle of repose of 30-35 degrees as verified by sonar surveys. 


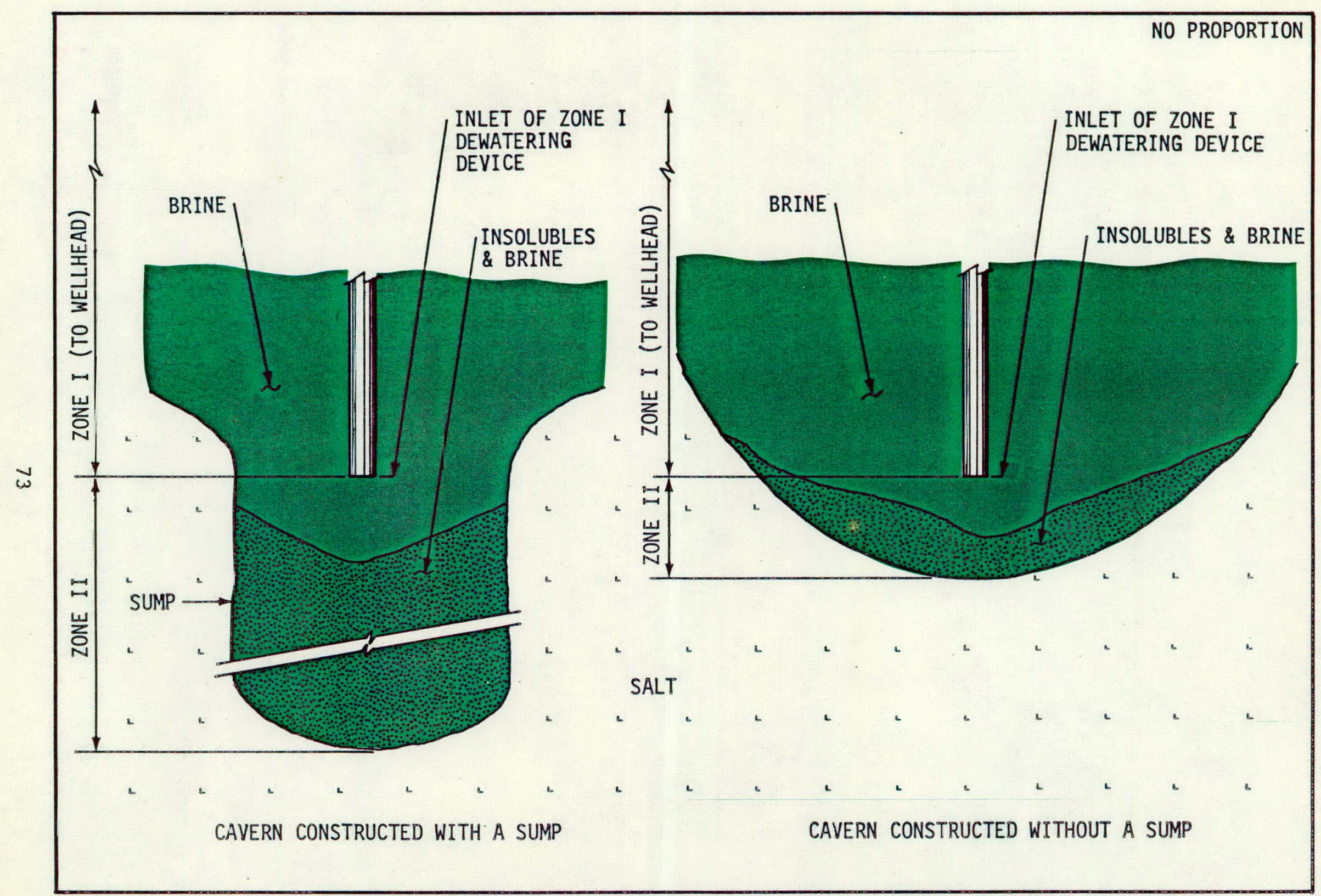

Figure 9-1. Partial view of caverns showing accumulation of insolubles \& dewatering zones 
SINGLE-WELL DEWATERING METHODS

Single-well methods are those based on the use of the well which was drilled for cavern leaching.

ZONE I DEWATERING

Pump out, gas displacement and gas lift are the three general methods used to dewater Zone I in both caverns constructed with a sump (see Figure 9-2) and those without sumps.

Pump Out--This technique involves locating a pump within the cavern to drive the brine to the surface. Wash and blanket casings are removed from the cavern before the pump is installed. Generally speaking, use of pump out becomes less desirable as cavern depth increases, because larger and more powerful pumps are needed at greater depths--requiring larger access holes. This progression compounds exponentially with depth with a comparable progression in costs.

Gas Displacement--With this method, a compressed gas (such as air) is used to displace the brine. Wash and blanket casings are removed from the cavern, and a dewatering string of high strength tubing--designed to withstand the high pressure of the compressed gas--is installed in the cavern with the bottom end near the top of the insolubles. Gas is then injected into the cavity through the product casing, and an interface is formed in the top of the cavity between the gas and the brine. As gas enters the cavern the interface moves downward, forcing brine up the tubing. This process continues until the interface reaches the bottom of the tubing. 


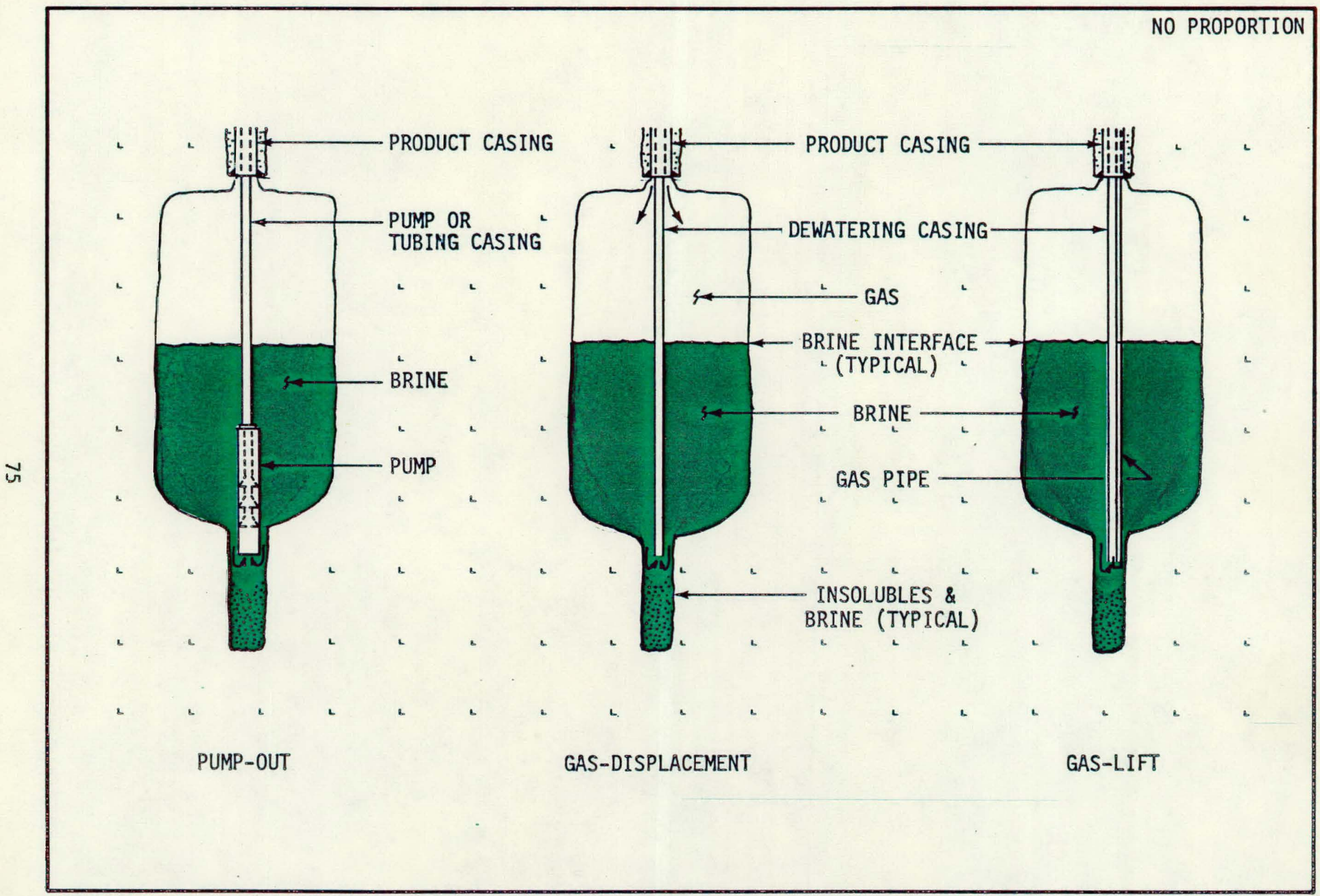

Figure 9-2. Zone I dewatering techniques 
A major expense involved in using this technique is the purchase and installation (or rental) and operation of the compressor equipment.

Gas-Lift--A dewatering string and a separate gas pipe are used with the pipe positioned so that compressed gas (possibly air or nitrogen) can be injected inside the dewatering string near its lower end. The compressed gas immediately rises in the dewatering string, forming a mixture of bubbles and brine. Because the mixture inside the string is lighter in weight than the brine in the cavern, the brine enters the dewatering string and displaces the mixture to the surface. The lifting action continues until the pressure head of brine in the cavern balances the pressure head developed by the mixture in the dewatering string.

A major expense of gas lift, like gas displacement, involves the compressor equipment.

ZONE II DEWATERING

Dewatering Zone II is a more complex procedure than is Zone I. The volume of brine contained in Zone II depends on the nature and amount of insolubles accumulated in the bottom of the cavern or in the sump.

Zone II dewatering techniques are based on the evacuation of brine through a dewatering string (see Figure 9-3).

In this illustration a concentric arrangement of a placement casing and the dewatering string are shown positioned near the bottom of the sump. The dewatering string will transport brine and some insoluble material to the surface. When insolubles are suspended inside a casing, there is always the possibility that the casing could become plugged. If it could be lifted out 


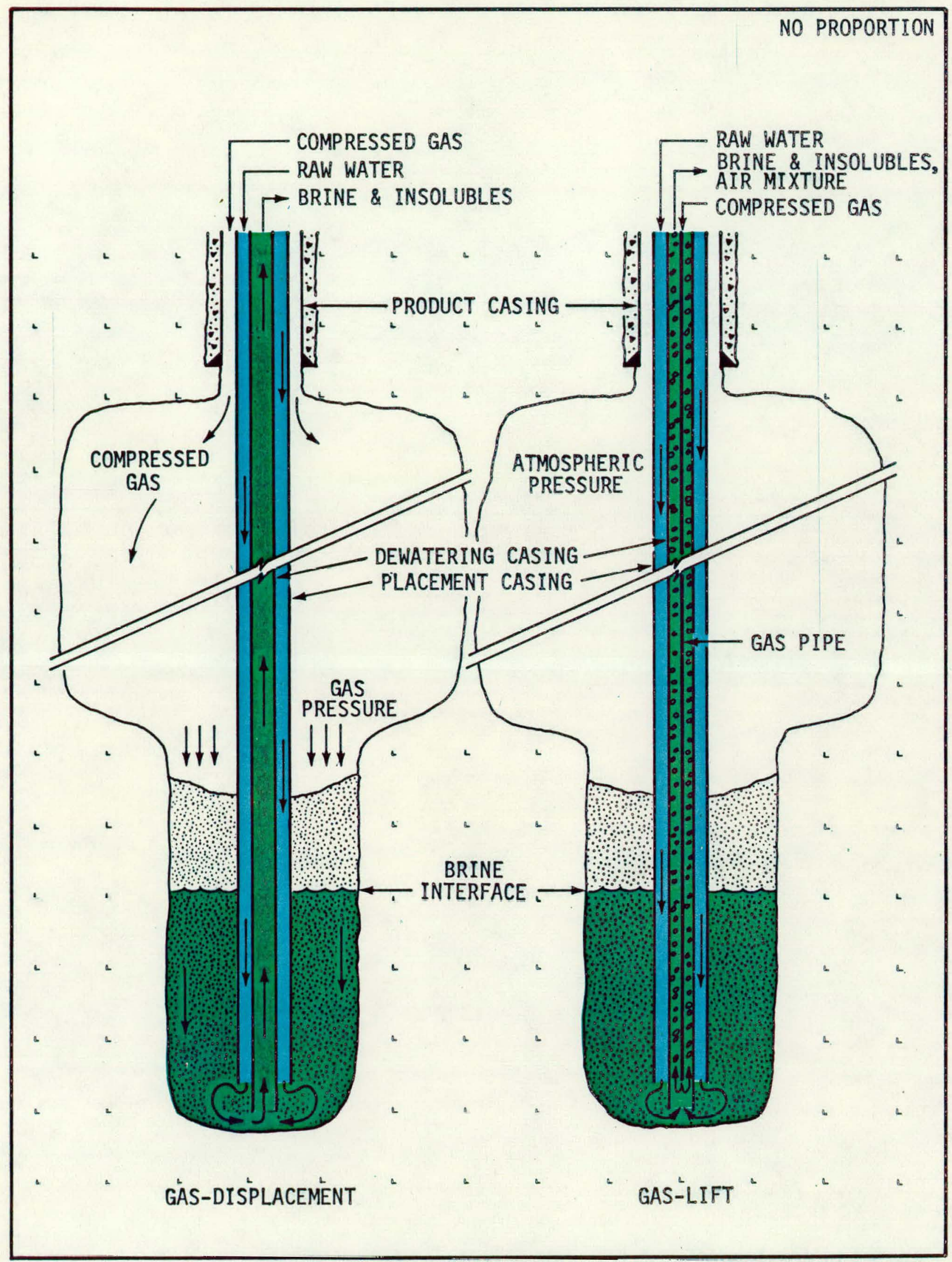

Figure 9-3. Single-well dewatering of Zone II 
of the cavern, it could be cleaned or replaced. But a casing buried in insolubles will be very difficult if not impossible to lift or remove. Therefore, placement casing is set as shown in the figure and is used to conduct a small flow of fresh water to the bottom of the dewatering string. The water 1 ) keeps the annulus between the placement casing and the dewatering string clear so that the dewatering string can be removed, and 2) decreases the salinity of the brine being evacuated, which reduces salt caking inside the evacuation system.

Gas Displacement--Compressed gas is forced into the cavern through the product casing, and the brine-insolubles-fresh water mixture is forced up the dewatering string.

Gas Lift--Using this technique of evacuation the cavern is at atmospheric pressure. Compressed gas is injected at the lower end of the dewatering string through a gas pipe, causing a mixture of brine, insolubles, fresh water and gas bubbles to be transported to the surface by the gas lift principle previously discussed.

Pump Out--A pump could also be installed in the placement casing after the dewatering string has heen removed. However, serious maintenance problems may result from pumping abrasive insolubles (such as sand) if the proper pump is not used.

After Zone II is dewatered, the dewatering string or pump is removed-leaving the placement casing. Placement casing may be used as an integral part of the cavern drying phase, after which it will either be removed or cut off at some level near the top of the remaining insolubles. 
This method requires the construction of a sump as part of the mining system. A second well is spaced a substantial distance from the cavern development well and directionally drilled to intersect the sump as close to the bottom as possible. If the offset well fails to intersect the sump, a small cavity can be leached at the bottom of the second well until communication is established with the sump. Figure 9-4 illustrates the well configuration for the offset well method.

ZONE I DEWATERING

Dewatering the major portion of the cavern can be accomplished using pump out, gas displacement or gas lift methods previously discussed.

ZONE II DEWATERING

The offset well is used to remove the brine from Zone II. The same methods used to dewater Zone II in the previous subsection can also be employed here.

Gas Displacement--If gas displacement was used to dewater Zone I then, without removing any casing but by shutting off flow through the dewatering string, additional gas entering the cavern would cause brine to be forced up the offset well. This process would continue until the gas and brine interface reached the entrance to the offset well.

Gas Lift--The gas lift method can also be used to evacuate the brine from the sump by running a small diameter gas injection string inside the offset well to a point near the sump.

Pump Out--Zone II could also be dewatered by operating a pump in the 


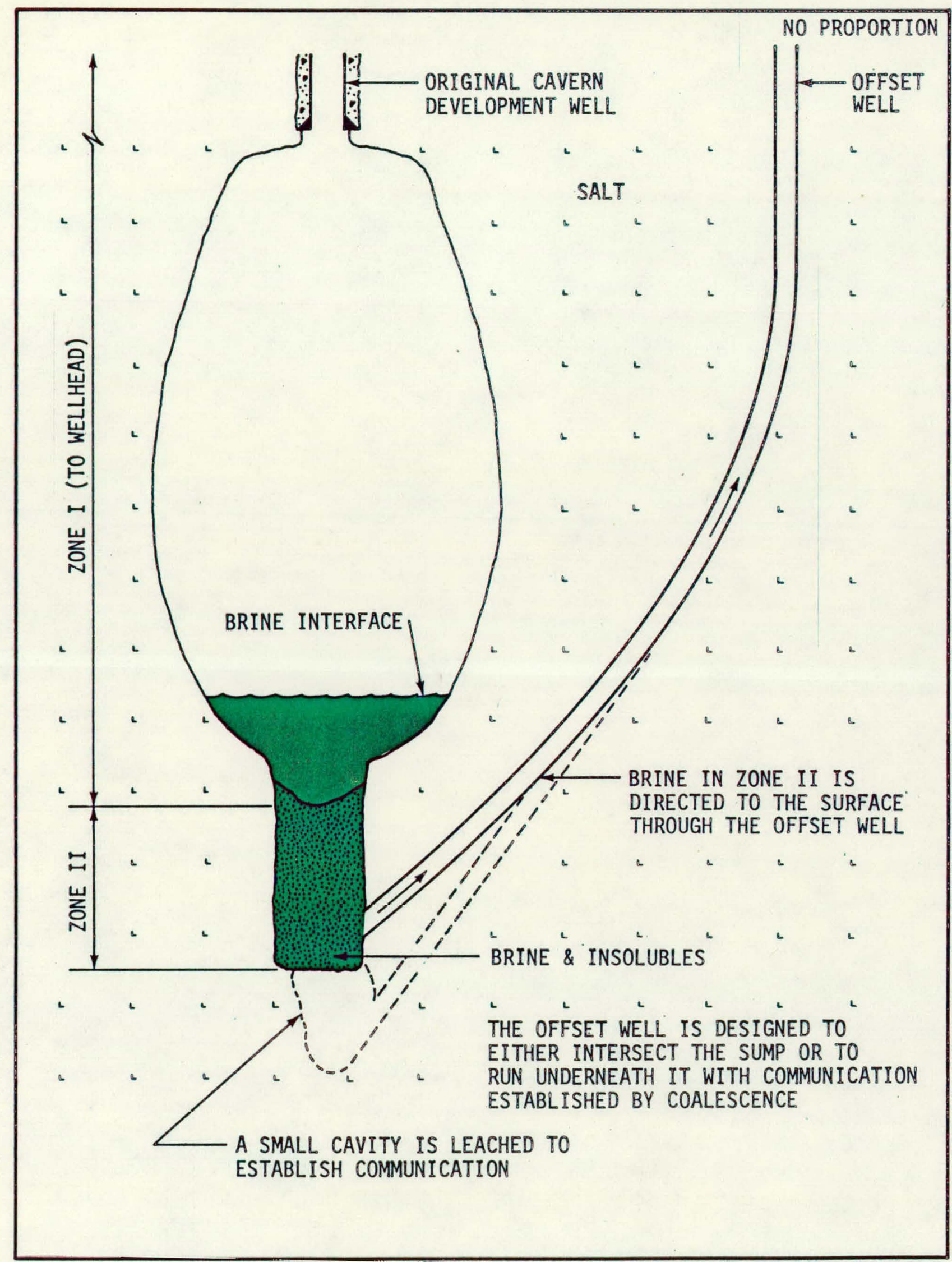

Figure 9-4. Well configuration for offset well dewatering methods 
offset well. However, maintenance problems arising from pumping velocity entrained insolubles. should be considered when using this particular evacuation technique.

A submersible, electrically driven pump or a standard oilfield rod type pump with a surface pumping unit can be used. Submersible pumps are quite sensitive to sand entrained fluids while oilfield rod pumps can handle high concentrations of sand.

\section{SALT CAKING AND PLUGGING}

A problem common to all of these methods of dewatering occurs when'salt crystals tend to form on the inside of the evacuation system, causing restriction of flow or plugging.

A means for either backwashing the evacuation system or reducing the salinity. of the brine can be used to alleviate this problem. Backwashing simply requires injection of fresh water in reverse flow through the system. This should be done periodically, perhaps daily, to remove caked salt from the dewatering string or pumping system. Salinity of the brine can be reduced by injecting fresh water at the inlet of the dewatering string or pump string through a separate small diameter pipe or tubing run from the surface.

HANDLING OF INSOLUBLES

Insolubles are transported to the surface whenever an insoluble removal technique is used for cavern construction and during Zone II dewatering. Most normal means of brine disposal, ranging from use of disposal wells to sale of brine to the chemical industry, require that insolubles be removed. One of the simplest means of separating insolubles from brine is to 
direct the effluent from the cavern to a settling pond; pond construction and maintenance, however, are expensive items.

State regulatory agencies will not approve brine disposal plans that allow brine to settle on the surface of the land where it might migrate into fresh water sands. For this reason, settling ponds are usually lined with expensive synthetic membrane liners.

The amount of insolubles removed depends on the construction and dewatering techniques used. For example, let us assume that a 14 million cubic foot cavern is built using a removal technique where the salt contains 10 percent insolubles. If all insolubles were removed, the resulting pile of 1.4 million cubic feet would represent a cone approximately 86 feet high and 240 feet in diameter at its base. In practice, however, only a small percentage of insolubles are usually removed from solution mined caverns.

DEWATERING

Zone I dewatering is now a routine procedure used by Fenix \& Scisson to prepare a cavern for dry, accumulator-type gas storage. Wash and blanket casings are removed, a dewatering string of high strength tubing is installed, and the gas that is incended for storage is simply injected into the cavern-displacing the brine to the surface through the dewatering string.

The need for brine removal from Zone II has not existed before, and therefore there is little or no experience on which to draw. In Figure 9-3, a dewatering string and placement casing are shown with the lower ends located near the bottom of a sump full of insoluble material. While this is technically possible, it is a very critical operation that is expensive and time consuming. 
Pigure 9-4 shows an offset well which is drilled to a target near the bottom of the sump. The art of directional drilling is over 25 years old and the degree of accuracy is directly related to the time and money invested. Completing the type of well required for dewatering is well within present technology. Figure 9-5 presents the plan view and vertical cross section of an actual offset well directionally drilled to.a specific target:

\section{CAVERN DRYING}

The purpose of dewatering is to remove accessible free liquid brine from the cavern. When this phase is completed it is likely that a moist atmosphere will exist in the cavern interval and that residual brine will be entrapped within the accumulation of insolubles.

CAVERNS CONSTRUCTED WITHOUT A SUMP

The concept for dehumidifying and drying insolubles consists of circulating conditioned air through the cavity. For caverns constructed without a sump, the insolubles accumulation may be shallow compared to the large surface area (see Figure 9-1b).

The pipe that conducts air to the cavern could be sunk into the insolubles and the air allowed to percolate through the accumulation, thus picking up moisture. But the effective radius of such drying would probably be small compared to the surface area of the insolubles, so the pipe would most likely not be buried but positioned at some point near the bottom of the cavern. Brine in the accumulation would therefore be evaporated by air circulation above the insolubles as illustrated in Figure 9-6a. 


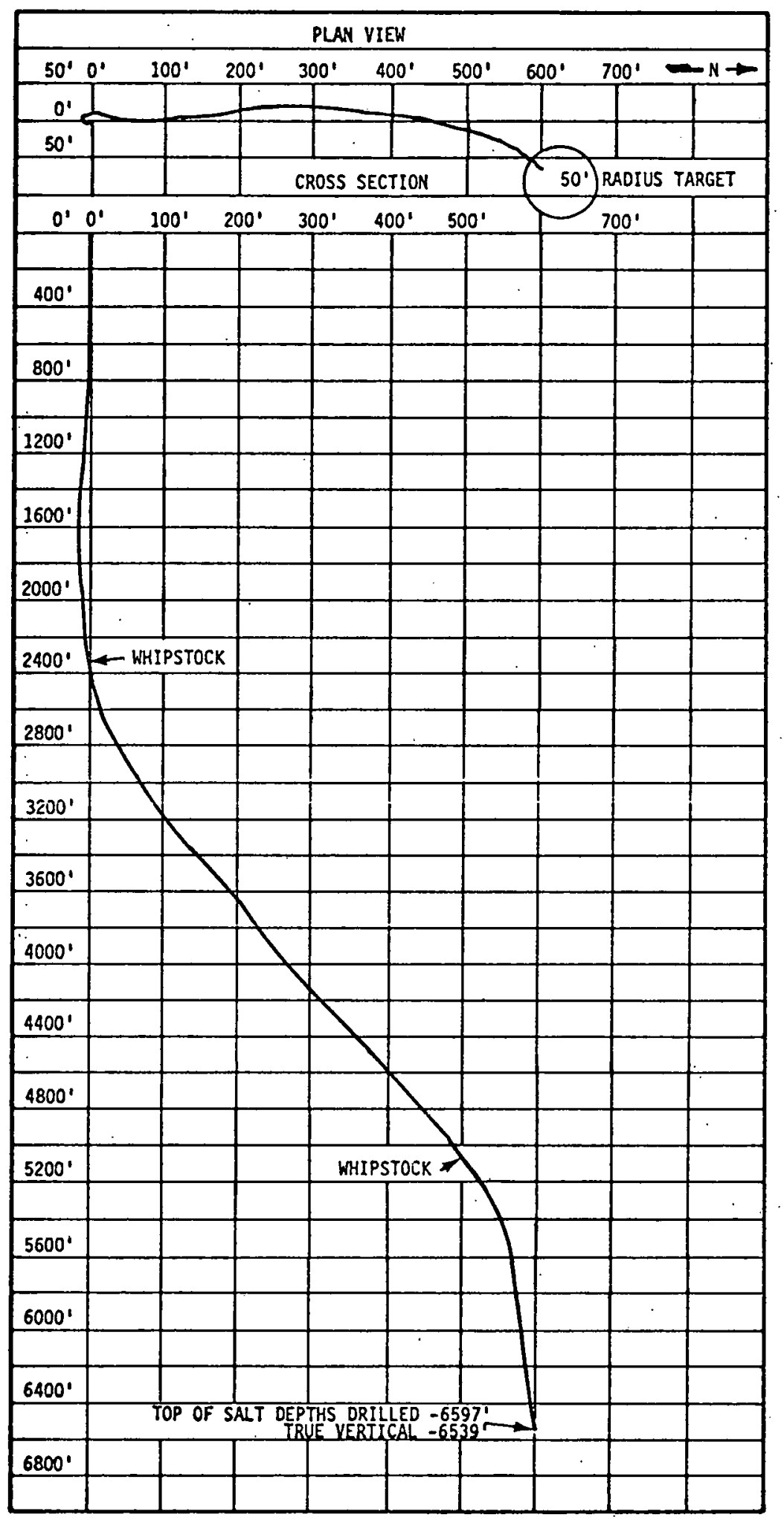

Figure 9-5. Plan view \& vertical cross section of offset well directionally drilled to a predetermined target 


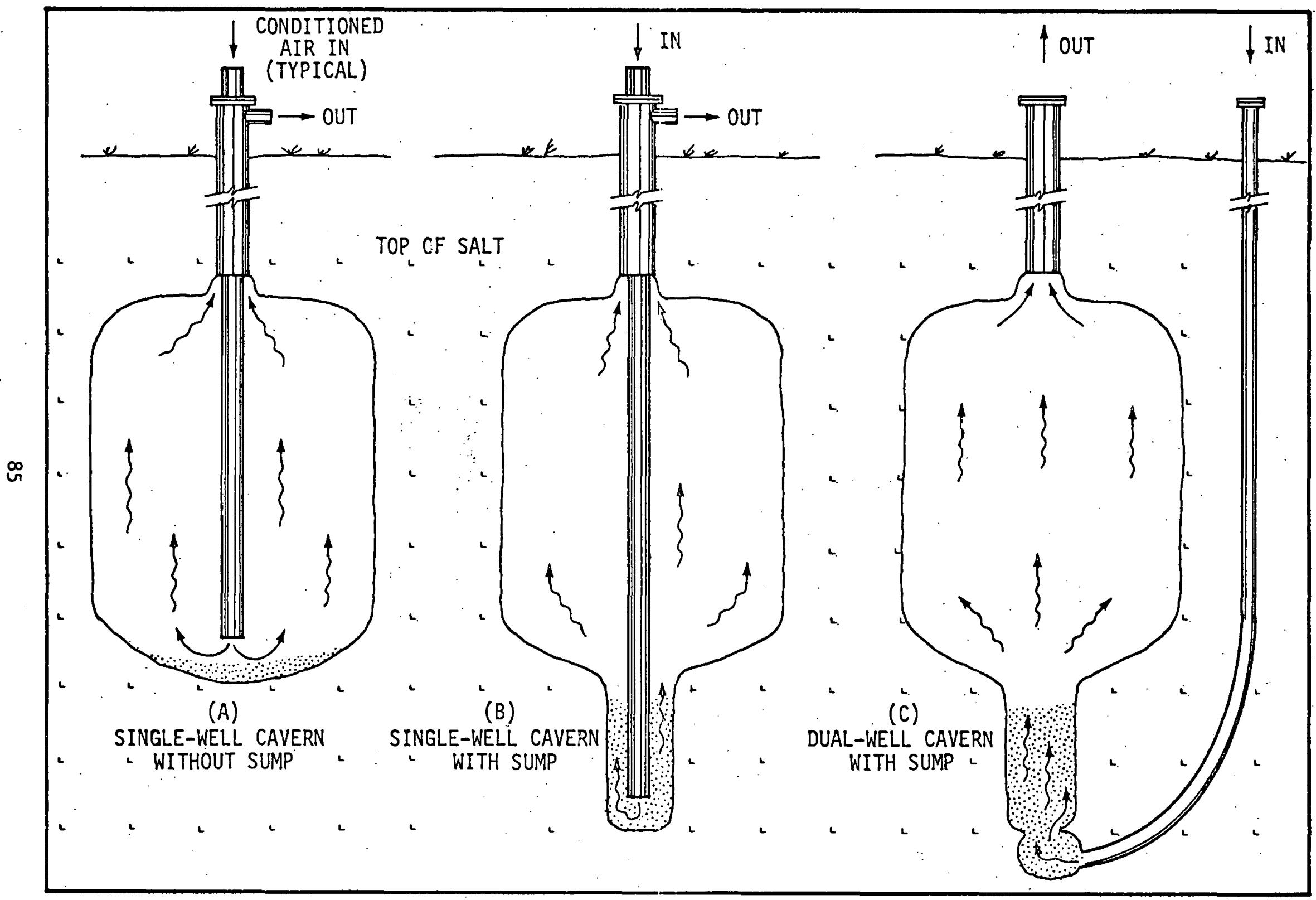

Figure 9-6. Circulation of drying air for different types of cavern construction 
No technical problems, such as positioning the air injection casing or circulating conditioned air, are anticipated. However, drying of insolubles in this manner will be very time consuming and the possibility exists that not all of the brine can be evaporated.

\section{CAVERNS CONSTRUCTED WITH A SUMP}

Caverns constructed with a sump may achieve a higher degree of drying in less time because of the flow of conditioned air past insoluble particles. The accumulation has much greater depth and smaller surface area than the previous case. Figure $9-6 b$ illustrates a circulation scheme in which air is injected into the cavern at a point near the bottom of the sump. Air is then forced to circulate upward through the accumulation, into the cavern interval and out of the cavern at the roof level.

As previously mentioned, problems are anticipated in placing the casing into the insolubles as shown in the figure. First of all, the well used for cavern development must be drilled under very close control in order to minimize horizontal deviation. Otherwise, the sump will be developed off-center, and re-entry into the sump with a casing may be impossible after the cavern Is developed because the casing will tend to hang vertically in the cavern interval. Ideally, a vertical center line would run from the surface through the well bore to the-bottom of the sump, but this is almost impossible to achieve.

The second problem deals with physically locating the casing near the bottom of the sump. To penetrate great depths of insolubles without bending and/or breaking the casing would require highly experienced personnel and could be very time consuming. 
An air circulation scheme is shown in Figure $9-6$ c for a cavern constructed with a sump which was dewatered using an offset well. The same general drying effectiveness is expected as for the single well case of Figure 9-6b.

Using this technique for drying insolubles, conditioned air can be circulated through the accumulation without problems associated with sinking a casing into the sump. The offset well must be drilled under close supervision and will be more expensive and time consuming than drilling a conventional straight well.

\section{LARGE DIAMETER ACCESS}

If large diameter access is intended for manned entry, then cavern drying can be conducted in a different manner. After Zone $I$ is dewatered, manned entry is made into the cavern. Mucking procedures, which are common-. place in conventional mining operations, can be used to completely remove insolubles and brine from Zone II.

Cavern atmosphere can then be dried by circulation of conditioned air.

SUME ISOLATION

If manned entry is planned in caverns constructed without sumps, mucking followed by drying would result in a dry cavern with a clean bottom. For caverns constructed with a sumpe, mucking operations may or may not be advantageous. A deep, empty sump may not be in line with storage requirements and operations.

For caverns built with a sump, isolating it from the cavern offers an 
alternative to either dewatering and drying insolubles or emptying it by mucking. The sump can be isolated without manned entry by using a concrete plug to seal it off from the cavern (see Figure 9-7); this method provides a reasonably level cavern floor. Zone II is not dewatered, but rather is left full of brine. If manned entry is used, the sloped contour of insolubles could be leveled and the top surface of the concrete plug could be shaped and textured as desired.

If the original cased well bore is not almost vertical the isolation technique cannot be used without manned entry because the tubing used to place concrete must be positioned directly over the sump. If the concrete plug is not needed, the sump could be filled in with several feet of sand or crushed salt to provide a dry working surface.

\section{ACTUAI EXPERIENCE}

About 10 years ago, in a project recalled by Fenix \& Scisson personnel who were on site at the time, the Atomic Energy Commission created a 110 foot diameter spherical cavity in a Gulf Coast salt dome. The cavity, constructed with the aid of a nuclear device, was centered about 2,700 feet below ground and had a rubble accumulation spread over the bottom.

Some time later the cavity was re-entered by completing two drilled post-shot holes. In preparation for re-entry, a cavity pressure bleed-down plant was constructed with a series of water traps to wash the gas as it was discharged. But the time lag between detonation and re-entry had allowed the cavern to cool to the point that, instead of being under pressure, it was actually under a vacuum. The vacuum forced the system to act in reverse and sucked an undetermined amount of water back into the cavern. 


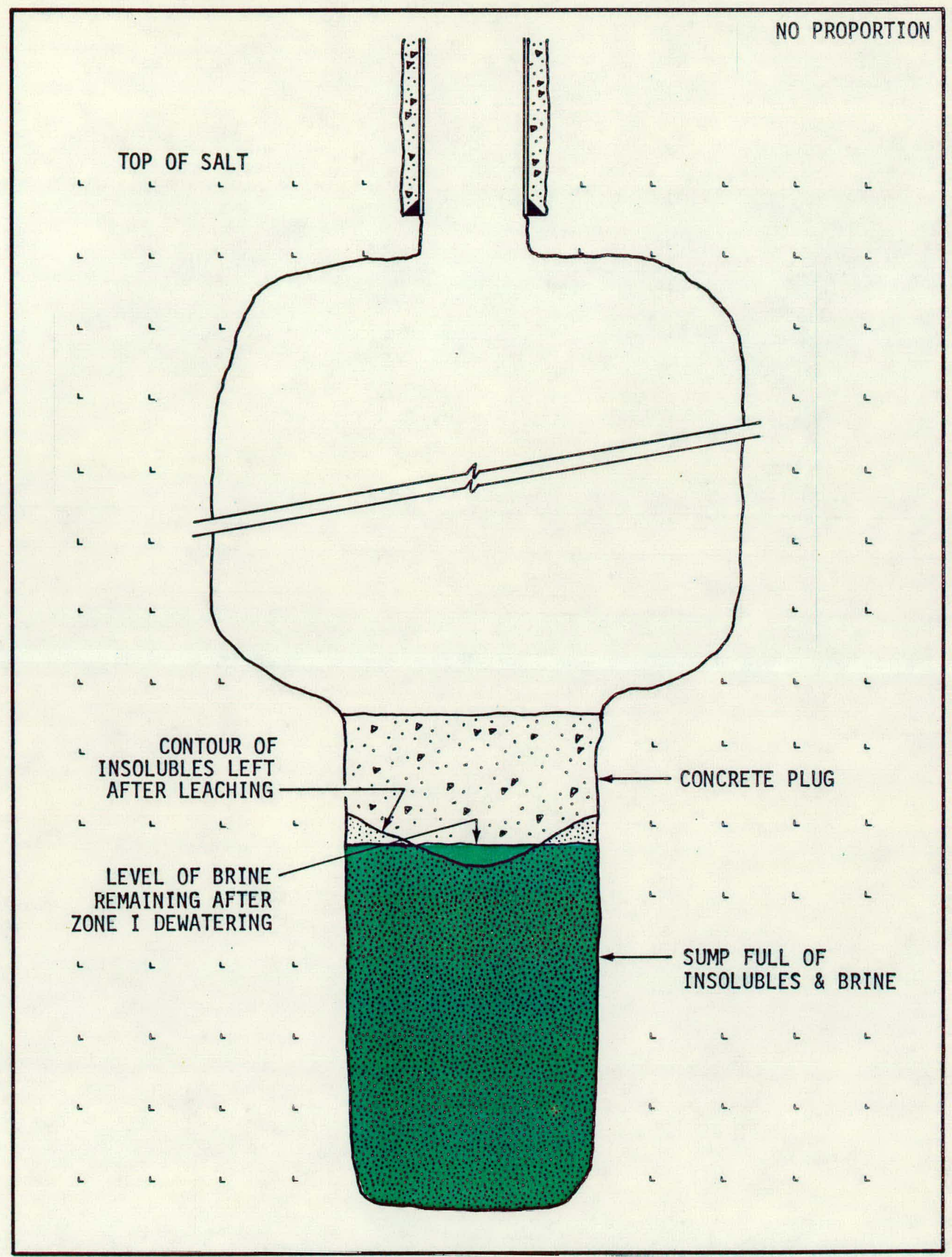

F1gure 9-7. Concept for 1solating sump from cavern (without manned entry) 
Fenix \& Scisson personnel were responsible for removing the water. Air, preconditioned on the surface, was circulated down one post-shot hole, through the cavity and out the second hole. Large compressors were used to expand ambient air through orifice plates, then into vessels with the hope of cooling it sufficiently so that any moisture in the air would condense and be drained off.

The procedure obtained reasonable results. Temperatures and relative humidity readings of the injection air and cavity discharge air were periodically monitored. The drying effect continued favorably for several weeks, then tended to level off.

Cavern temperature was about 180 degrees Fahrenheit and the chilled injection air was approximately 50 degrees Fahrenheit. The amount of water actually removed is not available, and the extent of drying was never known because the rubble at the botton was fractured and broken and could have contained water.

There is physical evidence, though, that the cavity atmosphere was sufficiently dehumidified. Several television camera runs were made and no condensation occurred in the post-shot hole used for the runs. 


\section{SECTION 10 \\ Cavern Stability}

Cavern stability is a subject unto itself.

Although many experts in rock mechanics have tackled the problem with such sophisticated mathematical tools as computerized analysis, the subject of cavern stability remains more art than science. The problem lies in how to accurately define in situ conditions. Salt is known to have high strength and stability when treated to uniaxial testing at the surface; it is also recognized that it can flow like plastic when subjected to triaxial loading and high temperatures.

Seldom is a particular salt mass thoroughly assessed prior to cavern construction. The salt can be cored in an exploration hole and/or in the hole to be leached, but testing of the core is hardly representative of in situ conditions. The instant the core is severed from the formation its stress level drops from a lithostatic gradient of about one psi/foot of depth to a brine gradient of about $0.5 \mathrm{psi} / \mathrm{foot}$.

During coring of the salt section a drilling mud approximately equivalent in weight to saturated brine is often used. By the time the core reaches surface, pressure has been further relieved to atmospheric conditions. Even if the core is repressured under laboratory conditions, relief of prior stress will have undoubtedly altered its characteristics.

Some testing can be done in an attempt to extrapolate borehole shrinkage. Such testing is expensive, however, and the validity of extrapolation remains unproven. Borehole logging may eventually prove useful in determining in situ properties of the salt, but current interpretation procedures are subject 
to question.

Precise techniques for predicting cavern stability are still beyond the present state of the art. However, some extensive analytjcal work and laboratory experimentation have been carried on for over 10 years. ${ }^{5,11,12}$ Reference will be made to conclusions and findings resulting from some of this past work in order to illustrate the possible trends that certain factors have on cavern integrity.

\section{FACTORS AFFECTING STABILITY}

Primary factors known to affect cavern stability are pressure, temperature and shape.

A continual adjustment of stress occurs at the cavern wall as salt is leached away. Before the cavern development hole is drilled, triaxial stress within the salt is roughly equivalent to the weight of the overburden. When the hole is drilled and cavern enlargement begins the triaxial loading of nearby salt becomes unequal, because cavern pressure equates to only about half the overburden pressure. Thus, the salt begins to extrude inward plastically, creating a pattern of reduced stress around the cavern.

The extrusion rate is significant as the wall is being leached away but falls off asymptotically after leaching is halted, and the system of unequal stress can spread far enough away from the wall to reduce differential loading at that point. This process of extrusion, called cavern closure, can become more pronounced as cavern depth increases because factors that influence closure--such as lithostatic pressure and temperature--increase with depth.

If a deep cavern is to be left open to atmospheric pressure, closure can 
be very critical because of the high differential pressure developed between the cavern and the salt. This is also true of deep caverns used for gas storage. If gas is withdrawn from the cavern by expansion rather than by brine displacement, cavern pressure can drop low enough to cause significant closure. In extreme instances, closure is believed to be as high as 30 percent per year.

Jessen and Nowotny ${ }^{12}$ conducted laboratory experiments on miniature spherical cavities, cut in five-inch diameter by six-inch long salt cores under a triaxial stress condition of $3,000 \mathrm{psi}$ and a constant temperature of 130 degrees Fahrenheit. The purpose of the investigation was.. to study the effects of overburden pressure and temperature on a spherical cavity in a salt dome. Some of the experimental curves developed by Jessen and Nowotny are shown in Figure 10-1. The time scale is unchanged, but the values of rate of closure were normalized to 1.00 to show only relative effects.

The curves show that closure has a large initial effect that rapidly decreases before it asymptotically approaches zero.

Curve No. 1 resulted from the following experimental procedure. Load was applied to the core in 600 psi increments every five minutes until the maximum load of 3,000 psi was reached. Pressure was held at 3,000 psi for 90 hours, at which time no further decrease in cavity volume was noticed. Then the pressure was increased to $4,000 \mathrm{psi}$ and held constant for 85 days.

Curve No. 2 resulted from applying load to the core in 102 psi increments each hour for 29 hours until the maximum load of 3,000 psi was reached. Constant pressure was then maintained for the duration of the test.

Curve No. 3 resulted from applying pressure uniformly but rapidly for five minutes until the maximum load of 3,000 psi was reached, after which it 


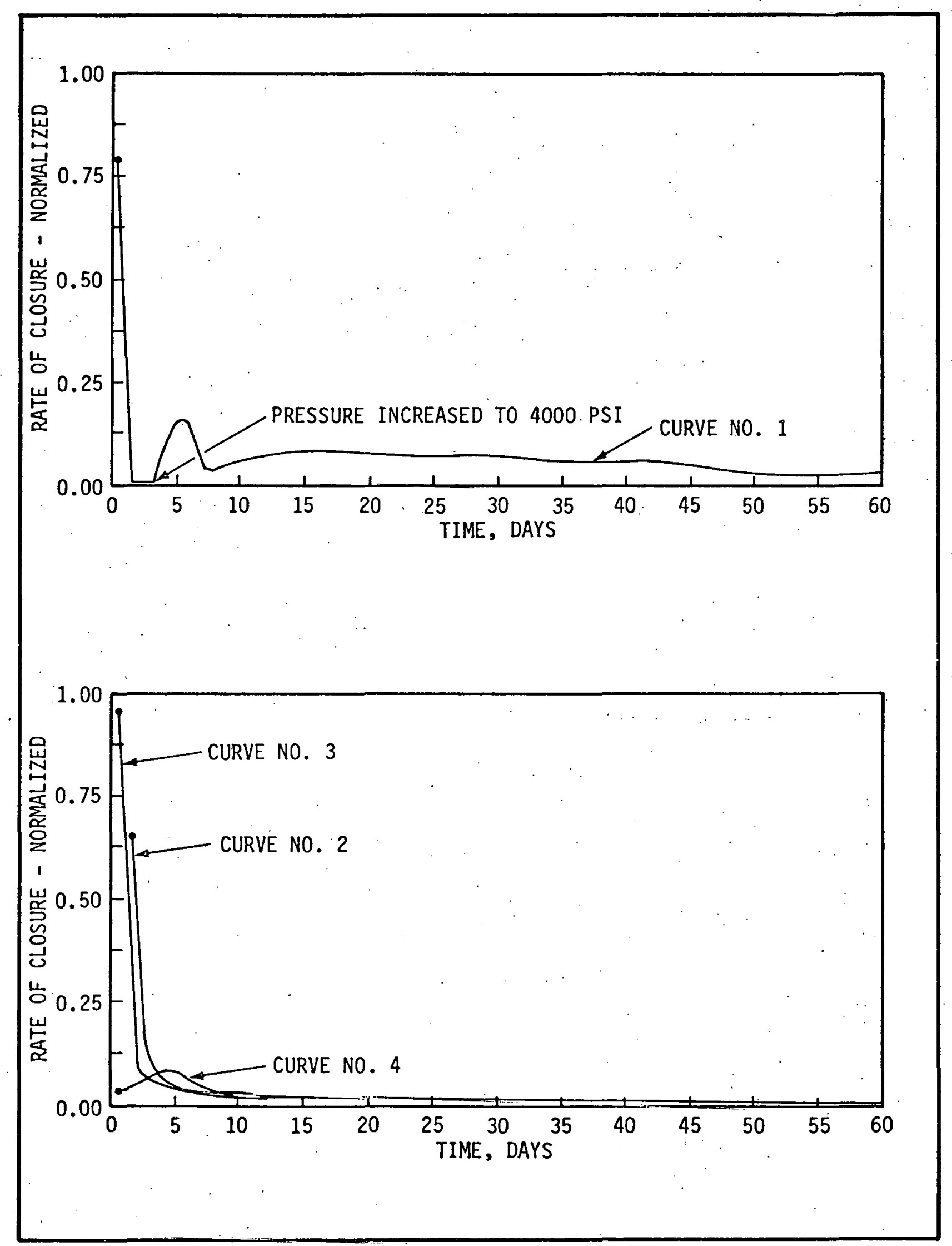

Figure 10-1. Experimental curve of closure rate vs time (modifled from Jessen \& Nowotny) 
was held constant. The purpose was to study fast application of load.

Curve No. 4 resulted from applying load to the core in 177 psi increments every six hours for $41 / 4$ days. The maximum pressure of 3,000 psi was then held constant. The purpose of the experiment was to study slow application of load.

In the same set of experiments it was shown that increased temperatures rapidly accelerated closure of a model cavity.

In tests performed in Project Salt Vault ${ }^{1}$ heat sources were inserted in the floor of a mine room. A thermal stress was produced whose effects were rapidly transmitted up the pillar walls to the roof. Heat increased the plastic flow rates in the bedded salt. Floor uplift, vertical pillar convergence and roof sag all increased with increasing temperatures.

In the same tests it was also found that small intracrystalline brine inclusions migrate to a source of heat, Small quantities of brine were found in the disposal holes: Figure 10-2 illustrates the underground laboratory used for Project Salt Vault.

A study ${ }^{11}$ was conducted for Fenix \& Scisson in which stress distributions were analytically determined for different cavity shapes. The four configurations investigated were the sphere, prolate spheroid, bell, and egg. Results of the analysis and a summarization of yielded zones for the different shapes and initial stress conditions are shown in Figure 10-3.

The variable " $K$ " heading each column represents the range of values for which the investigation was conducted and is defined as the ratio of initial horizontal stress to initial vertical stress. Values were believed to reasonably bracket conditions anticipated for the particular project. The study concluded that "While the effects of shape are evident and they follow the 


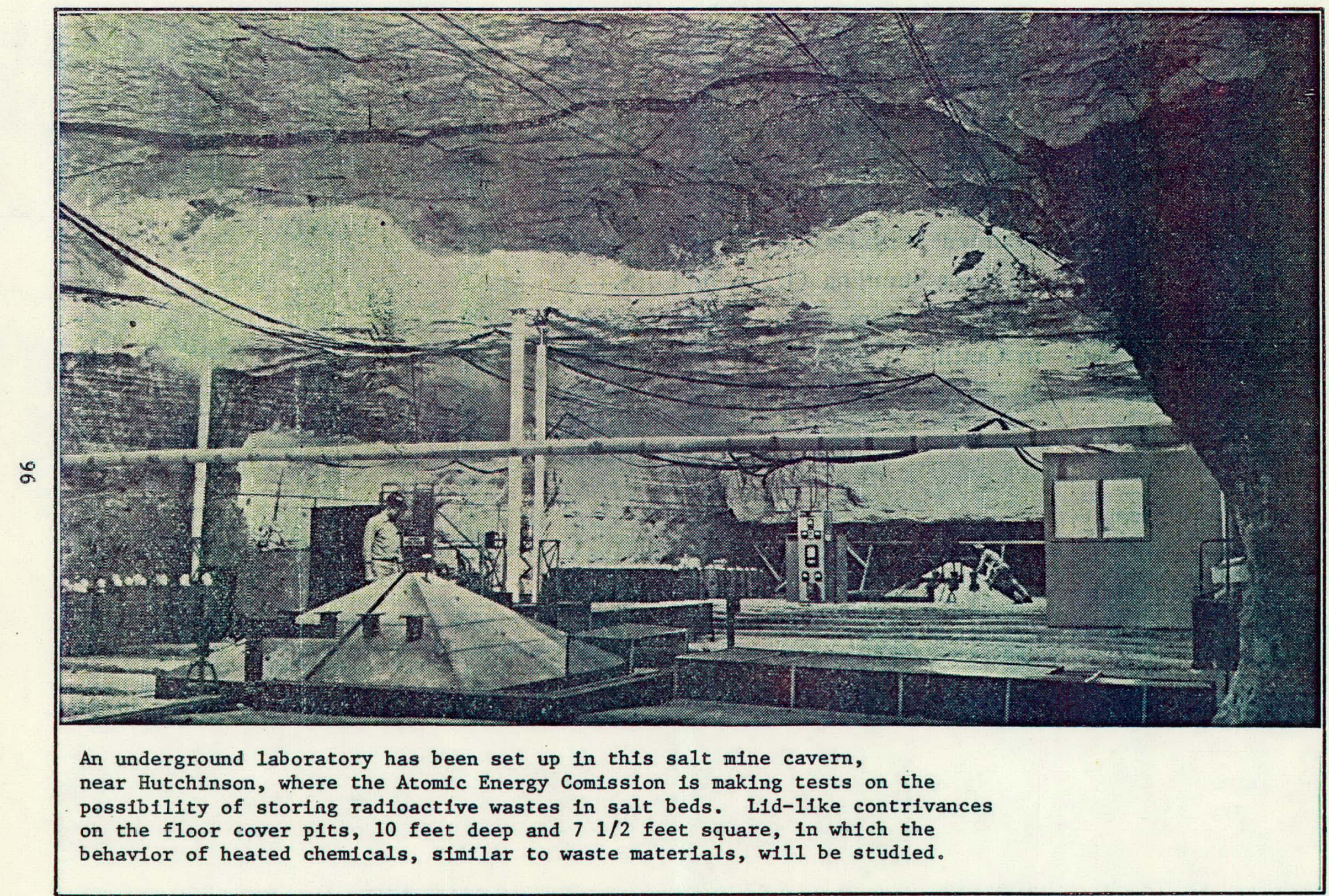

Figure 10-2. The underground laboratory for Project Salt Vault (The Kansas City Star, November 1, 1959) 


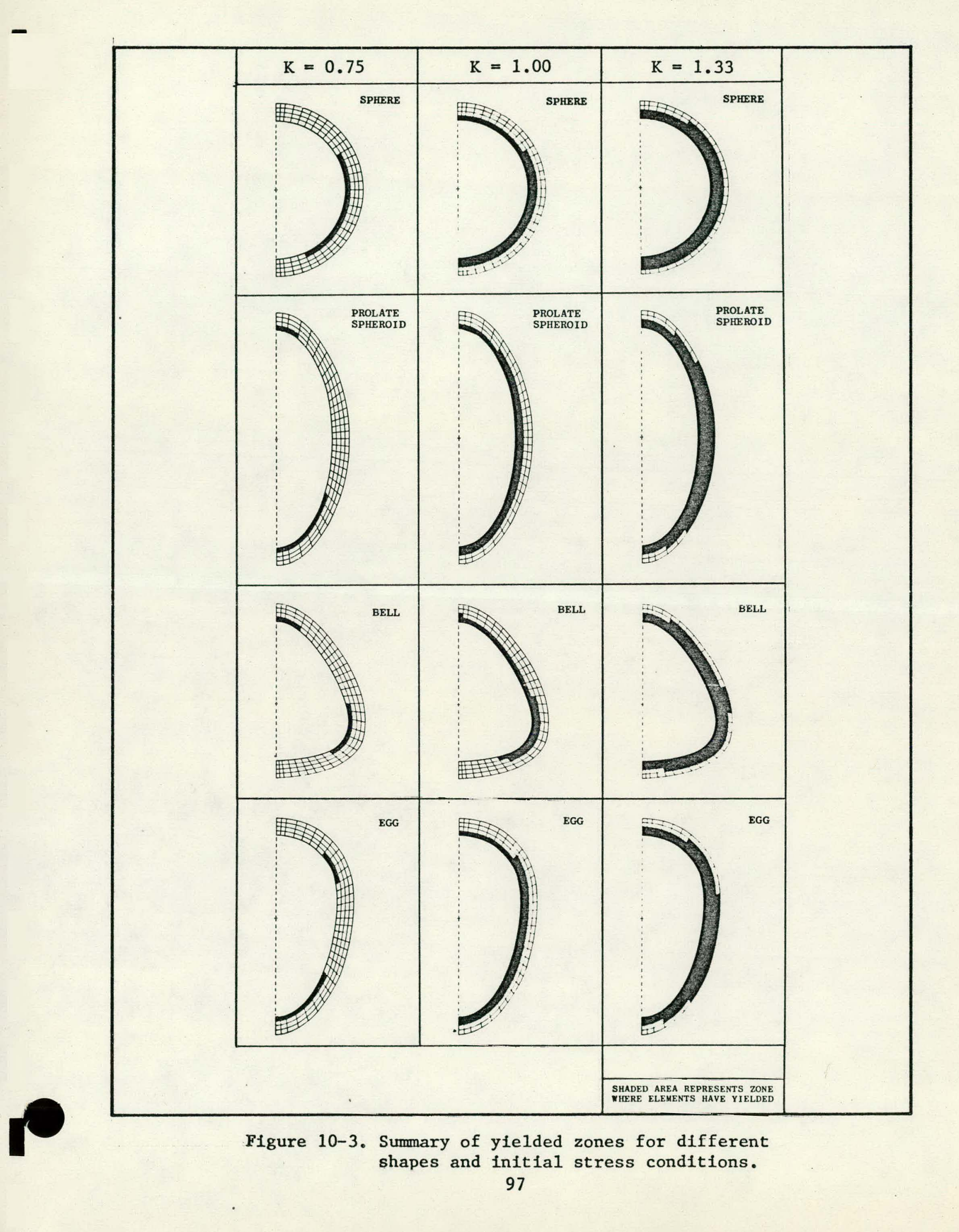


general trend established from previous investigations, it does appear that for the range of $\mathrm{K}$ values considered and the shapes investigated, the effect of shape will not be the most critical factor in stability."

\section{CAVERN FAILURES}

In this discussion of cavern failures it should be noted that all of the failures occurred in old brine production caverns where inadequate roof control allowed leaching into overlying formations. Although closure has been noted in deep gas storage caverns, no failures are known to have occurred in storage cavities which have been constructed with modern technology.

Failures here refer to situations where the loss of geophysical integrity has rendered the cavern unusable. Cases where caverns have been abandoned because of economic decisions or unsolvable technical problems will not be considered.

Allied Chemical Company's No. 7 well on the Bayou Choctaw dome in Iberville Parish, Louisiana is an example of cavern failure due to leaching of the cavern roof into the cap rock. When the roof of the cavern migrated into the fractured cap rock, circulation was lost and the cavern was no longer pressure tight.

Another rather spectacular collapse occurred recently in Van Zandt County, Texas, where a brine well is believed to have caved in on the Grand Saline dome (see Figure 10-4).

Subsidence over a dome is not always caused by collapse of a cavern. Extraction of sulfur from the cap rock has also resulted in caving of the overburden. This type of activity has occurred, for example, over the Sulphur 


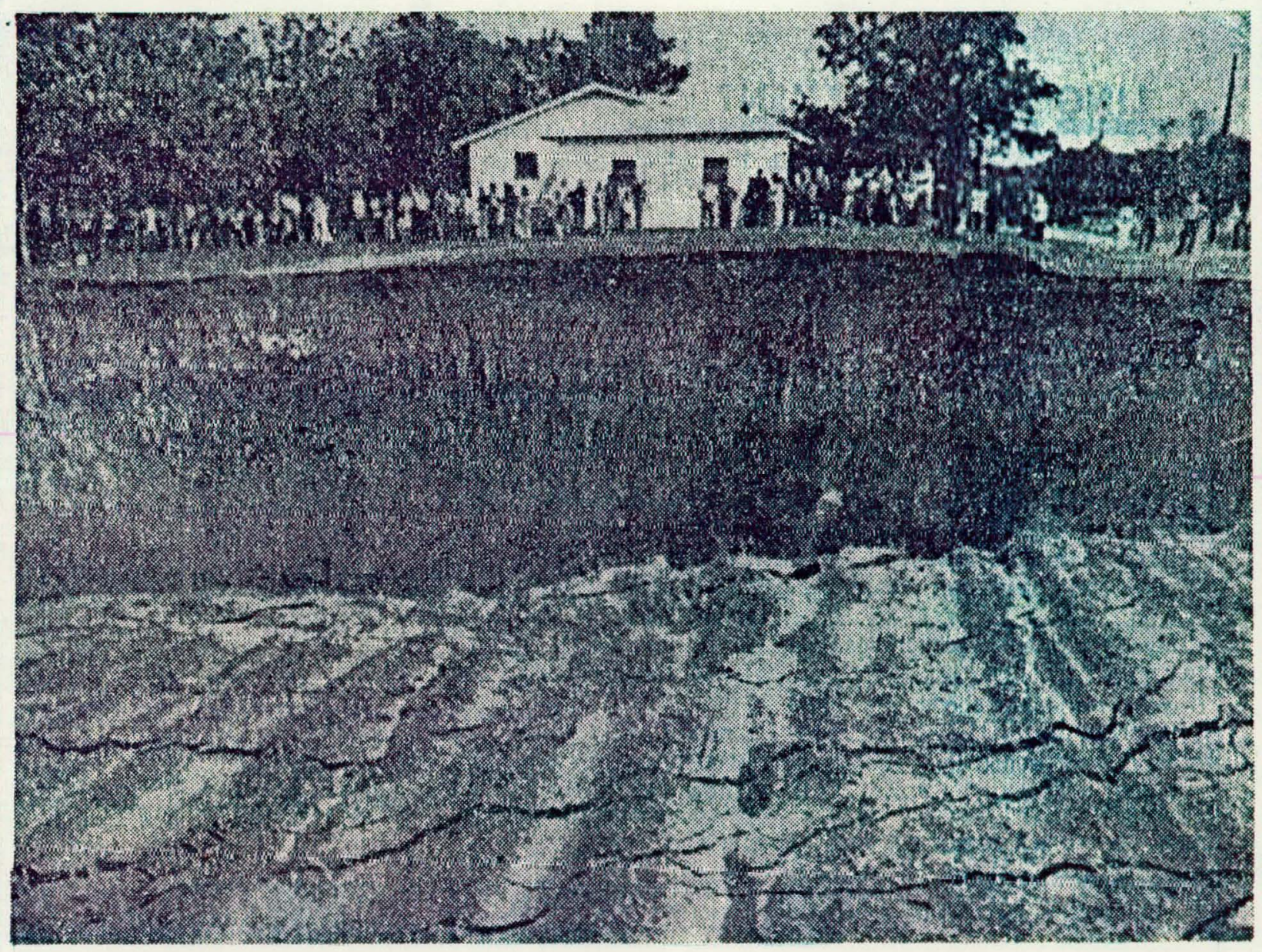

Residents of Grand Saline, Texas, were in for quite a shock Tuesday when a large hole developed in the earth. Authorities suspect an old brine well collapsed, taking out a local road and almost swallowing a house.

Figure 10-4. Surface subsidence due to collapse of an old brlne well (Tulsa Daily World, April 28, 1976) 
Mines dome in Calcasieu Parish, Louisiana. 


\section{SECTION 11 \\ Salt Dome Caverns not Used For HYDROCARBON STORAGE}

Hundreds of caverns have been mined in domes since solution mining was introduced. Some of them are only a byproduct of brining activities, while others are intentionally constructed for product storage. Many caverns originally created by brine production have been tested and, if found suitable, have been converted for storage purposes.

There are a number of existing caverns that presently are neither being used for storage nor are committed for future storage use. Some of these are now producing brine, some have been abandoned after brine production ceased, and others are inactive due to technical and economic considerations.

\section{REASONS FOR CAVERN ABANDONMENT}

Caverns are abandoned for a number of technical and economic reasons:

1. Communication between caverns. The growth in diameter of adjacent caverns may be such that continued leaching will cause communication between cavities. Also, if the wall thickness between adjacent caverns becomes too thin. it will make caverns unsuitable for high pressure product storage.

2. Communication between cavern and formations adjacent to the dome. Unintentional leaching and thus communication between a cavern located near the dome periphery and the permeable sedimentary formations pierced by the dome can occur, especially if an unknown 
structural overhang exists.

3. Violation of property lines. Continued leaching of a cavity may cause its diameter to cross a property line or exceed a predetermined distance from the property boundary.

4. Loss of roof control. Inadequate roof control may permit leaching to migrate upward into the porous cap rock.

5. Inadequate cementing of casing. Poor cementing between casing strings and geological formations may result in cavern leakage due to pressures developed during leaching or storage.

6. Inadequate casing. When a cavern is leached only with the intention of producing brine, casings cemented into the well bore and those suspended in the cavern may not have the capability to withstand high pressure storage service: Therefore, a cavern investigated for the purpose of converting it to storage may be rejected because of inadequate casing.

7. Extensive casing corrosion. Brine caverns developed beneath cap rocks with extensive migration of corrosive fluids have been abandoned due to casing failures.

8. Subsidence. Poorly completed brine caverns developed concurrent with extensive sulfur removal from the cap rock have experienced general failure of roof areas and have been abandoned due to the corresponding ground subsidence.

9. Economics of workover. Technical problems occurring in brine production or storage caverns many times can be remedied and the cavern replaced into service. But the expense of technical attention may exceed the value of the serviceable cavern. 
For example, replacing all or part of the suspended casing in brine production or storage caverns is not uncommon. Labor charges for removing old casing and replacing it with new casing are major expenses. If a brine production cavern has only a short life prior to planned abandonment, then replacing the casing may be more expensive than the value of its remaining service.

10. No brine market or product availability. A brine production cavern may be abandoned because there is no market for the brine, or a storage cavern may be abandoned if no commodity is available for storage.

TABULATION OF EXISTING CAVERNS NOT USED FOR HYDROCARBON STORAGE

A list compiled by Fenix \& Scisson of existing caverns that are not _being used for hydrocarton storage is shown as Table 11-1. While precise and updated information is not always readily available due to the classified nature of competitive industries, Table 11-1 presents data on caverns believed to be stable and pressure tight unless otherwise noted. Past contacts with owners and operators of brining and storage facilities have resulted in little detailed information. 


\section{SCREENING. PROCESS CRITERIA}

When searching for an existing cavern or for a new cavern site that would be suitable as a radioactive waste repository, the following criteria are suggested for use in the screening and selection process:

1. Is there production and/or storage operations already on the dome?

2. What are the existing surface facilities?

3. Does the dome underlie a town?

4. What is the proximity to highways, railroads, intracoastal waterways, and barge channels?

5. What is the nature of the surface terrain--dry, marshy, flat,--?

6. Is electrical power available?

7. If new construction is contemplated, is there adequate leach water, undeveloped salt and brine disposal sites? 


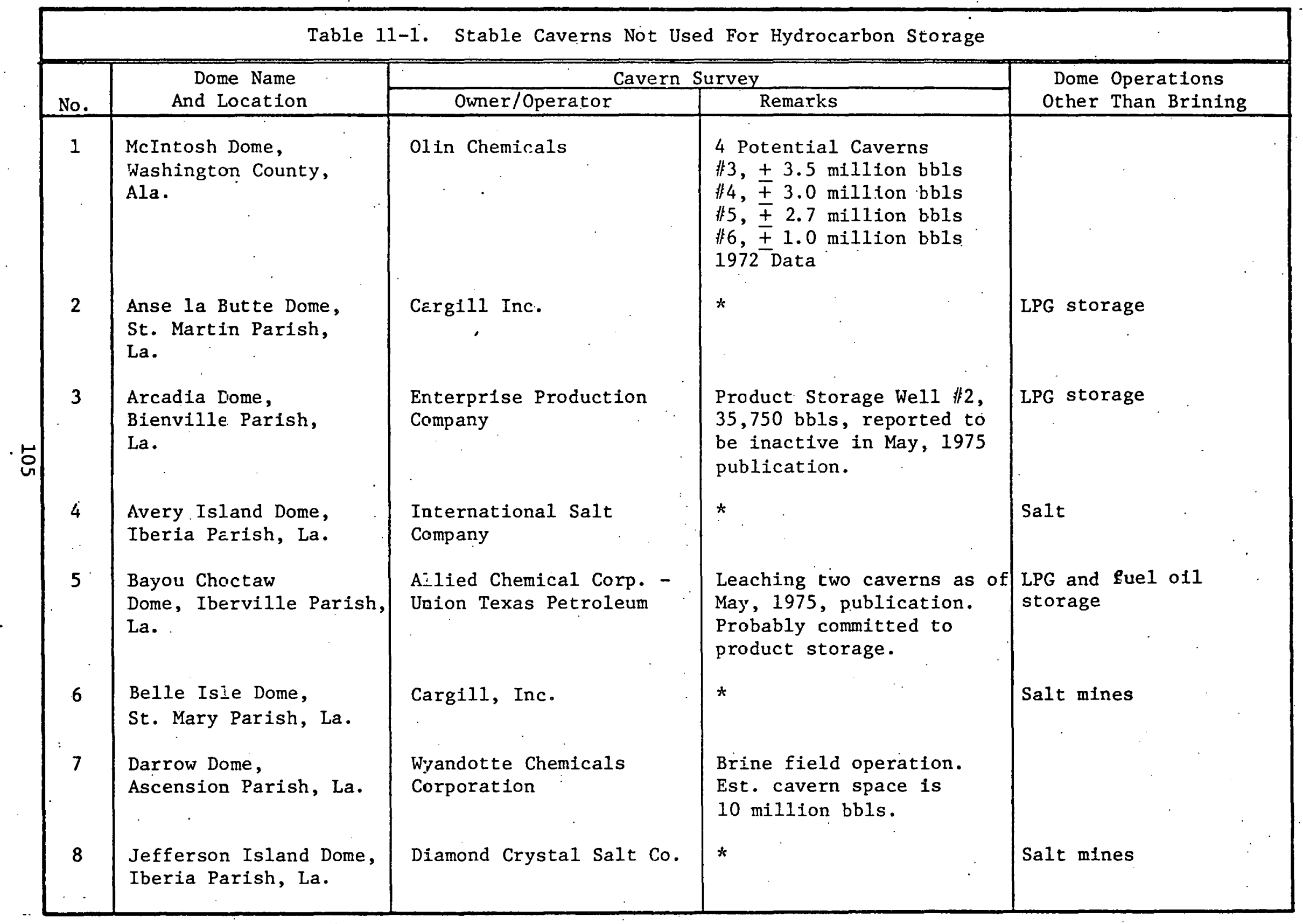

* Brining operations reported but cavern availability and size uncertain. 


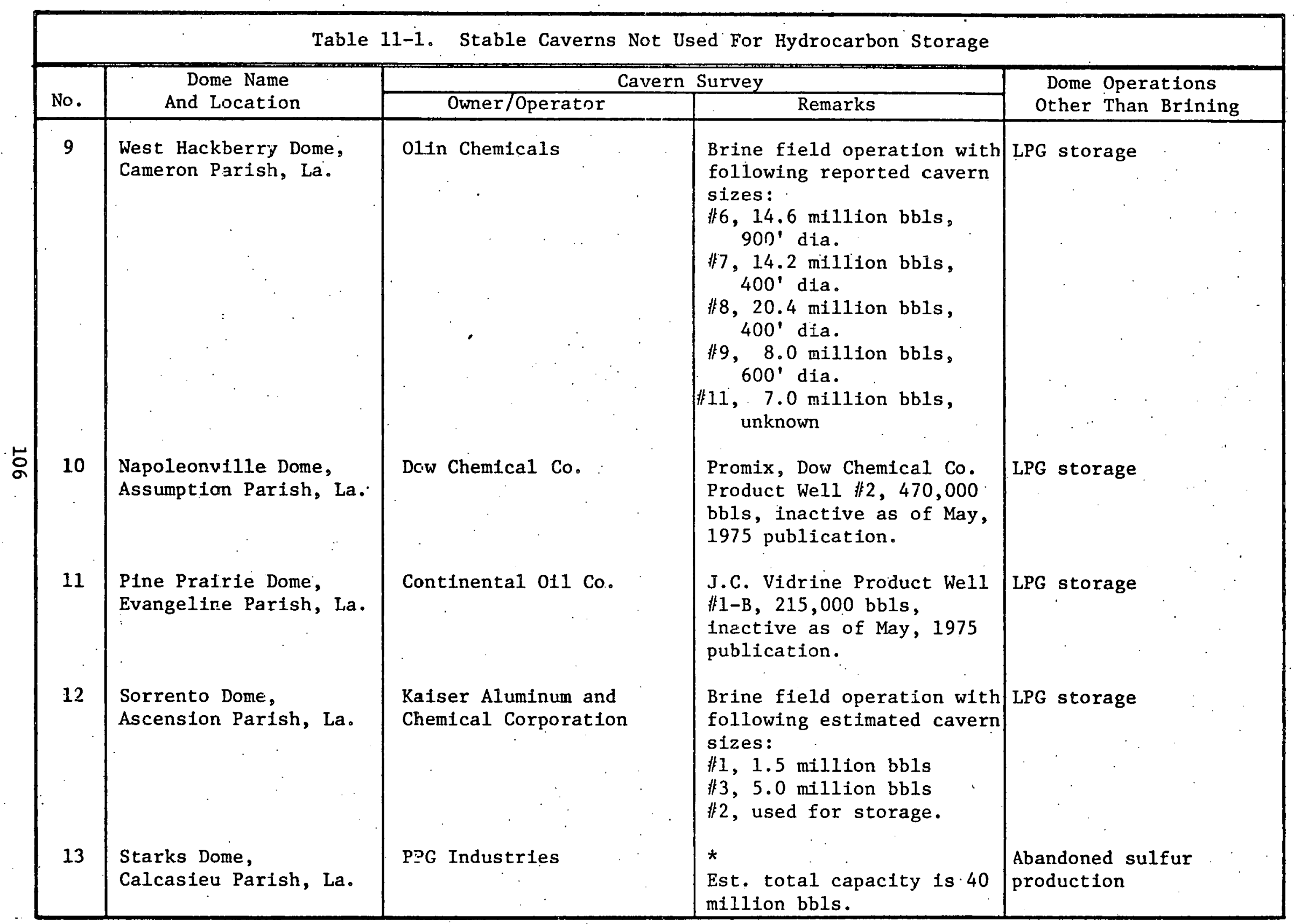




\begin{tabular}{|c|c|c|c|c|}
\hline \multirow[b]{2}{*}{ No. } & \multirow{2}{*}{$\begin{array}{c}\text { Dome Name } \\
\text { And Location }\end{array}$} & \multicolumn{2}{|c|}{ Cavern Survey } & \multirow{2}{*}{$\begin{array}{l}\text { Dome Operations } \\
\text { Other Than Brining }\end{array}$} \\
\hline & & Owner/Operator & Remarks & \\
\hline 14 & . & . & $\begin{array}{l}\text { Brine field operation with } \\
\text { following reported cavern } \\
\text { sizes: } \\
\text { \#6, } 4.4 \text { million bbls. } \\
\text { \#7, } 5.6 \text { million bbls. } \\
\# 2 \text {, \#4, \#5 caverns have } \\
\text { communicated and have an } \\
\text { estimated size of } 15 \\
\text { million bbls. }\end{array}$ & $\begin{array}{l}\text { LPG storage } \\
\text { Abandoned sulfur } \\
\text { production }\end{array}$ \\
\hline 15 & $\begin{array}{l}\text { Weeks Island Dome, } \\
\text { Iberia Parish, La. }\end{array}$ & Morton Salt Co. & $\begin{array}{l}\text { * } \\
\text { Very small caverns } \\
\text { reported. }\end{array}$ & Salt mines \\
\hline 16 & $\begin{array}{l}\text { Barbers Hill Dome, } \\
\text { Chambers County, Texas }\end{array}$ & $D \cong$ amond Shamrock. & * & LPG stọrage \\
\hline 17 & $\begin{array}{l}\text { Blue Ridge Dome, Ft. } \\
\text { Bend County, Texas }\end{array}$ & $\begin{array}{l}\text { United Salt Co. - Texas } \\
\text { Brine Corp. }\end{array}$ & * & LPG storage \\
\hline 13 & $\begin{array}{l}\text { Bryan Mound Dome, } \\
\text { Brazoria County, Texas }\end{array}$ & $\begin{array}{c}\text { Dow Chemical Co.: } \\
\\
\therefore\end{array}$ & $\begin{array}{l}\text { * } \\
\text { Reported approximately } \\
30 \text { million bbls. }\end{array}$ & $\begin{array}{l}\text { Abandoned sulfur } \\
\text { production }\end{array}$ \\
\hline 19 & $\begin{array}{l}\text { Grand Saline Dome, } \\
\text { Van Zandt County, Texas }\end{array}$ & Morton Salt Co. & $\begin{array}{l}\text { * } \\
\text { Very small }\end{array}$ & Salt mines \\
\hline 20 & $\begin{array}{l}\text { Markham Dome, } \\
\text { Matagorda County, Texas }\end{array}$ & Texas Brine Corp. & $\begin{array}{l}1.2 \text { million bbls. of space } \\
\text { under development for } \\
\text { Union Carbide }\end{array}$ & LPG storage \\
\hline 21 & $\begin{array}{l}\text { Palangana Dome, } \\
\text { Duval County, Texas }\end{array}$ & PPG Industries & 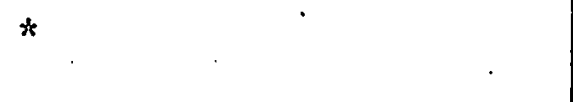 & $\begin{array}{l}\text { Abandoned sulfur } \\
\text { production }\end{array}$ \\
\hline
\end{tabular}




\begin{tabular}{|c|c|c|c|c|}
\hline & Dome Name & & irvey & Dome Operations \\
\hline No. & And Location & Owner/Operator & Remarks & Other Than Brining \\
\hline $\begin{array}{r}23 \\
24\end{array}$ & $\begin{array}{l}\text { Pierce Junction Dome, } \\
\text { Harris County, Texas } \\
\text { Stratton Fidge Dome, } \\
\text { Brazoria County, Texas } \\
\text { Tatum Dome, Lamar } \\
\text { County, Mississippi }\end{array}$ & $\begin{array}{l}\text { Texas Brine Corp. } \\
\text { Dow Chemical Co. } \\
\text { Dow Chemical Co. } \\
\text { Cavity under control } \\
\text { of ERDA }\end{array}$ & $\begin{array}{l}\text { Annual space created } \\
\text { committed to LPG storage } \\
\text { * } \\
\text { Annual space created } \\
\text { committed to LPG storage } \\
\text { * } \\
\text { Annual space created } \\
\text { committed to LPG storage } \\
\text { Existing cavity created by } \\
\text { nuclear device. Approx- } \\
\text { imately } 100 \text { ft. dia. } \\
\text { sphere. }\end{array}$ & 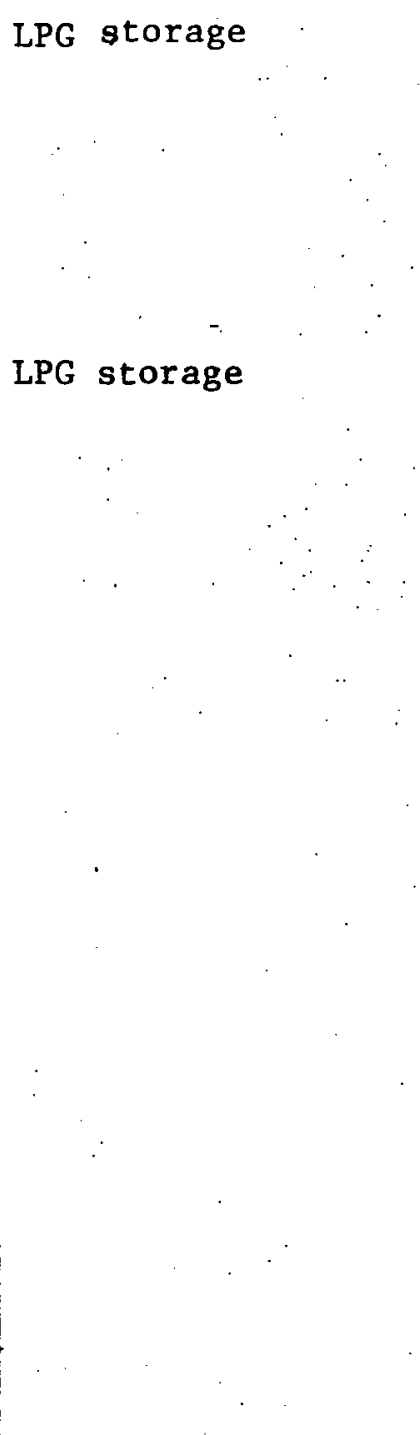 \\
\hline
\end{tabular}




\section{SECTION 12 \\ CONSTRUCTION COSTS}

Costs of constructing solution mined caverns in Gulf Coast salt domes depend on the following factors:

CAVERN DEPTH

Deeper caverns mean deeper holes and longer casing strings, both of which increase costs. Longer casings also directly relate to increased friction loss and require higher pumping pressures with correspondingly higher operating costs. In addition, the required collapse strength of the casing string increases directly with depth, necessitating use of heavier, more expensive casing.

CAVERN INTERVAL

The cavern interval is the vertical height of the cavern; as it increases, wash casing must be longer to wash the sump (if one is used) and to leach the cavern. Casing costs increase with length and operating costs increase with depth due to higher static pressure heads and friction losses.

\section{CIRCULATION RATE}

Circulation rates affect several major cost areas. Higher circulation rates increase the amounts of leaching water and brine disposal, with attendant jumps in the costs for water supply, brine disposal and associated piping. 
Increased circulation also requires greater expenses for pump purchase and operation, or it demands that more money be spent for larger diameter well casing and plant piping in order to avoid higher pumping pressures and operating costs.

\section{CAVERN SIZE}

Cavern size is a dirert measure of the amount of salt that must be removed, and therefore, is tied directly to operating costs and project development time.

MANNER OF CIRCULATION

The efficiency of salt removal is related to the technique used to circulate leaching water during construction. Direct circulation, for example; can result in a non-saturated discharge (see Figure 5-1). Reverse circulation usually results in a higher saturation discharge, and is more efficient than direct circulation because it requires a lower volume of leach water and energy consumption for construction.

\section{COST CURVES}

Figure 12-1 is a series of graphs illustrating the relationship of unit construction costs, circulation rates, and cavern depth and size. Costs plotted were based on certain general elements and simplified assumptions and are representative for current salt dome construction.

Construction cost data are contained in four sets of curves, each of 

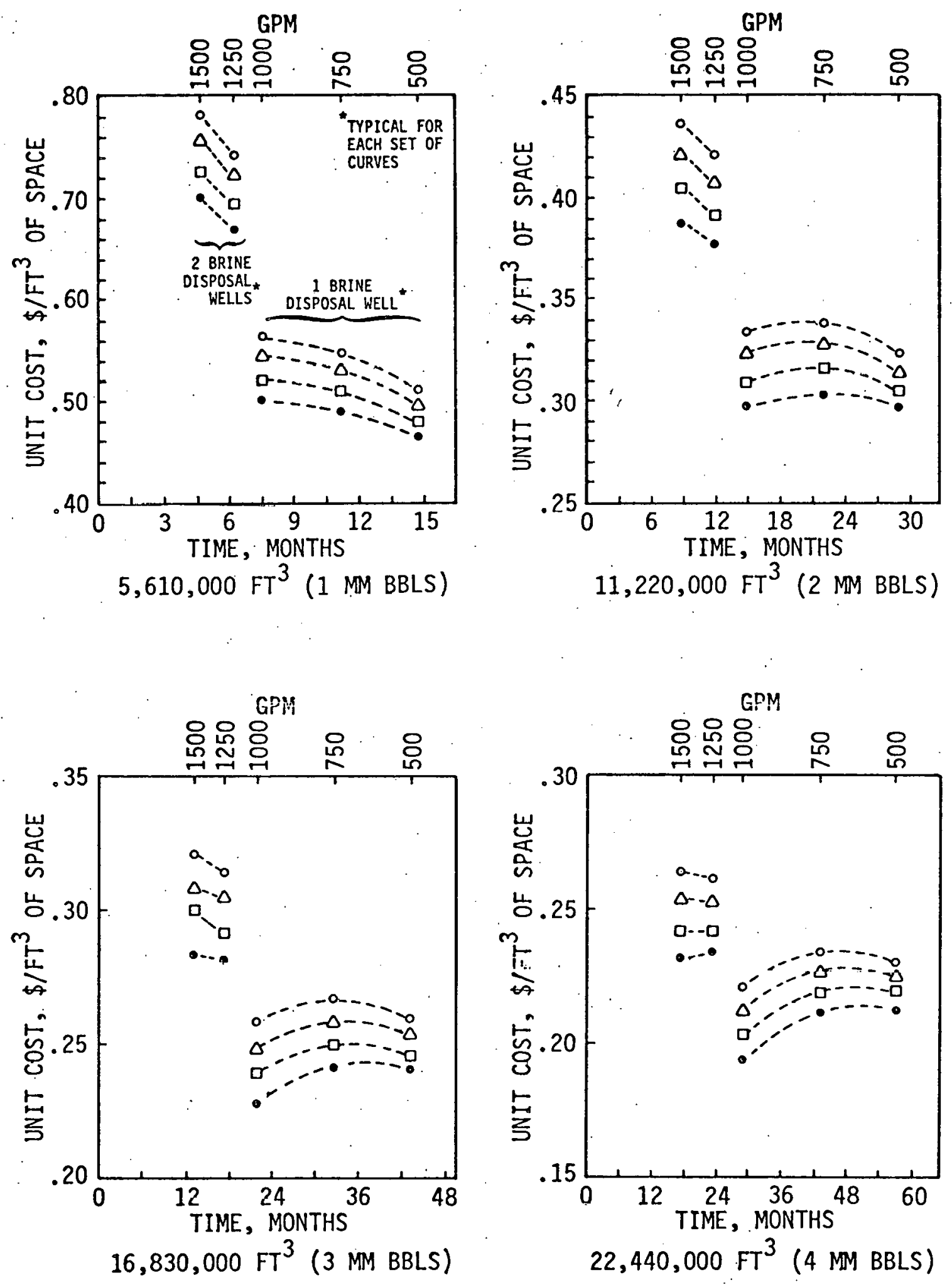

LEGEND: CAVERN ROOF $\begin{array}{rr}0-3000^{\prime} & 0-2000^{\prime} \\ \Delta-2500^{\prime} & \bullet-1500^{\prime}\end{array}$

Figure 12-1. Unit cost vs cavern development time for varfous cavern depth intervals 
which is plotted for a specific cavern size of varying cavern depth intervals. In general, the graphs show that 1) unit cost of space decreases as the depth interval decreases, and 2) the unit cost of space decreases as cavern size increases.

The discontinuity in each set of curves occurs between the 1,000 and 1,250 gpm construction rates, because a second brine disposal we11, costing $\$ 500,000$, must be built for rates above $1,000 \mathrm{gpm}$.

The shape of each cost curve is dependent on the capital investment and operating cost for each development rate. In general, as the development rate decreases the cost curve will decrease, if the reduction in capital is greater than the increase in operating costs. Conversely, the curve will increase if operating costs more than offset the reduction in capital investment.

GENERAL COST ELEMENTS AND ASSUMPTIONS

The following cost elements were used in preparing data for Figure 12-1:

\section{CAPITAL INVESTMENTS}

Water Supply--It was assumed that fresh water wells completed to a depth of 300 fect would be used to supply leaching water. The unit cost of $\$ 100$ per gpm of demand was used. In each case, an additional well was assumed for standby at a cost of $\$ 50,000$.

Brinc Disposal--It was assumed that the depth of brine disposal wells would be 5,000 feet. Each well was assumed to have a disposal capacity of $1,000 \mathrm{gpm}$ and a cost of $\$ 500,000$. A pipeline from the leaching plant to brine disposal wells was assumed to be two miles long; cost was estimated at $\$ 10,000$ per inch of diameter per mile of length. 
Leaching Plant--This element includes all pumping equipment installed in a building and ready for use. Unit cost for the leaching plant is $\$ 250 \mathrm{x}$ total pump horsepower.

Cavern Development Well--Drilling and casing of the well and other services such as cementing, coring and logging are included. A different well cost was determined for each cavern depth interval.

\section{MONTHLY OPERATING EXPENSES}

Electrical Power--A power cost of $\$ 0.03$ per kilowatt hour was used for operating all pumping equipment.

Pump Repairs--The cost of pump repairs was est1mated as $\$ 0.0007$ per gpm for each hour of operation.

Others--Salaries for construction supervisors, plant operators, engineering supervision, vehicles, supplies and repair parts were also included.

Design and construction fees were taken into account. Other assumptions used to develop costs are:

1. A sump will be used to collect insolubles.

2. The modified circulation technique was assumed for construction.

3. Although several different cavern depths will be evaluated, the cavern interval will be limited to 500 feet.

4. Cavern depth intervals range from 1,500 to 3,500 feet, which is representative of Gulf Coast dome construction.

5. Leaching rates are limited from 500 to $1,500 \mathrm{gpm}$, which is representative of current construction rates. 
6. Costs do not include cavern evacuation.

7. The same well configuration was used in each case.

ADDITIONAL COST ELEMENTS. NOT INCLUDED

Items not included in the study but relevant to total project development are:

1. Cost of 1 and and rights of way.

2. Cost of site confirmation. Preliminary drilling may be needed to determine the depth to the top of the salt if information is not available.

3. Cost of site work prior to leach plant construction.

4. Cost of running electrical power lines to the site.

5. Cost of office building, fences, etc. 


\section{APPENDIX \\ Brine Disposal Reservoir Analysis \\ NUMERI CAL EXAMPLE}

The following example illustrates brine disposal reservoir and brine well injectivity calculations for a hypothetical disposal situation of 1,500 : gpm for 18 months. Parameter values. selected are representative for the Gulf Coastal areas. For the hypothetical parameters chosen, it will be shown that two wells will meet disposal Eequirements. No additional wells were assumed for standby purposes.

I. FORMATION AND FLUID FLOW CHARACTERISTICS:

A. Formation Porosity: At the proposed disposal depths, formation porosities range from 30 to 34 percent. Therefore a conservative value of 30 percent has been selected for use in the calculations.

B. Permeability: Permeability values range from one to four darcies. Therefore, the conservative value of one darcy has been selected.

C. Formation Thickness: For calculation purposes it is assumed that each of two disposal wells will be completed in a zone 100 feet thick and that the sum of these zones will total approximately 200 feet in thickness. It is also assumed that there will be radial flow of disposal material in a horizontal plane.

D. Areal Extent: Geological investigation indicates that, for all practical purposes, the disposal aquifers are infinite in areal extent. 
E. Disposal Depth: We have estimated that the best disposal zones, considering economics and reservoir characteristics, will be from 5,000 to. 6,600 feet: Therefore, 5,000 feet will be the minimum disposal depth.

F. Reservoir Temperature: Temperature logs indicate that at the proposed disposal depths the formation temperature varies from $120^{\circ} \mathrm{F}$ to $160^{\circ} \mathrm{F}$. Therefore, the conservative value of $120^{\circ} \mathrm{F}$ has been selected.

G. Viscosity of Formation Water: The value of $0.8 \mathrm{cp}$. was obtained from a water viscosity vs temperature chart.

H. Formation Compressibility Factor: The formation water has a compressibility of $3.0 \times 10^{-6} \mathrm{\Delta v} / \mathrm{v} / \mathrm{psi}{ }^{13}$ and a conservative value for unconsolidated sandstone compressibility is $3.6 \times 10$ $-6 \Delta \mathrm{v} / \mathrm{v} / \mathrm{psi} .^{14}$ Therefore, the formation compressibility factor to be used in the calculations will be $3.0 \times 10^{-6} \Delta \mathrm{v} / \mathrm{v} / \mathrm{psi}+$ $3.6 \times 10^{-6} \Delta \mathrm{v} / \mathrm{v} / \mathrm{psi}=6.6 \times 10^{-6} \Delta \mathrm{v} / \mathrm{v} / \mathrm{psi}$

II. CALCULATION OF INITIAL RESERVOIR PRESSURE

This is the pressure that exists in the reservoir before injection begins. Assume the initial reservoir pressure equals a full hydrostatic column of formation water which has a pressure gradient of $0.45 \mathrm{psi} / \mathrm{ft}$. Therefore, the initial pressure, $\left(\mathrm{P}_{i}\right)$ would equal $0.45 \frac{\mathrm{psi}}{\mathrm{ft}} \times$ disposal depth $=0.45 \frac{\mathrm{psi}}{\mathrm{ft}} \times 5,000 \mathrm{ft}=2,250 \mathrm{psi}$.

III. CALCULATION OF ALLOWABLE RESERVOIR PRESSURE

The lithostatic or overburden pressure equals approximately 1.0 psi ft. Assume the formation pressure will be allowed to reach a maximum of 0.7 of the lithostatic pressure. Therefore, the allowable 
reservoir pressure $=0.7 \mathrm{psi} / \mathrm{ft} \times 5,000 \mathrm{ft}=3,500 \mathrm{psi}$. The allowable formation pressure increase $(\Delta P)$ is equal to the allowable reservoir pressure minus initial reservoir pressure or 3,500$2,250=1,250$ psi.

IV. CALCULATION OF INJECTION RATE

The disposal requirements are $1,500 \mathrm{gpm}$ for 18 months, or

$1,500 \frac{\mathrm{gal}}{\min } \times \frac{\mathrm{bb} 1}{42 \mathrm{gal}} \times 1,440 \frac{\mathrm{min}}{\mathrm{day}}=51,430 \frac{\mathrm{bb} 1}{\mathrm{day}}=$ injection rate

18 mo. $\times 30.4 \frac{\text { day }}{\text { mo. }} x^{24} \frac{\text { hrs }}{\text { day }}=13,133$ hrs $=$ injection duration

V. CALCULATION OF INCREASE IN FORMATION PRESSURE

The fluid flow equations which have been developed for producing wells are also applicable to brine injection wells, providing suitable modifications are made for the differences in the direction of flow and in the physical properties of the fluids. Although brine will be injected into the reservoir, the properties of the formation water are used to calculate formation pressure increases.

The equation for calculating the formation pressure increase $(\Delta \mathrm{p})$ during injection at a radial distance (R) from an injection well callsed hy injecting a fluid at a constant rate (Q) into an extensive reservoir of uniform thickness and permeability was adapted from equations developed by Theis and Horner and is presented below. 15 $\Delta \mathrm{P}=\frac{70.6 \mathrm{Q} \mu}{\mathrm{Kh}}\left\{-0.5772-\mathrm{Ln} \frac{948.2 \mathrm{R}^{2} \phi \mu \mathrm{C}}{\mathrm{KT}}+\frac{\left[\frac{948.2 \mathrm{R}^{2} \phi \mu \mathrm{C}}{\mathrm{KT}}\right]^{2}}{1 \cdot 1 !}-\frac{\left[\frac{948.2 \mathrm{R}^{2} \phi \mu \mathrm{C}}{\mathrm{KT}}\right]^{2}+\ldots+}{2 \cdot 2 !}+\right.$

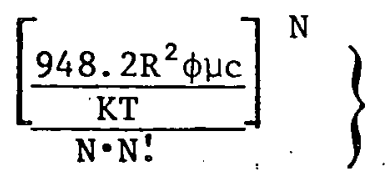


Where:

$Q=$ Barrels of fluid injected per day

$\mathrm{K}=$ Effective permeability to the injection flow = one darcy

$h=$ Reservoir thickness. For purposes of these calculations we have assumed that each disposal well will be completed in a 100 foot disposal zone.

$\mu=$ Reservoir fluid viscosity $=0.8 \mathrm{cp}$.

$\mathrm{Rw}=$ Effective we11 bore radius $=0.5$ feet .

$\operatorname{Re}=$ Radial distance to reservoir boundary $=30,000$ feet.

Referring to Figure 7-3, we have used the effective pressured radius as the effective reservoir boundary.

$F=$ Fraction of the reservoir periphery into which the brine is being injected. We have assumed that radial flow in the reservoir is limited by interference of the salt dome and adjacent disposal wells such that the reservoir periphery is decreased to 70 percent radial:

$\Delta \mathrm{P}=$ Pressure differential. The $\Delta \mathrm{P}$ is equal to the allowable reservoir pressure - initial reservoir pressure - reservoir pressure increase at the reservoir boundary $=$ $3,500-2,250-25=1,225$ psi.

Therefore:

$$
\begin{aligned}
& Q=\frac{7.07 \times 1 \times 100 \times 1225 \times 0.7}{0.8 \times \operatorname{Ln} \frac{30,000}{0.5}} \\
& Q=68,880 \text { barrels per day } \\
& Q=2,009 \text { gallons per minute }
\end{aligned}
$$

The calculated well injectivity of 2,009 gallons per minute per disposal 
well is the maximum injection rate per well that the formation will allow after 18 months of continuous injection. Therefore, the formation will accept brine at a minimum rate of 2,009 gallons per. minute per well throughout the projected injection period.

Well completions, the process of creating conduit from the disposal well casing to the formation, are not 100 percent effective. Stress relief cracks created when the formation is penetrated by the drill-bit, drilling mud, and cement placed against the formation after running casing all tend to reduce the natural formation permeability near the well bore. Collectively, these factors are commonly referred to as the "skin effect.". Perforations and formation stimulation by fracturing with propping agents or acid treatments are norma11y employed to reduce the "skin effect" and provide a clean conduit to the formation. As a result of these factors, a completion success ratio of $50 \%$ gives a conservative result.

The calculations show that one disposal well, which has an injectivity of 2,009 gallons per minute, would be needed to meet the 1,500.gallons per minute requirement. However, the completion success ratio of $50 \%$ necessitates the construction of a second disposal well. 


\section{REFERENCES}

1. Empson, F.M.; Boegly, W.J., Jr; Bradshaw, R.L.; McClain, W.C.; Parker, F.L.; Schaffer, W.F., Jr.; "Demonstration of Disposal of High Level Radioactive Solids in Salt", Proceedings of Second Symposium on Salt, Cleveland, Ohio, 1966, Northern Ohio Geological Society, Vol. I, pp. 432443.

2. Empson, F.M.; Bradshaw, R.L.; McClain, W.C.; Houser, B.L.; "Results of the Operation of Project Salt Vault, "A Demonstration of Disposal of High Level Radioactive Solids in Salt", Proceedings of Third Symposium on Salt, Cleveland, Ohio, 1970, Northern Ohio Geological Society, Vo1. I, pp. 455462 .

3. Remson, D.R.; Dommers, O,B.; Jessen, F.W.; "Techniques for Developing Predetermined Shaped Cavities in Solution Mining", Proceedings of Second Symposium on Salt, Cleveland, Ohio, 1966, The Northern Ohio Geological Society, Inc., Vol. II, pp. 297-310.

4. Dommers, O.B.; Jessen, F.W.; "Feasibility of Creating Spherical Cavities In Underground Salt Domes", Final Report of the U.S. Atomic Energy Commission Contract AT-(29-2)-1015, January 14, 1961, Published by the University of Texas, Department of Petroleum Engineering.

5. Dommers, O.B.; Remson, D.; Sears, G.; Durie, R.W.; Kazemi, H.; Nowotny, B.; Jessen, F.W.; "Feasibility of Creating Spherical Cavities in Underground Salt Domes", Final Report to the U.S. Atomic Energy Commission Contract AT-(29-2)-1051, June 30, 1963, Published by the University of Texas, Department of Petroleum Engineering.

6. Allen, Kermit, Jr.; "PROJECT PAYETTE - A Solution Mining Program for the Creation of a 315-Foot Diameter Sphere at a Depth of 2,700 Feet", paper written for presentation at the Fall Meeting of AIME at Minneapolis, Minn., September 18-20, 1968, AIME Preprint No. 68-I-350.

7. Hawlins, M.E.; Jirik, C.J.; Sall Domes In Texas, Louisiana, Mississippi, Alabama, and Offshore Tidelands: A Survey, IC8313, United States Department of the Interior, Bureau of Mines, 1966.

8. "Advance Review of Varlous Engineering Socioeconomic and Environmental Factors Related to Development and Operations of a Strategic Storage System" published by Radian Corporation on 21 February 1975.

9. Subsurface Salt-Water Disposal, Committee on Vocational Training, American Petroleum Institute, Division of Production, 1960.

10. "Project Payette - Phase I - A Study of The Technical Feasibility of Constructing A Large Cavity In Tatum Salt Dome", for the Nevada Operations Office, U.S. Atomic Energy Commission, by Fenix \& Scisson, Inc., Tulsa, Oklahoma, and Petroleum Consultants, Houston, Texas, a joint venture for the execution of AEC AE Conlract AT (26-1)-38. 
11. Nair, Kershavan; "Stability Studies for Project Payette", submitted to Fenix \& Scisson, Inc. October 1967 by Woodward-C1yde-Sherard and Associates, Materials Research \& Development, Inc., Oakland, California, Section VII.

12. Nowotny, B.; Jessen, F.W.; "Pressure-Temperature Effect on Spherical Cavities in Massive Salt", Proceedings of Second Symposium on Salt, Cleveland, Ohio, 1966, Northern Ohio Geological Society, Vol. II, pp. 363385.

13. Katz, D.L.; M.R. Tek, K.H. Coasts, M.L. Katz, S.C. Jones, and M.C. Miller, "Movement of Underground Water in Contact With Natural Gas,". AGA Monograph on Project No. 31 American Gas Associates, 605 Third Avenue, N.Y., N.Y. 10016 (1963).

14. Newman, G.H.; "Pore-Volume Compressibility of Consolidated, Friable, and Unconsolidated. Reservoir Rocks Under Hydrostatic Loading," Journal of Petroleum Technology, February 1973.

15. Lester, G.W. and Nowak, T.J.; "Analysis of Pressure Fall-Off Curves Obtained in Water Injection Wells to. Determine Injectlve Capacity and Formation Damage," from Pressure Analysis Methods, published by Society of Petroleum Engineers of AIME, 1967, p. 62.

16. Cole, Frank W.; Reservoir Engineering Manual, Gulf Publishing Co., Houston, Texas (1969).

17. Caihoun, John C.; Fundamentals of Reservoir Engineering, University of Oklahoma Press, Norman, Oklahoma (1953). 